Linköping Studies in Science and Technology

Dissertations No. 1807

\title{
Optical Monitoring of Cerebral Microcirculation
}

\author{
Peter Rejmstad
}

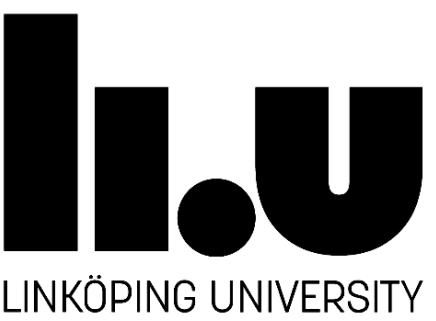

Department of Biomedical Engineering

Linköping University, Sweden

Linköping 2017 


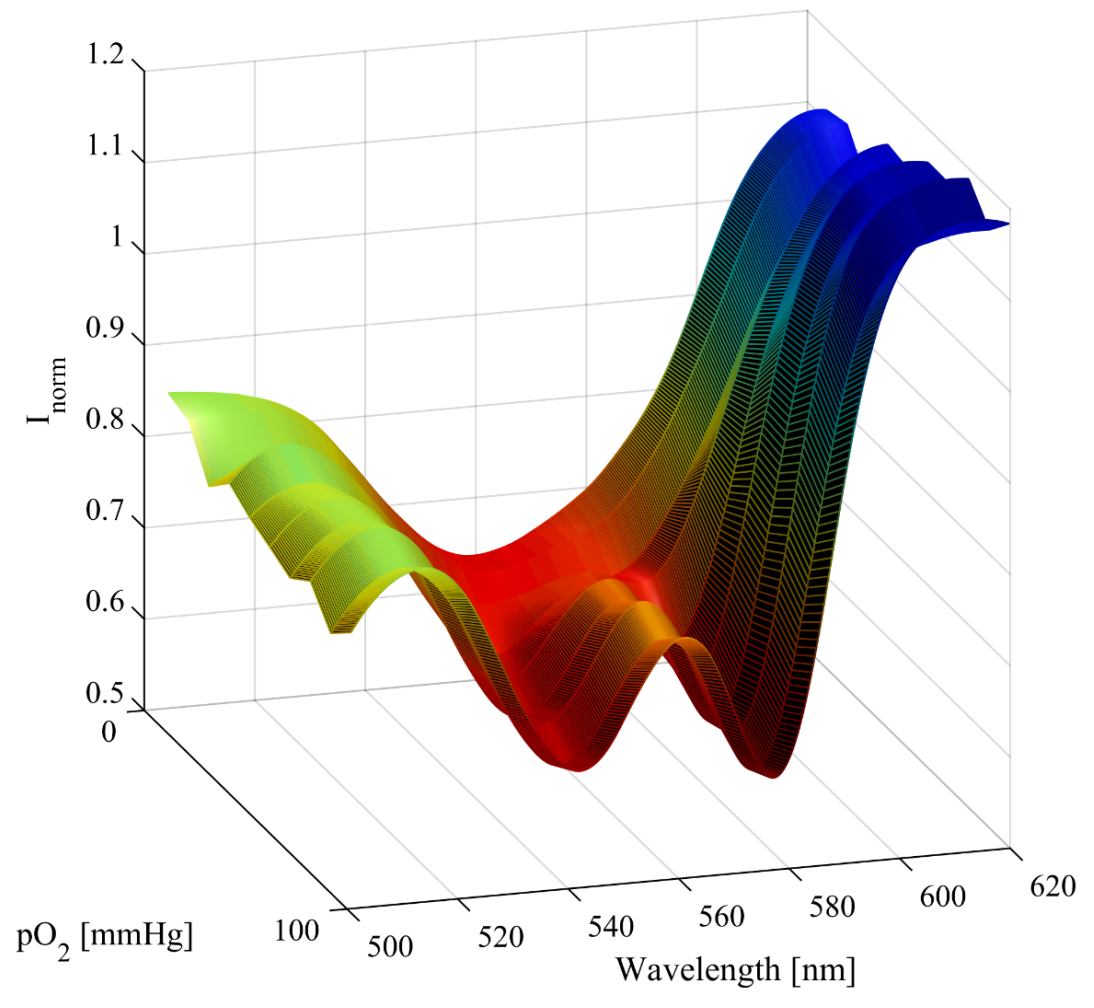

Cover page: Hemoglobin reflectance changes related to variations in $\mathrm{pO}_{2}$ and $\mathrm{SO}_{2}$ from optical phantom mimicking brain tissue

\section{Optical Monitoring of Cerebral Microcirculation}

(C) 2017 Peter Rejmstad, unless otherwise noted

Linköping Studies in Science and Technology

Dissertations No. 1807

\section{Department of Biomedical Engineering \\ Linköping University \\ SE-581 85 Linköping, Sweden}

ISBN 978-91-7685-634-5 ISSN 0345-7524

Printed in Linköping, Sweden, by LiU-Tryck 2017 


\section{Abstract}

The cerebral microcirculation consists of a complex network of small blood vessels that support nerve cells with oxygen and nutrition. The blood flow and oxygen delivery in the microcirculatory blood vessels are regulated through mechanisms which may be influenced or impaired by disease or brain damage resulting from conditions such as brain tumors, traumatic brain injury or subarachnoid hemorrhage (SAH). Monitoring of parameters relating to the microvascular circulation is therefore needed in the clinical setting. Optical techniques such as diffuse reflectance spectroscopy (DRS) and laser Doppler flowmetry (LDF) are capable of estimating the oxygen saturation $\left(\mathrm{SO}_{2}\right)$ and tracking the microvascular blood flow (perfusion) using a fiber optic probe. This thesis presents the work carried out to adapt DRS and LDF for monitoring cerebral microcirculation in the human brain.

A method for real-time estimation of $\mathrm{SO}_{2}$ in brain tissue was developed based on the $\mathrm{P}_{3}$ approximation of diffuse light transport and quadratic polynomial fit to the measured DRS signal. A custom-made fiberoptic probe was constructed for measurements during tumor surgery and in neurointensive care. Software modules with specific user interface for LDF and DRS were programmed to process, record and present parameters such as perfusion, total backscattered light, heart rate, pulsatility index, blood fraction and $\mathrm{SO}_{2}$ from acquired signals.

The systems were evaluated on skin, and experimentally by using optical phantoms with properties mimicking brain tissue. The oxygen pressure $\left(\mathrm{pO}_{2}\right)$ in the phantoms was regulated to track spectroscopic changes coupled with the level of $\mathrm{SO}_{2}$. Clinical evaluation was performed during intraoperative measurements during tumor surgery $(\mathrm{n}=10)$ and stereotactic deep brain stimulation implantations $(n=20)$. The LDF and DRS systems were also successfully assessed in the neurointensive care unit for a patient treated for SAH. The cerebral autoregulation was studied by relating the parameters from the optical systems to signals from the standard monitoring equipment in neurointensive care.

In summary, the presented work takes DRS and LDF one step further toward clinical use for optical monitoring of cerebral microcirculation. 


\section{Sammanfattning}

Hjärnans mikrocirkulation består av ett komplext nätverk av små blodkärl som försörjer nervceller med syre och näring. Blodflödet och syretransporten i mikrocirkulationen regleras via olika mekanismer som kan påverkas eller försämras vid sjukdom eller hjärnskada som till exempel vid hjärntumörer, traumatisk hjärnskada eller subaraknoidalblödning (SAH). Diffus reflektansspektroskopi (DRS) och laserdopplerteknik (LDF) kan användas för att uppskatta syremättnaden $\left(\mathrm{SO}_{2}\right)$ och övervaka det mikrocirkulatoriska blodflödet, också kallat perfusion, med hjälp av en fiberoptisk prob. Den här avhandlingen beskriver arbetet med att anpassa DRS och LDF för att övervaka den cerebrala mikrocirkulationen.

En metod för realtidsuppskattning av $\mathrm{SO}_{2}$ i hjärnvävnad utvecklades baserat på $\mathrm{P}_{3}$ approximationen av diffus ljustransport och en kvadratisk polynomanpassning till den uppmätta DRS signalen. En specialbyggd fiberoptisk prob konstruerades för att passa mätapplikationen vid tumörkirurgi och neurointensivvård. Mjukvarumoduler med specifika användargränssnitt för LDF och DRS utvecklades för att behandla, spara och presentera parametrar såsom perfusion, reflekterad ljusmängd, puls, pulsativt index och $\mathrm{SO}_{2}$ från insamlade signaler.

Systemen har utvärderats på hud och experimentellt med optiska fantomer med hjärnvävnadslika egenskaper där syretrycket $\left(\mathrm{pO}_{2}\right)$ reglerades för att följa ändringar i reflekterat spektra kopplat till olika nivåer av $\mathrm{SO}_{2}$. Klinisk utvärdering gjordes via intraoperativa mätningar vid tumöroperationer $(n=10)$ och vid djup hjärnstimuleringsimplantation $(n=20)$. En monitoreringsmätning på neurointensivvårdsavdelningen genomfördes hos en patient med skador från SAH. Genom att relatera parametrar från de optiska mätningarna till signaler från standardutrustning för övervakning i neurointensivvård kunde ett sätt att uppskatta statusen för den cerebrala autoregulationen studeras.

Sammanfattningsvis tar det presenterade arbetet DRS och LDF ett steg närmare klinisk användning för optisk monitorering av cerebral mikrocirkulation. 


\section{List of Papers}

I. Peter Rejmstad, Gustav Åkesson, Jan Hillman, and Karin Wårdell, “A laser Doppler system for monitoring of intracerebral microcirculation”, 34th Annual International Conference of the IEEE Engineering in Medicine and Biology Society (EMBC), 2012:1988-91, 2012

II. Peter Rejmstad, Gustav Åkesson, Oscar Åneman, Karin Wårdell, “A laser Doppler system for monitoring cerebral microcirculation: implementation and evaluation during neurosurgery" Medical \& Biological Engineering \& Computing, Vol. 54, pp 123-131, 2016

III. Peter Rejmstad, Johannes Johansson, Neda Haj-Hosseini, Karin Wårdell "A Method for Monitoring of Oxygen Saturation Changes in Brain Tissue using Diffuse Reflectance Spectroscopy" Journal of Biophotonics, 1-10, 2016

IV. Peter Rejmstad, Peter Zsigmond, Karin Wårdell, "Oxygen Saturation Estimation in Brain Tissue using Diffuse Reflectance Spectroscopy along Stereotactic Trajectories”, Submitted, 2016

V. Peter Rejmstad, Neda Haj-Hosseini, Oscar Åneman, Karin Wårdell, "Optical Monitoring of Cerebral Microcirculation in Neurointensive Care", Submitted, 2017

\section{Related Publication}

i. Karin Wårdell, Simone Hemm-Ode, Peter Rejmstad, Peter Zsigmond, "High Resolution Laser Doppler Measurements of Microcirculation in the Deep Brain Structures - a Method for Potential Vessel Tracking", Stereotactic and Functional Neurosurgery, 2016;94:1-9, 2016 



\section{Abbreviations}

This list contains common abbreviations and acronyms used in this thesis

$\begin{array}{ll}\text { ATP } & \text { Adenosine triphosphate } \\ \mathrm{BPG} & \text { Biphosphoglyceric acid } \\ \mathrm{CBF} & \text { Cerebral blood flow } \\ \mathrm{CMBC} & \text { Concentration of moving red blood cells } \\ \mathrm{CMRO}_{2} & \text { Cerebral metabolic rate of oxygen } \\ \mathrm{CPP} & \text { Cerebral perfusion pressure } \\ \mathrm{CSF} & \text { Cerebral spinal fluid } \\ \mathrm{DCI} & \text { Delayed cerebral ischemia } \\ \mathrm{DRS} & \text { Diffuse reflectance spectroscopy } \\ \mathrm{ECG} & \text { Electrocardiogram } \\ \mathrm{f}_{\mathrm{B}} & \text { Blood fraction } \\ \mathrm{Hb} & \text { Deoxygenated hemoglobin } \\ \mathrm{HbO} 2 & \text { Oxygenated hemoglobin } \\ \mathrm{HR} & \text { Heart rate } \\ \mathrm{ICP} & \text { Intracranial pressure } \\ \mathrm{LDF} & \text { Laser Doppler flowmetry } \\ \mathrm{MRI} & \text { Magnetic resonance imaging } \\ \mathrm{NICU} & \text { Neurointensive care unit } \\ \mathrm{NIRS} & \text { Near infrared spectroscopy } \\ \mathrm{ODC} & \text { Oxygen dissociation curve } \\ \text { perf } & \text { Microvascular perfusion } \\ \text { pH } & \text { Hydrogen ion activity } \\ \text { pO } & \text { Partial oxygen pressure } \\ \mathrm{RBC} & \text { Red blood cell } \\ \mathrm{SAH} & \text { Subarachnoid hemorrhage } \\ \mathrm{SO}{ }_{2} & \text { Oxygen saturation } \\ \mathrm{TBI} & \text { Traumatic brain injury } \\ \mathrm{TCD} & \text { Transcranial Doppler ultrasonography } \\ \mathrm{TD} & \text { Thermal diffusion flowmetry } \\ \mathrm{TLI} & \text { Total backscattered light intensity } \\ \mathrm{Xe}-\mathrm{CT} & \text { Xenon-enhanced computed tomography } \\ & \end{array}$




\section{Mathematical symbols}

\begin{tabular}{|c|c|}
\hline$E$ & Energy \\
\hline$h$ & Planck's constant \\
\hline$f$ & Frequency \\
\hline$\lambda$ & Wavelength \\
\hline$n$ & Refractive index \\
\hline$c$ & Speed of light in vacuum \\
\hline$v$ & Velocity \\
\hline$\theta$ & Angle \\
\hline$\varepsilon$ & Extinction coefficient \\
\hline$\sigma$ & Cross-sectional area \\
\hline$\mu_{a}$ & Absorption coefficient \\
\hline$\mu_{s}$ & Scattering coefficient \\
\hline$\mu_{s}^{\prime}$ & Reduced scattering coefficient \\
\hline$g$ & Anisotropy factor \\
\hline C & Concentration \\
\hline$\pi$ & $\mathrm{Pi}$ \\
\hline$l_{m f p_{s}}$ & Scattering mean free path length \\
\hline$l_{t r}$ & Transport mean free path length \\
\hline$\mu_{t}$ & Total attenuation coefficient \\
\hline I & Intensity of photons \\
\hline$e, \exp$ & Euler's number or natural exponential function \\
\hline $\ln$ & Natural logarithm \\
\hline$\mu_{e f f}$ & Effective attenuation coefficient \\
\hline$L$ & Sample length \\
\hline$D$ & Diffusion coefficient \\
\hline$U$ & Fluence rate \\
\hline$P$ & Power or power spectral density \\
\hline$r$ & Radial distance to point source \\
\hline$\rho$ & Fiber separation (source-detector distance) \\
\hline$z_{b}$ & Extrapolated boundary \\
\hline$R_{\text {eff }}$ & Effective reflectance \\
\hline$v^{-}$ & Asymptotic exponential decay constant \\
\hline$p_{H G}$ & Henyey-Greenstein phase function \\
\hline$G_{P 1, s i}$ & Green's function for the semi-infinite $\mathrm{P}_{1}$ approximation \\
\hline$G_{P 3, s i}$ & Green's function for the semi-infinite $\mathrm{P}_{3}$ approximation \\
\hline $\mathbf{v}$ & Velocity vector \\
\hline $\mathbf{q}$ & Scattering vector \\
\hline $\mathbf{k}$ & Particle propagation vector \\
\hline$\varphi$ & Velocity-scattering angle \\
\hline$\omega$ & Angular frequency \\
\hline$\alpha, \beta, \gamma$ & Polynomial coefficients \\
\hline$k, m_{1}$ & Constants for $f_{B}$ model \\
\hline$C, D, E, m_{2}$ & Constants for $\mathrm{SO}_{2}$ model \\
\hline
\end{tabular}




\section{Table of contents}

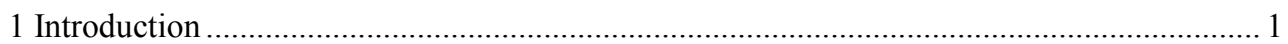

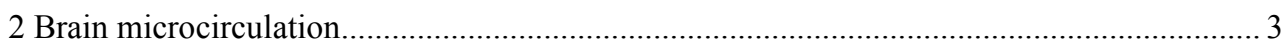

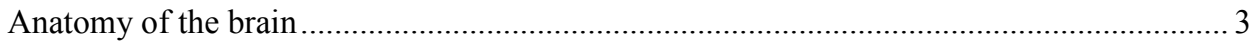

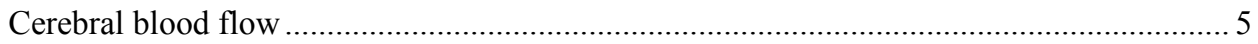

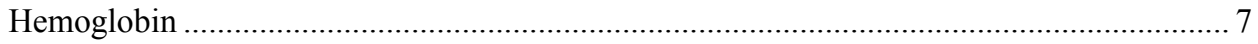

3 Brain impairment and neurosurgical intervention...................................................... 9

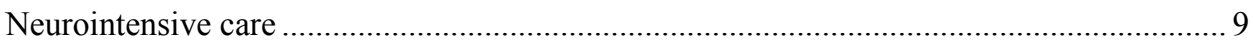

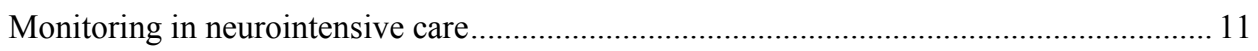

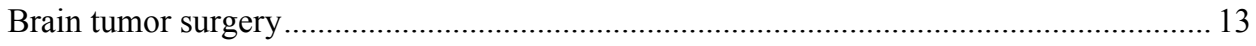

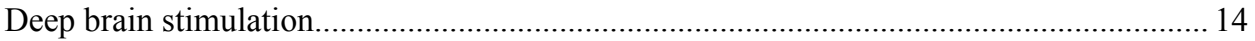

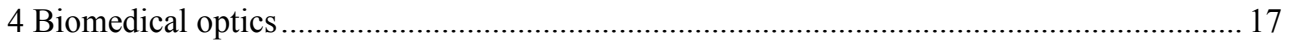

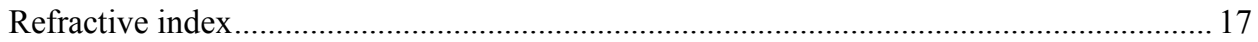

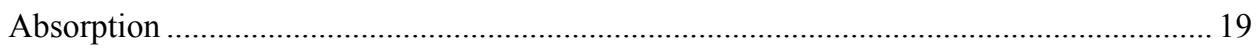

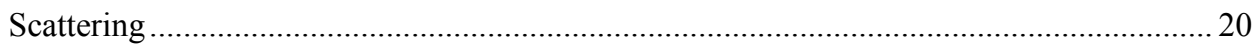

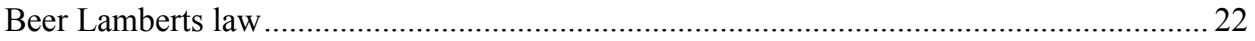

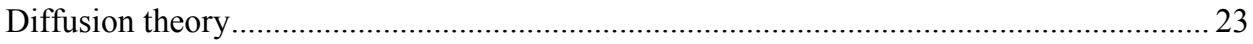

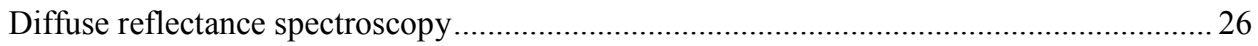

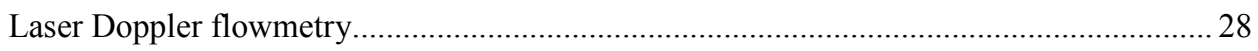

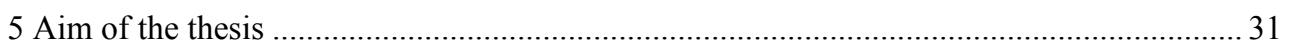

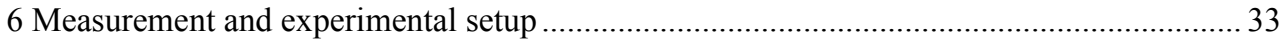

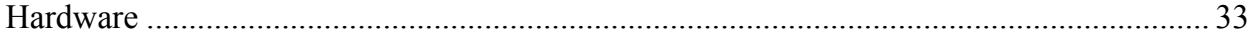

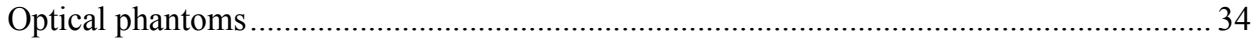

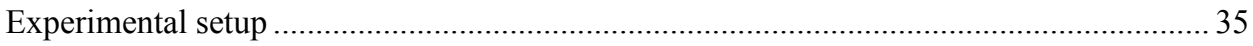

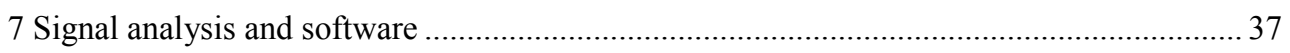

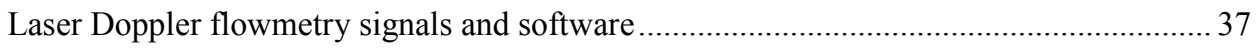

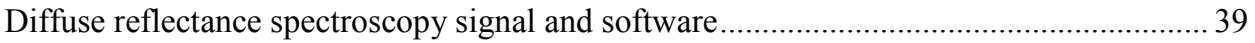

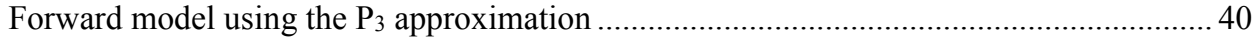

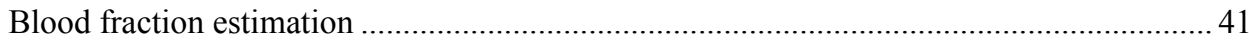

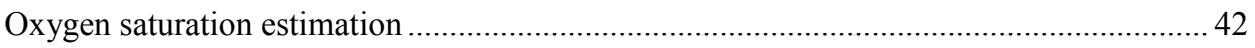

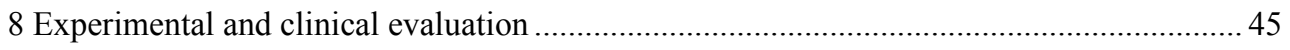

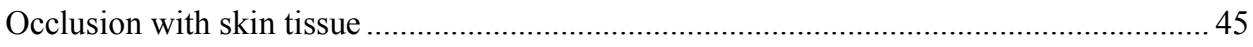




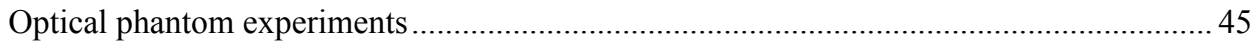

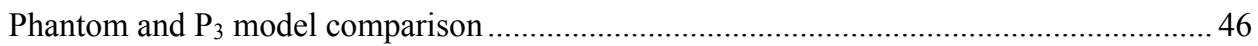

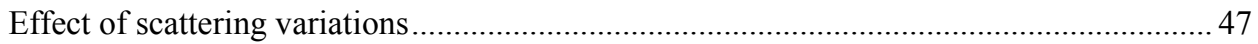

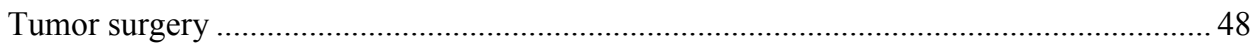

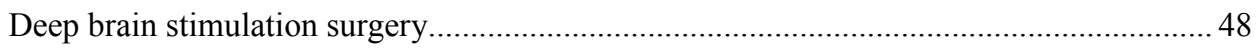

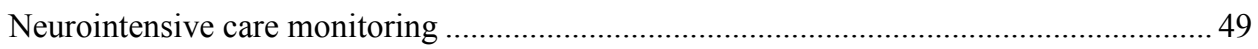

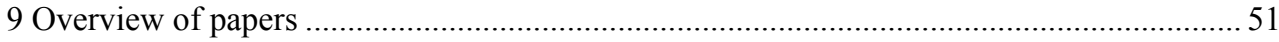

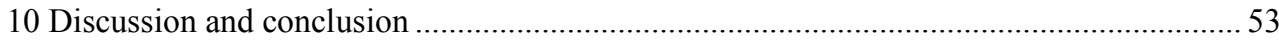

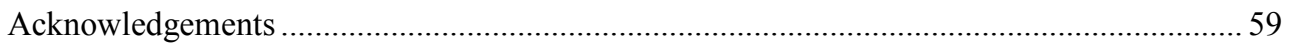

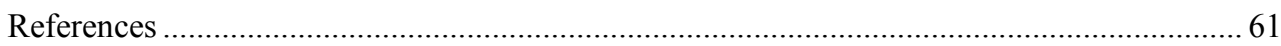




\section{Introduction}

The cerebral microcirculation plays a crucial part in supplying the brain with oxygen and nutrients as well as transporting away waste products. For intact circulation a balance between metabolic supply and demand is met whereas unbalance can cause undesired conditions such as ischemia and hypoxia i.e. shortage of blood and oxygen.

Neurointensive care involves careful monitoring of patients treated for traumatic brain injury (TBI) or subarachnoid hemorrhage (SAH). These patients run the risk of developing delayed brain injury, occurring days after the initial damage, which is difficult to detect or predict using current neuro-monitoring methods [1]. A short time between onset and detection of delayed brain injury would enable a quick intervention that could greatly improve patient outcome [2]. Continuous monitoring of cerebral blood flow (CBF) could for example be used to enable timely detection of reduced or increased blood flow [2]. To provide clinicians with sufficient information and tools to obtain a clear view of the patient's current health there is a need for research on how to improve patient monitoring. Literature reviews of brain monitoring refer to multimodal monitoring as a way to combine diagnostic tools to get more information on the health of the patient [3-5].

Monitoring of the microcirculation includes assessing the vascular throughput by investigating the blood flow and the state of oxygenation. Many studies have been conducted to investigate the blood flow and the oxygen delivery in the microcirculation where for example microscopy of thin skin flaps has been used. However, with the advent of Doppler based techniques that take advantage of the scattering properties of moving red blood cells (RBC) there is now an efficient tool for measuring microcirculatory blood flow using laser light known as laser Doppler flowmetry (LDF) [6]. With the use of diffuse reflectance spectroscopy (DRS), the oxygenation of the blood can be studied through the optical properties of hemoglobin that change depending on the oxygen carrying status [7]. DRS has also been studied as a method to perform tissue characterization using fiber optics in clinical applications such as oncology, neurosurgical navigation and endoscopic investigation.

There are currently several clinical environments such as the neurointensive care unit (NICU) or the neurosurgical operating room that would benefit from the use of optical techniques to guide therapeutic or surgical procedures. Previous animal studies with optical measurements in myocardial and brain tissue have shown a potential for using LDF to study the microvascular perfusion [8-10]. Currently the techniques are being adapted for human studies together with research and in close collaboration with clinics for different interventions and treatments.

Neurosurgical interventions such as brain tumor surgery and deep brain stimulation (DBS) electrode implantation are examples of procedures that may benefit from using optical techniques for guidance $[11,12]$. Brain tumor surgery is a procedure where tumor tissue is surgically removed in order to cure or prolong life expectancy for patients [13]. As tumor tissue can be hard to distinguish from normal tissue with the naked eye, optical techniques such as DRS and fluorescence spectroscopy can be of use [11]. LDF has for example been suggested 
as a potential method to provide optical guidance during DBS electrode implantation [13-15]. LDF has mainly been used to measure skin perfusion and is widely applied in the field of dermatology for example to assess the process of "wound healing" or to investigate viability of tissue in skin flap surgery [16]. From being well established for skin applications such as burn treatment, tumor and allergy investigations the work presented in this thesis takes LDF a step further towards clinical use in neurosurgical and NICU applications.

The perfusion signal from the LDF system was used to calculate the heart rate (HR) and pulsatility index (PI) using detection of pulsation peaks and troughs relating to the systolic and diastolic phases in the heart cycle. A method for real-time estimation of $\mathrm{SO}_{2}$ and blood fraction $\left(f_{B}\right)$ was developed based on a forward model with spectra generated using the $\mathrm{P}_{3}$ approximation for diffuse light transport in tissue. The $\mathrm{P}_{3}$ approximation was used as normal diffusion theory is limited to large s-d distances where the light has lost its directional preference. The method was calibrated using optical phantoms for different blood concentrations. Software modules were made to present parameters related to the microcirculation from the LDF and DRS signals. The presented parameters were: perf, TLI, $\mathrm{HR}, \mathrm{PI}$ from the LDF signals and $\mathrm{SO}_{2}$ and $\mathrm{f}_{\mathrm{B}}$ from the DRS signals. The work described here includes an observational study of differences between brain tissues and was performed by measuring with LDF and DRS during brain tumor surgery. Spectra collected with DRS along stereotactic trajectories during DBS implantation were analyzed to extract $\mathrm{SO}_{2}$ and $\mathrm{f}_{\mathrm{B}}$ estimations. The LDF and DRS systems were used to monitor the microcirculation in a patient in the NICU suffering from SAH, in order to investigate the feasibility of using these systems as a compliment to existing monitoring equipment.

The research presented in this thesis describes how the optical techniques LDF and DRS were adapted and can be applied in the fields of neurosurgery and neurointensive. The work has provided insight regarding questions related to the adaptation of LDF and DRS for monitoring the cerebral microcirculation in clinical settings. 


\section{Brain microcirculation}

Cerebral microcirculation plays a crucial part in the function of the brain as it provides a close connection between blood and tissue that is needed for the exchange of oxygen, nutrients and waste products. The microcirculation consists of a large network of small blood vessels that distribute the blood throughout different organs. All living cells are dependent on oxygen and nutrients in order to survive. Oxygen is used in cells to produce the energy transporting molecule adenosine triphosphate (ATP) through phosphorylation [17].

The heart pumps oxygen-rich blood from the lungs through larger vessels starting with the aorta out to smaller and thinner branches reaching the smallest capillaries in the microcirculation. The walls of the capillaries are so thin that oxygen can diffuse out to the surrounding cells and waste products can be transported away. Oxygen is mainly transported through the blood stream in RBCs or erythrocytes that are filled with hemoglobin molecules each carrying up to four oxygen atoms. One of the most energy demanding organ in the body is the brain. Although the brain only weighs around two percent of the total body weight this organ consumes $20 \%$ of the total oxygen consumption and require $15-20 \%$ of the total cardiac output. The brain contains approximately 86 billion $\left(10^{9}\right)$ neurons [18].

\section{Anatomy of the brain}

The central nervous system comprises the brain together with the spinal cord where sensory information from various parts of the body through afferent nerve signals is transmitted to the brain, is processed and efferent signals are sent to the respective effector organs. The anatomy and physiology of the human brain is briefly described in order provide a basic understanding some of the injuries and illnesses that could affect the brain.

\section{Skull, meninges and cerebral spinal fluid}

The soft brain tissue is protected against external forces by the skull. Beneath the skull three membrane layers of connective tissue known as dura, arachnoid and pia mater protects the brain tissue [19]. The subarachnoid space takes its name from the trabecular structure with fibers spanning between the arachnoid and pia (Fig. 2.1) which resemble the appearance of spider's web [20]. The brain and spinal cord are surrounded by cerebrospinal fluid (CSF) which is a liquid similar to blood plasma that fills the space between arachnoid and pia mater as well as the four compartments known as ventricles. While acting as a shock absorber to the brain the CSF is also part of the brain circulation by transporting nutrients and waste products. The CSF is formed in the capillary rich zones (choroid plexus) lining the ventricles where water and a few other substances such as $\mathrm{O}_{2}, \mathrm{CO}_{2}$ can pass through from the blood stream [21]. The brain resides in a compartment encased with bone with a limited volume. As a result of the limited cranial volume any increase in volume inside the skull has to be compensated for. For example, an increase in blood volume must be made up by a decrease in CSF volume, in order to avoid increased intracranial pressure (ICP) and potential brain damage. If the ICP increases above normal values, there will be a high risk of drain damage as the vulnerable soft brain tissue is easily deformed and left without sufficient blood flow. 


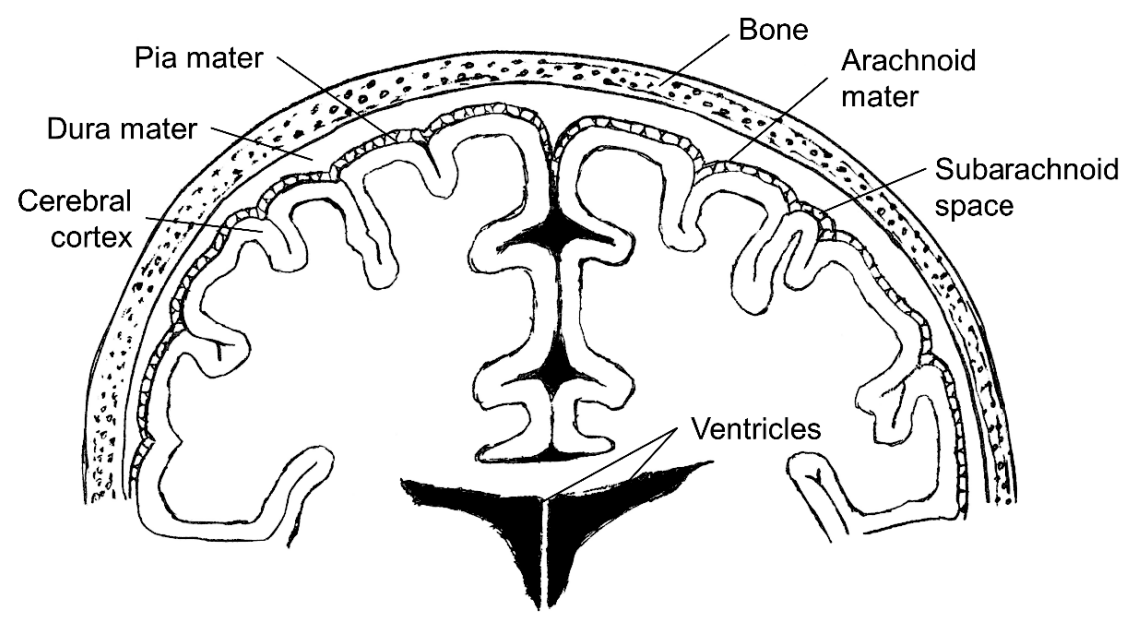

Figure 2.1 Brain anatomies with skull, meninges and ventricles in a coronal view

\section{Gray and white matter}

The brain tissue comprises of gray and white matter where gray matter at the surface of the cerebrum referred to as cortex, consists of neuronal cell bodies, dendrites, and synapses. The white matter located beneath the cortex layer consists mostly of bundles of axons covered with myelin that act as wires and connect various parts of the brain [21]. The gray matter needs more oxygen and energy as its cells constantly relay signals throughout the brain and is thus vascularized to a larger extent containing about three times as many capillaries as white matter [22]. There are also areas that are a mix of gray and white matter, for example in the thalamic region of the brain. The gray and white matters have a blood flow of approximately 50 and 20 $\mathrm{ml} / 100 \mathrm{~g} / \mathrm{min}$ respectively at rest $[23,24]$. However, gray matter may have blood flows of up to $400 \mathrm{ml} / 100 \mathrm{~g} / \mathrm{min}$ at full dilation compared to white matter with only $80 \mathrm{ml} / 100 \mathrm{~g} / \mathrm{min}$ [24].

\section{Vasculature}

The brain is supplied by blood through the four main arteries (two internal carotids and two vertebral arteries) that connect to the circle of Willis at the base of the brain where the blood is distributed by branching blood vessels to different parts of the brain. The blood is then led through arterioles with thick walls lined with smooth muscle cells that react to stimuli to control the blood flow [25]. After passing through the microvascular capillaries, illustrated in Fig. 2.2, the blood passes through venules and is drained, mainly in a radial pattern, into larger veins that transport it back from the brain by the jugular veins [26].

\section{Microcirculation and capillaries}

The main purpose of the microcirculation is to facilitate the transport of oxygen and nutrients to the cells. The vascular network contains a range of different types of blood vessels with varying sizes and shapes. The infrastructure of the circulatory network is made up of large blood vessels whose foremost purpose is to transport blood from the lungs and heart to different 
tissues through smaller vessels and capillaries, Fig 2.2, where an exchange of important molecules such as oxygen and glucose between RBCs and the surrounding tissue takes place. Early microcirculation studies made by Krogh [27] showed that a small pressure gradient was enough to enable oxygen to diffuse from capillaries into the tissue of mammals. The arterioles in the brain have thin walls compared with other organs due to lower transmural pressure [22].

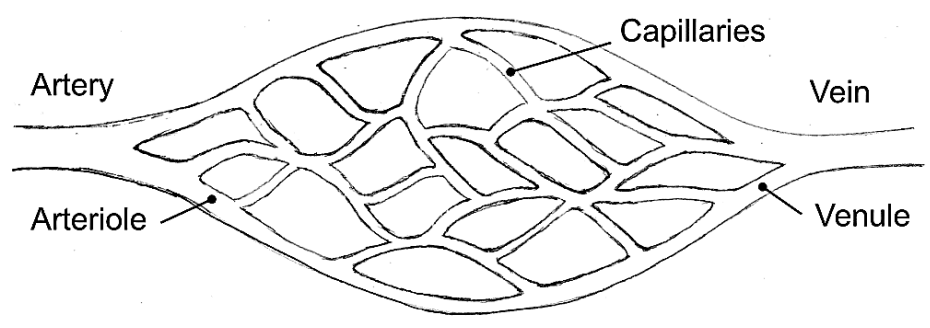

Figure 2.2 Illustration of a vascular network where blood passes from artery to vein through capillary blood vessels

The blood flow in the largest blood vessels $\left(\varnothing_{\text {aorta }}=25 \mathrm{~mm}\right)$ has a speed of $40 \mathrm{~cm} / \mathrm{s}$ compared to the flow velocity of less than $0.1 \mathrm{~cm} / \mathrm{s}$ in the capillary blood vessels $\left(\emptyset_{\text {capillary }}=0.005-0.01 \mathrm{~mm}\right.$ with a cross sectional area of about $5000 \mathrm{~cm}^{2}$ in total) [28].

\section{Blood brain barrier}

The blood brain barrier (BBB) refers to the restrictive nature of the capillaries in the brain with tight junctions between endothelial cells lining the blood vessel walls which lack micro-pores or discontinuations that otherwise would permit substances to passively diffuse into the brain tissue [24]. The few substances that can pass through the $\mathrm{BBB}$ are the lipid-soluble $\mathrm{O}_{2}$ and $\mathrm{CO}_{2}$ molecules whereas other crucial substances such as glucose need to be actively transported through the vessel walls by facilitated diffusion.

\section{Cerebral blood flow}

The CBF is of the utmost importance for keeping the cells of the central nervous system vital. The brain needs a constant supply of oxygen and glucose to survive and has limited reserves that only last for a few seconds if the blood supply should be cut off [29]. The limited energy reserve of the brain makes it vulnerable to damage if the blood flow is not quickly restored.

The flow in the blood vessels of the brain is regulated through different mechanisms [30]. The microcirculatory blood flow can be affected either by systemic regulation or locally through autoregulation where reactions to changes in physical and chemical factors affect the muscles in the vasculature. The distribution of blood to tissues in need of oxygen and nutrition is in part controlled by autoregulation. All mechanisms of autoregulation are not yet fully understood but can generally be described by the three following principles. 
The first principle is the neurogenic regulation that involves sympathetic nerve regulation, the second is the myogenic response, which reacts to transmural pressure variation, and the third is metabolic control, which activates based on local changes in partial oxygen pressure $\left(\mathrm{pO}_{2}\right), \mathrm{pH}$ and partial carbon dioxide pressure $\left(\mathrm{pCO}_{2}\right)$. Almost every organ is innervated by nerves of the autonomic nervous system where the sympathetic nervous system relays the blood to the tissues that need it the most and away from secondary organs in "fight-or-flight" situations. The sympathetic nervous system plays an important role in regulating blood pressure and cardiac output. However, the neural control of brain vasculature is relatively small. Another mechanism is the myogenic response where the blood flow is regulated on a local level. Smooth muscle cells are triggered by signals from stretch sensitive channels which indicate changes in blood pressure and modulate the contractility of the vessel wall. In the metabolic demand mechanism, the smooth muscle cells may also react to information from chemoreceptors sensitive to changes in $\mathrm{pO}_{2}, \mathrm{pCO}_{2}$ and $\mathrm{pH}$ in a type of neuronal reflex. A reduction of $\mathrm{pH}$ in the extracellular fluid will, for example, result in dilation of the vasculature with increased cerebral blood flow [30].

The blood vessels can contract or dilate through input from signal substances such as endothelin and nitric oxide (NO) [31]. Concentration variations of substances affecting the capillary blood flow, e.g. NO, may sometimes result in intermittent oscillations known as vasomotion that may occur 5-10 times per minute [26, 28].

\section{Cerebral autoregulation}

The CBF remains constant within a wide range of systemic blood pressures due to the intrinsic autoregulation in the vasculature of the brain. This effect can be used to review the status of the autoregulation in the brain that is reflected by a constant blood flow despite rather large variations in the cerebral perfusion pressure (CPP) [26, 32]. CPP is the blood pressure gradient over the cerebral vascular bed which can be derived using the mean arterial pressure (MAP) and ICP signals as shown in Eq. 2.1 [2]. The cerebral autoregulation can be assessed through studying the relation between CPP and CBF illustrated in Fig. 2.3, also known as the Lassen's curve. Intact autoregulation is characterized by a horizontal relation between CPP and CBF for CPP between 50 and $150 \mathrm{mmHg}$ whereas CBF increases linearly with MAP or CPP in case of impaired autoregulation [33].

$$
C P P=M A P-I C P
$$




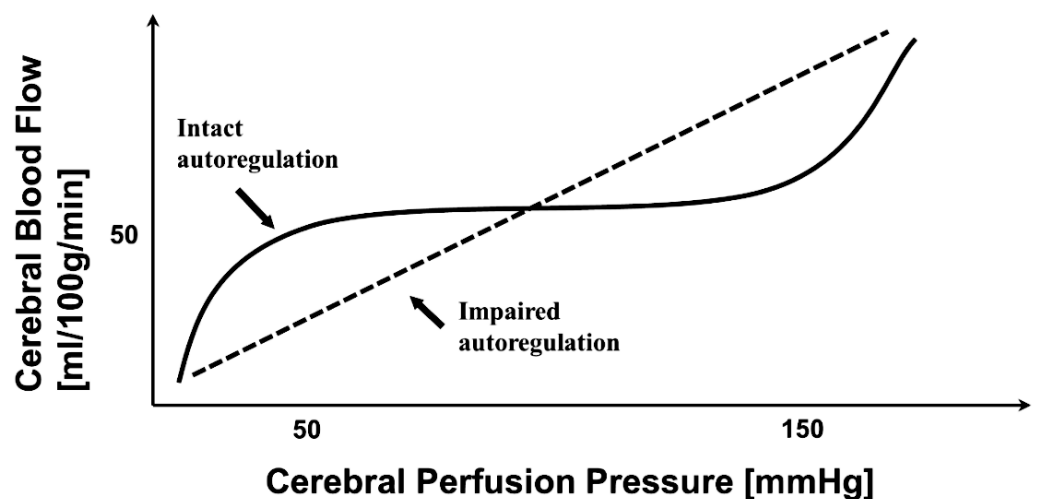

Figure 2.3 Cerebral blood flow against cerebral perfusion pressure for intact and impaired autoregulation known as the Lassen's curve

\section{Normal cerebral conditions}

In normal conditions, the adult human brain maintains a balance of blood flow in relation to the metabolic demand of the tissue. Normal ranges of parameters related to brain physiology are listed in Tab. 2.1. Parameters that are commonly monitored to ensure brain homeostasis are for example CBF, ICP and CPP. Other important parameters are the $\mathrm{pO}_{2}$, oxygen saturation $\left(\mathrm{SO}_{2}\right)$ and the cerebral metabolic rate of oxygen $\left(\mathrm{CMRO}_{2}\right)$, the latter being a measure of the oxygen consumption in the brain tissue [34].

Table 2.1 Normal range for adult human brain circulation parameters

\begin{tabular}{|l|l|l|}
\hline Parameter & Normal values & Reference \\
\hline $\mathrm{CBF}$ & $48-58 \mathrm{ml} / 100 \mathrm{~g} / \mathrm{min}$ & Hartmann et al. [23] \\
\hline $\mathrm{ICP}$ & $7-15 \mathrm{mmHg}$ & Steiner et al. [35] \\
\hline $\mathrm{CPP}$ & $60-160 \mathrm{mmHg}$ & Cipolla et al. [30] \\
\hline $\mathrm{pO}_{2}$ & $20-35 \mathrm{mmHg}$ & Roh et al. [36] \\
\hline $\mathrm{SO}_{2}$ & $30-60 \%$ & Roh et al., Severinghouse [36, 37] \\
\hline $\mathrm{CMRO}_{2}$ & $3.0-3.5 \mathrm{ml} / 100 \mathrm{~g} / \mathrm{min}$ & Murray et al. [34] \\
\hline
\end{tabular}

\section{Hemoglobin}

Hemoglobin is a globular protein which is the main oxygen-transporting molecule in the body. The protein consists of four subunits known as heme groups that can bind one oxygen molecule each. The chemical process of oxygen binding to hemoglobin causes a conformational change in the four subunit structures of hemoglobin which increase the oxygen affinity and binding of additional oxygen molecules [38]. The increased oxygen affinity is known as the cooperativity of hemoglobin and a reason as to why the oxygen dissociation curve (ODC) has a sigmoidal shape as seen in Fig. 2.4 [37]. 
Hemoglobin binds oxygen reversibly to enable its release when there is a small concentration gradient present as in the capillaries e.g. in tissues with low $\mathrm{pO}_{2}$ and $\mathrm{pH}$ [38]. There are several different types of hemoglobin and molecules in the globin family where some are hemoglobin, myoglobin and neuroglobin [39]. Normal hemoglobin can carry other molecules apart from oxygen and these are subsequently named after what they carry namely carboxyhemoglobin, and sulfhemoglobin which carries carbon monoxide or sulfur instead of oxygen. Methemoglobin is another variant where the iron of the heme group resides in a ferric state $\left(\mathrm{Fe}^{3+}\right)$, instead of the normal ferrous $\left(\mathrm{Fe}^{2+}\right)$, which makes it unable to carry oxygen [40]. Myoglobin is found in the muscle tissue and is similar to hemoglobin in transporting oxygen with the difference that it contains a single heme group and thereby carries one oxygen molecule at a time. Neuroglobin, which contains a single heme group, is suggested to be involved in the protection of neurons in states of ischemia or hypoxia, and may play a role in NO regulation, which is important to the local control of blood flow [39]. Normal physiological conditions in the human body are $\mathrm{T}=37^{\circ} \mathrm{C}, \mathrm{pCO}_{2}=50 \mathrm{mmHg}$ and $\mathrm{pH}=7.4$ represented by the green ODC curve in Fig. 2.4. If a lowering of the $\mathrm{pH}$ occurs this will induce a right-shift in the ODC, also known as a Bohr shift, which causes the release of hemoglobin-bound oxygen. Higher concentrations of $\mathrm{CO}_{2}$ give a right shift while also a lower temperature, for example room temperature $\left(21^{\circ} \mathrm{C}\right)$ instead of $37^{\circ} \mathrm{C}$ for physiological conditions, result in a left-shift in the ODC. Increased concentration of biphosphoglyceric acid (BPG), which is involved in cell metabolism (glycolysis), lowers the oxygen binding affinity of hemoglobin causing a right shift in the ODC. An example of when these factors together affect the oxygen affinity of hemoglobin is in the muscles during activation when more oxygen is needed and the temperature locally rises and where $\mathrm{CO}_{2}$ is produced and $\mathrm{pH}$ is reduced as acid is formed through anaerobic cell respiration [26]. These changes will all influence hemoglobin's affinity to oxygen and enhance the release of oxygen.

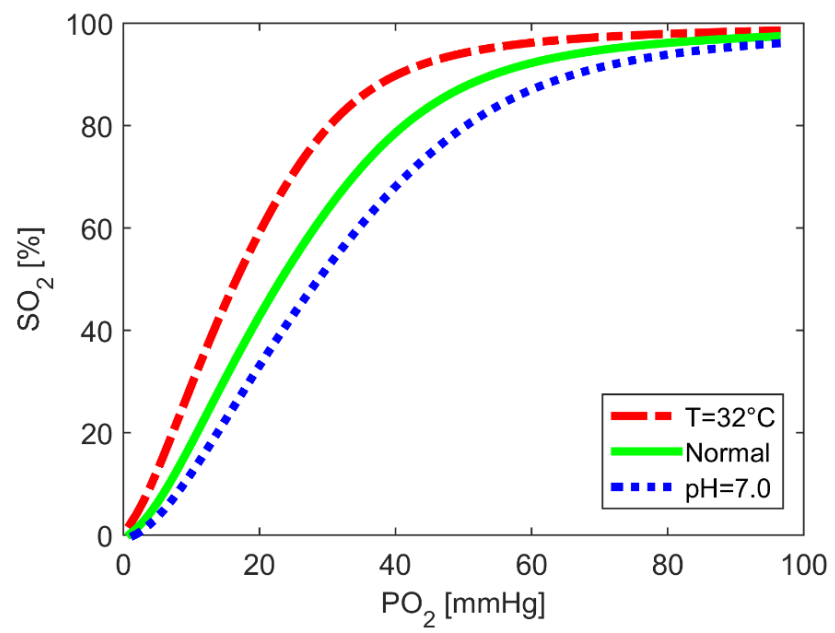

Figure 2.4 The oxygen dissociation curve (ODC) of hemoglobin for normal physiological conditions represented by the solid green curve $\left(\mathrm{T}=37^{\circ} \mathrm{C}, \mathrm{pCO}_{2}=50 \mathrm{mmHg}\right.$ and $\left.\mathrm{pH}=7.4\right)$, an ODC for $\mathrm{T}=32{ }^{\circ} \mathrm{C}$ is represented by the red dashed-dotted curve and an ODC for $\mathrm{pH}=7.0$ is represented by the blue dotted curve 


\section{Brain impairment and neurosurgical intervention}

There are several brain disorders and interventions in neurosurgery that would benefit from additional knowledge regarding cerebral microcirculation. To give a short background of and motivation for the research included in this thesis, some of these areas are introduced and described below.

\section{Neurointensive care}

The NICU is a highly specialized unit with a range of monitoring and life supporting equipment. Patients treated in the NICU suffer from different types of neurological damage. For example, TBI and SAH are serious conditions associated with high mortality. Work in the NICU is focused on keeping injured patients stable and preventing or detecting the onset of secondary brain injury that may occur in the aftermath of the primary damage.

\section{Traumatic brain injury}

Traumatic brain injury is one of the oldest and most common injuries known to humans. Skeletons with fatal skull fractures have been found and estimated to be 3 million years old. Findings of prehistoric human craniums with skull trauma show evidence of warfare and accidents from hunting or interaction with a harsh environment. TBI is a wide definition of an injury to the brain caused by trauma to the head resulting in brain damage through direct force, hematoma (bleeding), contusion or skull fracture. TBI is classified as mild moderate or severe using the "Glasgow Coma Scale" (GCS) [41]. TBI is today a leading cause of disability and mortality in young people where one main reason is motor-vehicle use in low and middle income countries [42]. The primary injury occurs at the time of the trauma resulting in tissue shock, penetrating injury or skull fractures. Secondary insults are initiated by the primary damage but first appear a time after the initial trauma and are possible to treat if detected in time. The main reason for neurological monitoring in TBI patients is to prevent or recognize the onset of secondary injuries in order to start treatment and avoid further damage [2]. TBI leads to complications such as delayed ischemia in $10-30 \%$ of the cases [42].

\section{Subarachnoid hemorrhage}

The subarachnoid mater, Fig. 2.1, is a membrane of connective tissue where the subarachnoid space, Fig. 3.1, which contains fibrous threads and blood vessels, resides between the arachnoid and pia mater [20]. As the name suggests SAH consists of bleeding in the subarachnoid space which can be caused by different reasons. The most common cause of SAH is head trauma. However, most cases that are not caused by trauma occur due to the rupture of aneurysms, Fig. 3.1, in the brain [31]. Aneurysms are bulging malformations of arteries, which are caused by weak vessel walls. Most aneurysms will go unnoticed unless they are very large, burst or are found by medical imaging. If an aneurysm bursts it will result in SAH. Smoking and hypertension are risk factors for SAH where physical exercise is a factor that shows a lower 
risk. The intracranial space is limited in volume and any extra blood volume that gathers will exert pressure on the surrounding tissue. SAH is categorized as a subset of stroke and it accounts for $5 \%$ of the cases and has a high risk of mortality ( $\sim 50 \%$ within 30 days) or chronic disability. $\mathrm{SAH}$ has a great social and economic cost as it commonly affects individuals at a relatively young age with an average onset at 55 years of age and often results in lifelong cognitive disability [31, 43]. Treatments to prevent rebleedings after SAH are endovascular coiling or surgical clipping [31, 43].

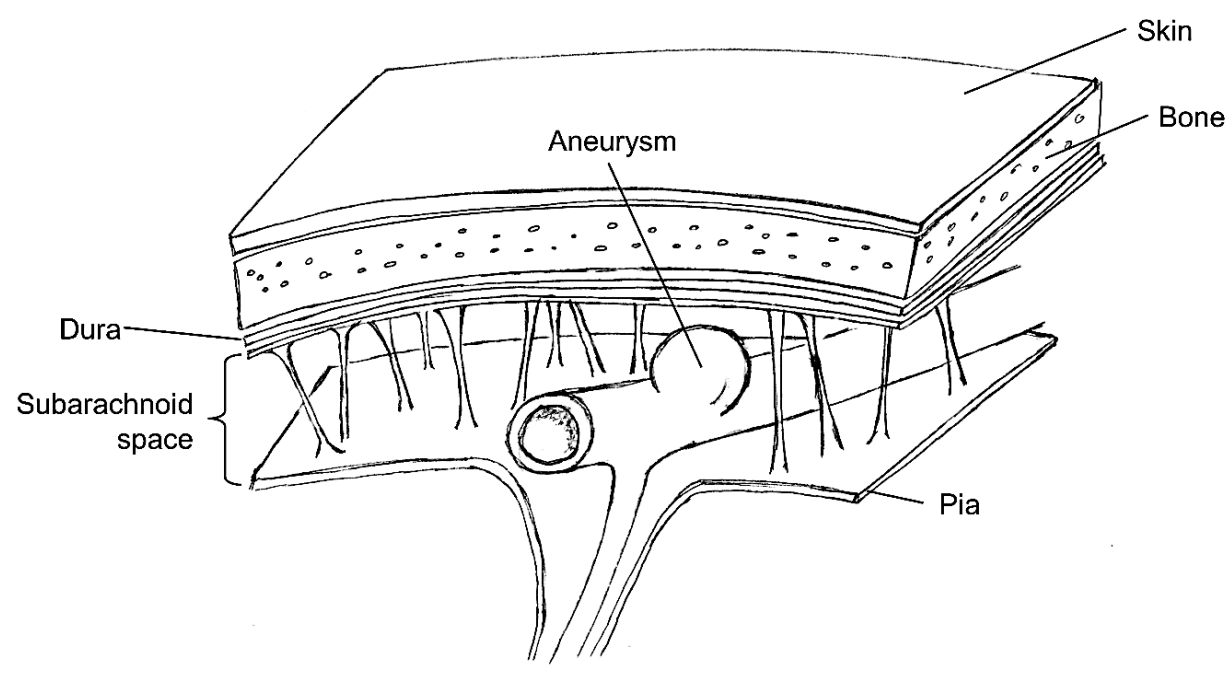

Figure 3.1 Subarachnoid aneurysm as a possible cause of brain hemorrhage

\section{Secondary brain injury}

Patients suffering from severe brain damage have a risk of deteriorating a time after the primary insult due to what is known as secondary brain injury. The primary injury may be physical in nature whereas secondary injury may occur hours or days after the initial insult. This is believed to result from the release of intracellular signaling substances as a reaction to damaged cells. The damaged cells trigger a metabolic cascade where the tissue reacts in an unfavorable way [44]. Secondary brain injury can also be caused by brain swelling resulting in ICP that damages brain tissue by deforming the cells or reducing blood flow resulting in ischemia and hypoxia in the tissue [45].

Vasospasm is a phenomenon related to secondary brain injury and can occur after SAH. Vasospasm is characterized by abnormal vasoconstriction of blood vessels in the brain. The onset of vasospasm correlates with that of secondary brain injury and is diagnosed radiologically by medical imaging using an angiogram or an examination with transcranial Doppler ultrasound (TCD). Delayed cerebral ischemia (DCI) can be a result of vasospasm and has a regional effect on the brain [43]. About 30-40\% of the cases of SAH have been found to develop DCI [32]. The mechanisms of secondary injury may include production of free radicals, 
apoptosis (unscheduled programmed cell death), disrupted BBB, inflammation, release of NO, imbalance of ion gradients and ischemia. The cause for vasospasm is not fully understood but is associated with the reduction in the NO level which may be caused by the breakdown of cells and release of hemoglobin in the subarachnoid space after hemorrhage [31]. The delayed ischemia may be caused by hypotension, microvascular failure, hypoxia or elevated ICP [41].

\section{Monitoring in neurointensive care}

Many different sensor techniques are used to monitor the status of a patient during neurointensive care. These methods monitor physiological parameters used to guide therapy in clinics where the measured parameters should be kept within a normal range to avoid impaired function or tissue damage. Multimodal monitoring is commonly used in neurointensive care where combined information from the different signals is interpreted in order to make informed decisions. Some of the parameters that can be measured in multimodal brain monitoring are described in the following sections.

\section{Electric activity of the brain}

The electroencephalogram or EEG measures the electrical signals from the brain through the use of skin surface electrodes. The EEG technique requires experts for signal interpretation and is influenced by variations in the level of anesthesia, oxygenation and blood flow. One attempt to simplify the interpretation is the bispectral index where the phase and power between frequencies in the signal is statistically processed into a number ranging from 0 to 100 where 100 represents a fully awake patient, 60 an unconscious state and 0 represents a non-changing signal or death. [46]

\section{Intracranial pressure}

The ICP is a parameter of high importance in neurocritical care where an increase over $20 \mathrm{mmHg}$ for extended periods results in brain damage through herniation (compressed tissue) or ischemia. ICP can be monitored using an intraventricular catheter connected to a pressure transducer, or with a manometer equipped with fiber optics [46]. The catheter is inserted into the ventricles through a burr hole in the skull and kept in place during the monitoring process. The time used to monitor with an invasive ICP catheter is kept as short as possible to minimize the risk of infection. Normal ICP values should stay below $15 \mathrm{mmHg}$ with a treatment threshold of $20 \mathrm{mmHg}$, localized or focal ischemia occurs for ICP $>20 \mathrm{mmHg}$ and general (global) ischemia for ICP above $50 \mathrm{mmHg}$ [46]. Elevated ICP is an important predictor for edema and can be treated by draining CSF with an external ventricular drain or by administrating mannitol. Mannitol is a sugar derivate that acts as an osmotic agent resulting in a gradient that draws water from the tissue into the vascular system. A third option to reduce ICP is to sedate the patient further using barbiturates, thereby lowering the brain activity and its metabolic need for oxygen which acts as a vasoconstrictor reducing blood flow [47]. The CPP is derived using the MAP and ICP signals from invasive catheters and can be of help when studying the autoregulation of the brain as described in chapter two, Fig. 2.3. 


\section{Cerebral blood flow}

Cerebral blood flow can be measured intermittently or continuously by means that are either noninvasive or invasive in nature. A few methods relevant to neuro-monitoring are briefly described.

TCD is based on the Doppler shifted ultrasound and is used to noninvasively "listen" through bone windows to assess blood flow velocities in large brain arteries such as the middle cerebral artery [48]. Normal middle cerebral artery flow values are between 35 to $90 \mathrm{~cm} / \mathrm{s}$. The PI is a variable derived from the TCD signal, which may be used to represent distal vascular resistance and correlates with CPP. The PI (or Gosling PI) is calculated as in Eq. 3.1 where the diastolic flow velocity $\left(F V_{\text {dias }}\right)$ is subtracted from the systolic flow velocity $\left(F V_{s y s}\right)$ and divided by the mean flow velocity $\left(F V_{\text {mean }}\right)$ [49-51].

$$
P I=\frac{F V_{\text {sys }}-F V_{\text {dias }}}{F V_{\text {mean }}}
$$

TCD of the middle cerebral artery can be used to detect vasospasm after SAH where flow velocities exceeding $120 \mathrm{~cm} / \mathrm{s}$ indicate vasospasm [46].

Functional maps of cerebral perfusion can be made using a technique known as Xenonenhanced CT (Xe-CT). Inhalation of Xenon gas during CT scans can be used in order to track the level of cerebral perfusion. The xenon gas diffuses into the brain parenchyma through the walls of blood vessels and attenuates the X-rays making it a contrast agent for tissue perfusion. The amount of parenchymal xenon is proportional to the blood flow and is used to create functional maps of the regional CBF [31]. By using a mobile CT together with xenon to examine the blood flow, patients treated in the NICU can benefit from this imaging modality [52].

Two methods for continuous monitoring of $\mathrm{CBF}$ are currently being explored. Methods evaluated for CBF monitoring are thermal diffusion (TD) and LDF [53]. LDF was used in this thesis (Papers I, II and V) and is further described in a following chapter. The TD system from Hemedex ${ }^{\circledR}$ heats up a region around the probe by $2{ }^{\circ} \mathrm{C}$ and measures the brain temperature at $5 \mathrm{~mm}$ away from the produced heat [54]. The power needed to heat up the region around the thermistor is indirectly related to the blood flow.

\section{Cerebral oxygenation}

The jugular venous saturation $\left(\mathrm{SjvO}_{2}\right)$ provides an indirect parameter for assessing the cerebral oxygenation and can be measured intermittently or continuously by inserting a catheter that either is used to collect blood samples directly from the jugular bulb or a catheter that is equipped with a fiber optic sensor that works like a normal pulse oximetry device [55]. Normal $\mathrm{SjvO}_{2}$ values range from 50 to $70 \%$ and reflects global cerebral oxygen extraction [2].

Local oxygenation can be assessed by measuring the $\mathrm{pO}_{2}$ in brain tissue using a Clark type microelectrode with a semipermeable membrane. The membrane permits oxygen to diffuse through it and the $\mathrm{O}_{2}$ concentration can be measured from the generated current [56]. These 
sensors $\left(\right.$ Licox $^{\circledR}$ and Neurotrend ${ }^{\circledR}$ ) have a sampling zone of about $15-22 \mathrm{~mm}^{2}$ and take up to $30 \mathrm{~min}$ to stabilize. A recommended lower threshold of $15-20 \mathrm{mmHg}$ is advised for therapy initiation to reverse hypoxia when monitoring with $\mathrm{pO}_{2}$ sensors [2]. In this thesis (Papers III, IV and V) a method based on DRS was developed and used to estimate the local $\mathrm{SO}_{2}$.

\section{Brain tissue metabolism}

The metabolism of brain tissue can be monitored using microdialysis where thin probes are placed close to the injured part of the brain. The probes are equipped with semipermeable membranes which connect channels inside the probe and filled with a saline based liquid mimicking CSF which is slowly circulated. Molecules involved in metabolic processes such as lactate, pyruvate, glutamate, and glucose can diffuse into the probe from the extracellular space and be collected into sample vails which are analyzed [57]. The radius for the tissue volume of influence around the catheter was estimated to $0.85 \pm 0.25 \mathrm{~mm}$ according to simulations [58].

\section{Brain tumor surgery}

Brain and central nervous system cancer had an age-standardized incidence rate of 6.9 per 100000 people in Europe 2012 [59]. Tumors caused by brain cancer are treated by different means where surgery, chemotherapy and radiotherapy are the most common methods. Tumors of the nervous system have different origins, types and malignancy grades. Classification of tumors can be made based on the WHO scale from one to four (I to IV) where I and II are categorized as benign and III and IV are malignant [31].

Glioma is the most common malignant tumor type in adult human brains, which originates from abnormal cell growth of the nerve supporting glial cells such as astrocytes, oligodendrocytes and ependymal cells. Most gliomas are found in white brain matter and can be of various shapes. An example of an axial MRI slice of a brain tumor is seen in Fig. 3.2. As gliomas have an infiltrative nature the border between the tumor and the surrounding tissue is usually hard to distinguish which is why neurosurgical removal may be troublesome. If the tumor grows without sufficient blood supply the center of the tumor may be necrotic and consist of dead tissue $[31,60]$.

The microenvironment inside solid tumors is often related with hypoxia, low $\mathrm{pH}$ and may consist of necrotic tissue caused by insufficient blood flow. The blood vessels in tumors are characterized by unstructured growth with irregular shape and diameters where the blood flow can be static and might change direction with time [61]. The tumor blood vessels often grow in a coiling shape [62]. Tissue with a volume less than $1 \mathrm{~mm}^{3}$ is able to get enough oxygen and nutrition through diffusion whereas larger tumors need vascularization [63]. Tumor blood vessels are more abundant in the border neighboring normal tissue and sparser in the center. The rapid tissue growth results in 'leaky' blood vessels proposedly due to lack of proper formations of intracellular junctions [64]. This kind of "leakage" allows molecules that otherwise would not reach the brain to enter it. 


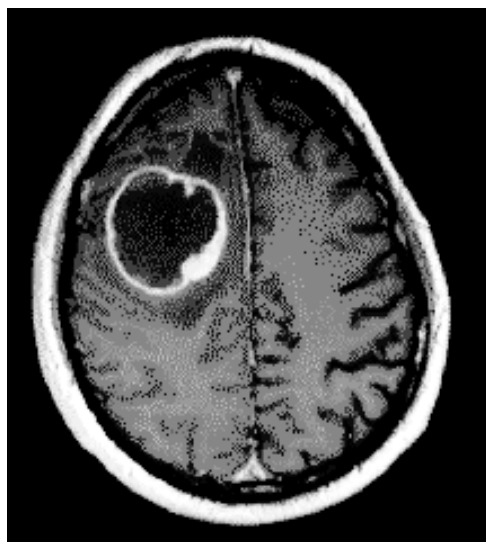

Figure 3.2 Example of a brain tumor MR image [65]

Surgery for the removal of highly malignant brain tumors can be used to extend patient life expectancy [13]. Fluorescence spectroscopy or blue light microscopy are recent methods to aid the surgeon and visualize the tumor marginal zone, and bordering surrounding tissue, in addition to conventional white light microscopy. These techniques are applied when removing tumor tissue in high-grade gliomas. The method is based on detecting fluorescence where 5 -aminiolevulinic acid is administered prior to the surgery, which transforms into a fluorophore, protoporphyrin-IX, that accumulates in the tumor cells $[66,67]$.

\section{Deep brain stimulation}

Patients with movement disorders such as Parkinson's disease, essential tremor or dystonia may have a possibility to receive symptom reduction using DBS [12]. Such patients have a shortage of neurons that produce dopamine in the substantia nigra, in the deep regions of the brain, that may relay movement associated signals in the thalamus [19]. DBS involves the implantation of electrodes, illustrated in Fig. 3.3, that deliver current with high frequency to treat malfunctioning neurons in deep brain structures. 


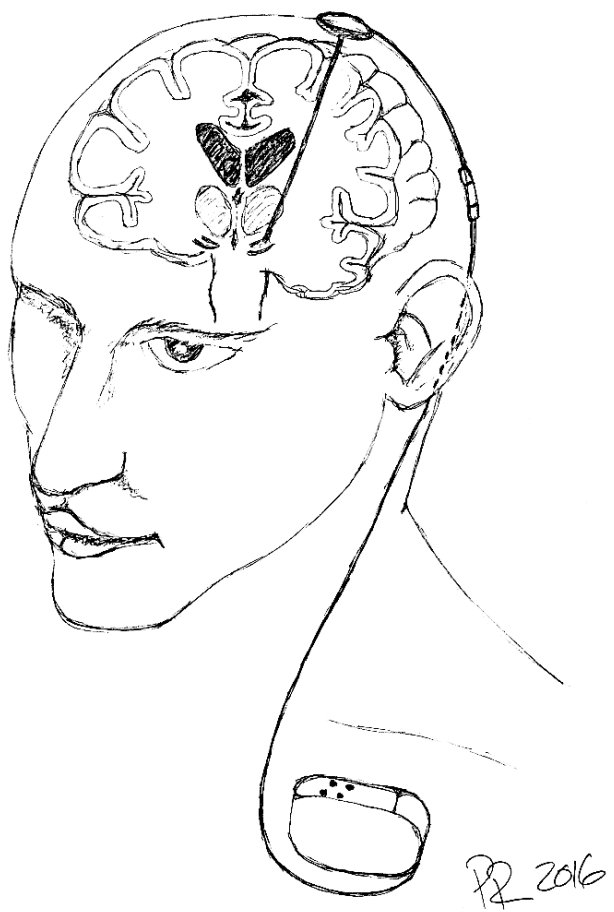

Figure 3.3 Deep brain stimulation with electrodes placed in the sub thalamic brain region

DBS surgery is performed with the aid of medical imaging modalities such as MRI and CT together with a stereotactic system to place the thin electrodes in the intended brain area. An example of a stereotactic frame is the Leksell system from 1949 which uses a coordinate system with the target of the frame always in the center of an arc [68]. Targets for relieving movement disorders are found in the basal ganglia. The subthalamic nucleus (STN), the ventral intermediate nucleus (Vim), the globus pallidus internus (GPi) and the zona incerta (Zi) are commonly used targets. A trajectory through the brain tissue towards the DBS target is planned using software and preoperative images such as MRI. After localizing anatomical landmarks, a human brain atlas can be superimposed onto the patient-specific images. The implanted electrodes are attached to an impulse generator that delivers a voltage commonly in the range of $1-4 \mathrm{~V}$ and frequency of $130-185 \mathrm{~Hz}$, in order to control the effect of the malfunctioning neurons [69]. The surgical procedure can be performed either during local or general anesthesia depending on the need for intraoperative feedback from the patient.

Opening of the skull during brain surgery may cause tissue deformation known as brain shift. Brain shift is caused by CSF leaking out or air entering the skull and replacing volume when tissue is removed. Brain shift leads to deviations between initial medical imaging and the shifted tissue which causes inaccuracy in targeting during surgical procedures. Systems for intraoperative guidance can therefore be used to counter inaccurate targeting caused by brain shift. Surgeries using local anesthesia can benefit from instant patient feedback during electrical 
stimulation using microelectrode recoding [70]. The electrodes are used to record the activity of neurons in local regions that are eligible for DBS electrode placement. Another type of electrode could be used to measure the impedance along the trajectory towards the target region as an intraoperative navigational tool. Changes in impedance can be used to notify the surgeon when the electrode passes through gray and white matter as well as regions with CSF [71]. Optical measurements using LDF have recently shown to be capable of detecting blood vessels in front of the electrode guide towards the target. The optical probe can also distinguish between gray and white matter as well as acting as a potential intraoperative warning system to reduce the risk of hemorrhages [72]. 


\section{Biomedical optics}

In this chapter biomedical optics is introduced along with important theoretical and mathematical relations which are briefly explained and commonly used in the field.

The word light is generally used in referring to electromagnetic radiation in the visible wavelength range (400-700 $\mathrm{nm}$ ) that is detectable by the human eye. Light can be described as either waves or particles. This is known as the particle-wave duality where the particle concept (photons) represent discrete packages or quanta of energy $(E)$, Eq. 4.1, where $h$ is Planck's constant, and $f$ is the frequency. The wavelength $(\lambda)$ of the light is considered in the wave concept where $f=c / \lambda$, and $c$ is the speed of light in vacuum [73].

$$
E=h f
$$

In biomedical optics the light interaction with tissue is used to retrieve information regarding functions such as blood flow and oxygenation but can also be used to cut tissue by using e.g. laser surgery. The optical properties of tissues play a central role in biomedical optics which is usually described in terms of refractive index, scattering and absorption. Absorption and scattering can be described using absorption and scattering coefficients $\left(\mu_{a}\right.$ and $\left.\mu_{s}\right)$ where the reduced scattering coefficient $\left(\mu_{s}^{\prime}\right)$ includes the effect of forward scattering of the tissue through the anisotropy factor $(\mathrm{g})$.

\section{Refractive index}

The index of refraction $(n)$, Eq. 4.2, is a fundamental optical property that describes the ratio between $c$ and the speed of light in the medium $(v)$. Difference in the refractive index, for example at boundaries, gives rise to scattering, refraction and reflection. Gradients or discontinuities in the refractive index at a microscopic level are reasons as to why light is scattered in tissue [74].

$$
n=\frac{c}{v}
$$

When light travels from one medium to another the refractive index mismatch $\left(n_{1} \neq n_{2}\right)$ will determine the change in direction from the incident light with angle $\theta_{1}$ to the refraction angle $\theta_{2}$ in the second medium following Snells' law in Eq. 4.3 [73].

$$
\frac{\sin \theta_{1}}{\sin \theta_{2}}=\frac{n_{2}}{n_{1}}
$$




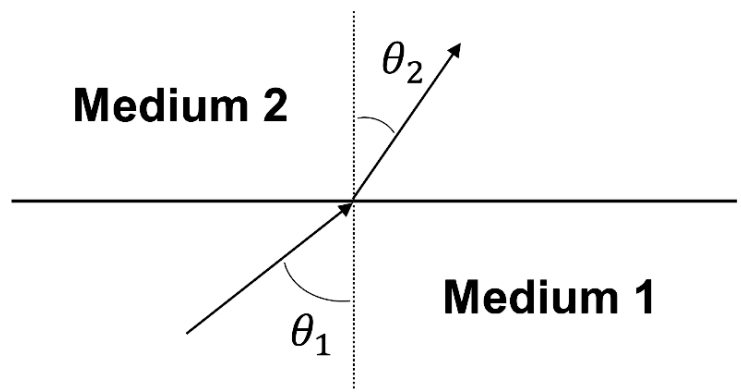

Figure 4.1 Refraction of light when passing between different media

Biological tissue or media are generally inhomogeneous and have a refractive index in the range between 1.3 and 1.7 which can be compared with that of air $(n=1.0)$ and water $(n=1.33)$ [75]. Tissue components such as fibrous-tissue and cell organelles such as mitochondria and lysosomes give mismatches in the refractive index of tissue, which affect the light transport [76].

The numerical aperture (NA) is used in fiber optics to describe the angles for which light is accepted into or out of a system. In an optical fiber the NA is defined according to Eq. 4.4 by the refractive index of the core and cladding [77]. The light is transported through the optical fiber with minimal energy loss due to total internal reflection where the refractive index of the clad material is slightly less than that of the core material [77]. The maximum acceptance angle at which light is subject to internal reflection through the fiber, Fig. 4.2, is $\theta_{\max }$ which depends on the refractive index of the initial medium, the core $\left(n_{\text {core }}\right)$ and the cladding $\left(n_{\text {clad }}\right)$. An example of NA for an optical fiber is 0.37 resulting in an acceptance angle of $\theta_{\max } \approx 21.7^{\circ}$.

$$
N A=n \sin \theta_{\text {max }}=\sqrt{n_{\text {core }}^{2}-n_{\text {clad }}^{2}}
$$

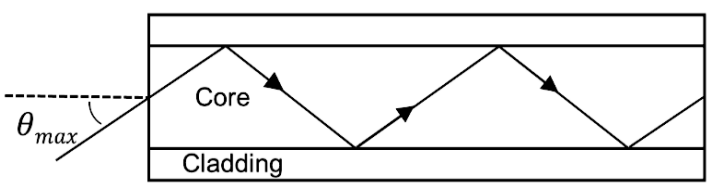

Figure 4.2 Optical fiber with different refractive indices $\left(n_{i}\right)$ for core and cladding materials 


\section{Absorption}

Absorption occurs when photon energy is transferred to molecules in the medium. The absorbed photon energy excites the absorbing molecule to a higher energy state. Excess photon energy will dissipate over time commonly through heat transfer to the surrounding molecules but may also result in fluorescence or phosphorescence where a new photon is emitted [78]. Molecules that absorb light are called chromophores which usually can be characterized by their specific absorption spectrum. Absorption spectra can thereby be associated with a specific chromophore and used in spectroscopy to characterize a sample. The absorption is described by the absorption coefficient, $\mu_{a}(\lambda)$, which corresponds to the average length a photon can travel in a sample before being absorbed. The absorption coefficient is proportional to the density $\left(\rho_{a}\right)$ of absorbers and their absorbing cross-sectional area $\left(\sigma_{a}\right)$. The absorption coefficient, $\mu_{a}(\lambda)\left[\mathrm{mm}^{-1}\right]$, can also be described as in Eq. 4.5 , by the molar extinction coefficient $\varepsilon(\lambda)[\mathrm{L} /(\mathrm{mol} \cdot \mathrm{mm})]$ and concentration $C[\mathrm{~mol} / \mathrm{L}][74]$.

$$
\mu_{a}(\lambda)=\varepsilon(\lambda) C
$$

\section{Brain tissue chromophores}

Primary chromophores that are found in diffuse reflectance spectra from brain tissue are hemoglobin and water (Fig. 4.3). Examples of additional chromophores that can be found in brain tissue are lipids, cytochromes, lipofuscin, neuromelanin and neuroglobin [39, 79]. Cytochromes are light absorbing molecules with iron containing heme groups that are involved in the electron transport which is used for ATP production in the mitochondria [79]. Lipofuscin is a pigment found in lysosomes, for example of neurons, that accumulates with age. Melanin is a pigment that absorbs damaging ultraviolet light and can be found throughout the body [79]. Melanin is found in melanocytes that are abundant in the skin and contribute to its color whereas neuromelanin is found in the substantia nigra region of the human brain and accumulates with age similar to Lipofuscin [80]. The function of neuroglobin is not yet understood but is suggested to play a role in protecting neurons in the brain during hypoxic conditions. Animal studies with mice found active genes coding for neuroglobin locally in the brain, for example in the amygdala, however the neuroglobin is estimated to be less than $0.01 \%$ of the total protein content in the brain [39]. 


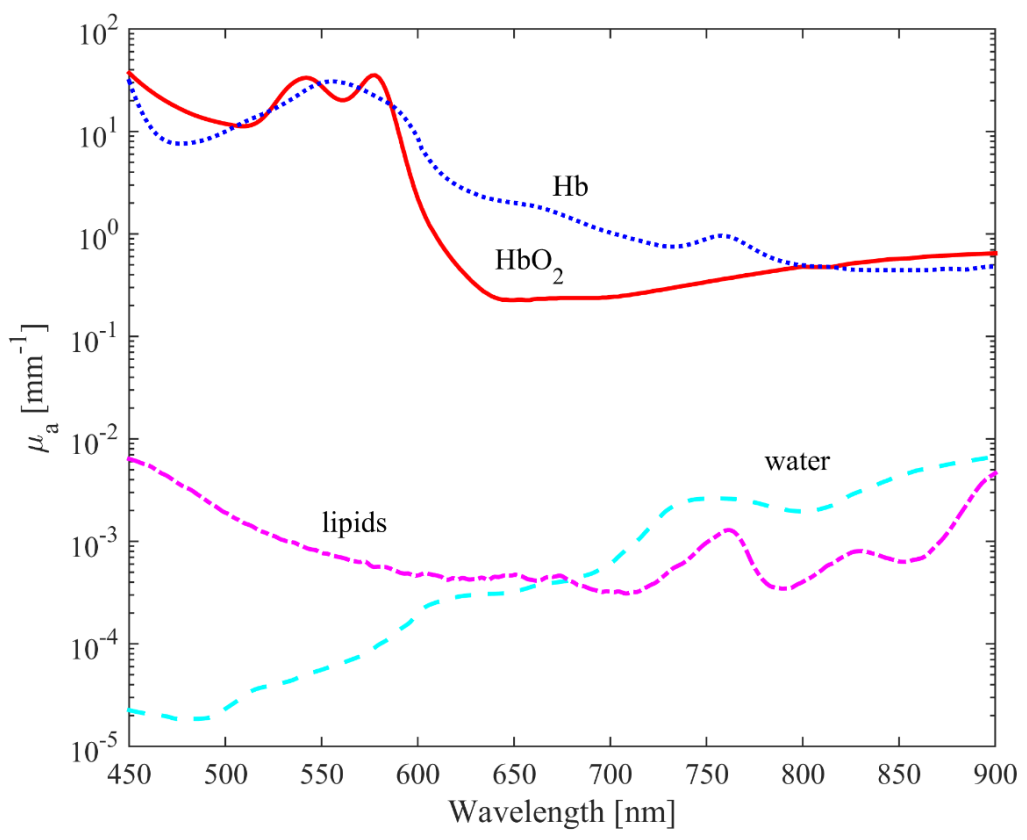

Figure 4.3 Absorption of hemoglobin $\left(\mathrm{HbO}_{2}\right.$ and $\left.\mathrm{Hb}\right)$ [81], water [82] and lipids [83]

\section{Scattering}

Scattering of light is a process where the light changes direction after encountering an object with a different refractive index compared to the surrounding media, illustrated in Fig 4.3 [75]. The scattering may be elastic, inelastic, or quasi-elastic depending on the type of interaction with matter. Inelastic light scattering, also known as Raman scattering, occurs when the part of the photon energy is transferred resulting in the emission of a photon with a different (usually lower) energy [73]. If the scattering is elastic the photon changes direction without losing energy, the scattering can be explained using Mie or Rayleigh theory [73]. Mie theory can be used to describe the scattering interaction with spherical particles. Rayleigh scattering is a subset of Mie scattering which occurs when light is scattered by particles much smaller than its wavelength [84]. Quasi-elastic scattering may occur when light interacts with moving particles due to the Doppler effect which induces small frequency shifts in the light [85]. The scattering in a medium is described by the scattering coefficient $\left(\mu_{s}\right)$ which represents the probability of a photon being scattered per unit length. The anisotropy factor $(g)$, Eq. 4.6, is defined as the average scattering angle $(\theta)$. A value of $g>0$ corresponds to forward scattering and $g<0$ corresponds to backward scattering. Total forward scattering corresponds to $g=1$ whereas $g=0$ represents mainly isotropic scattering [86].

$$
g=\langle\cos \theta\rangle
$$


The diffuse scattering can be represented with the reduced scattering coefficient $\left(\mu_{s}^{\prime}\right)$, Eq. 4.7, with $\mu_{s}$ and $g$. Biological tissue usually exhibits a $g$ between 0.6 and 0.9 [76] whereas the value for blood is closer to one [87].

$$
\mu_{s}^{\prime}=\mu_{s}(1-g)
$$

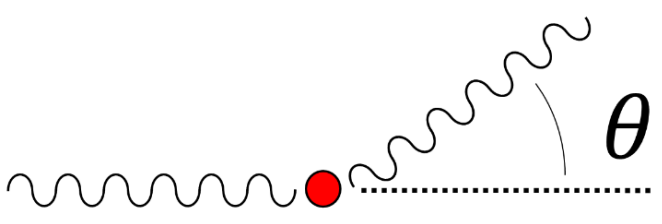

Figure 4.3 A single scattering event between a photon and a scattering particle resulting in a new direction according to the scattering angle $(\theta)$

The phase function represents a probability density function for a photon traveling in the initial direction to scatter in another direction. The analytical model known as the Henyey-Greenstein phase function, $p_{H G}(\theta)$ in Eq. 4.8, is useful for accurate approximation of photon scattering in tissue [76]. Examples of the $p_{H G}(\theta)$ for three different values of the anisotropy factor are displayed in Fig. 4.4.

$$
p_{H G}(\theta)=\frac{1}{4 \pi} \cdot \frac{1-g^{2}}{\left(1+g^{2}-2 g \cdot \cos (\theta)\right)^{3 / 2}}
$$

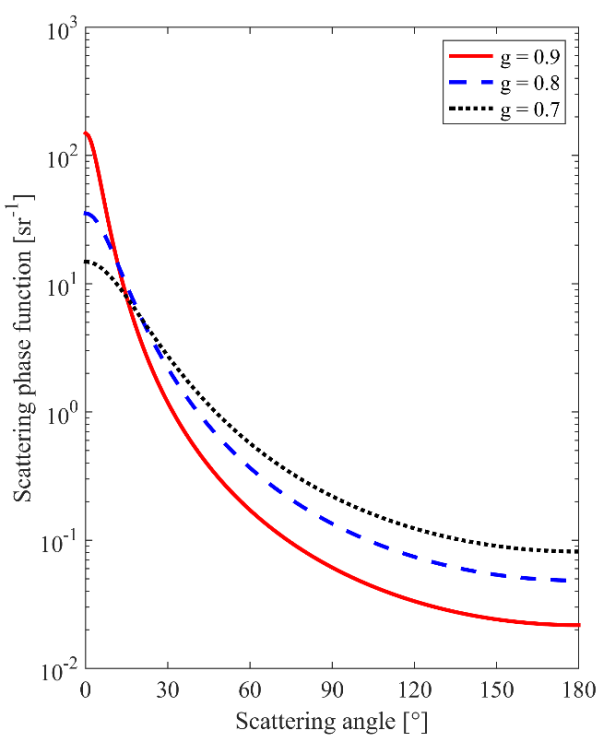

Figure 4.4 Example of phase functions (probability density function) of a photon in a medium for three different values of the anisotropy factor $(\mathrm{g})$ described by Henyey-Greenstein 
The scattering mean free path length $\left(l_{m f p_{s}}\right)$ is the average distance a photon travels before being scattered in a diffuse medium $\left(\mu_{s}^{\prime} \gg \mu_{a}\right)$, which corresponds to one step in Fig. 4.5 [73]. The distance a photon travels before losing its initial direction is known as the transport mean free path $\left(l_{t r}\right)$, Eq. 4.9 , which corresponds to ten steps of the photon traveling in a diffuse medium and for the anisotropy factor $\mathrm{g}=0.9$, illustrated in Fig 4.5 [76].

$$
l_{t r}=\frac{1}{\mu_{s}^{\prime}}
$$

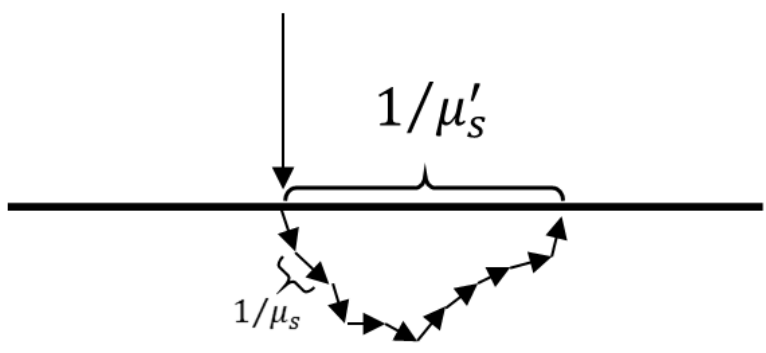

Figure 4.5 Mean free path and multiple scattering in tissue

The attenuation from both absorption and scattering can be described by the total attenuation coefficient $\left(\mu_{t}\right)$, Eq. 4.10 .

$$
\mu_{t}=\mu_{a}+\mu_{s}
$$

\section{Beer Lamberts law}

To assess the optical properties in a sample, the absorbance i.e. the intensity loss of light that traveled through a sample cuvette, Fig. 4.6, can be measured. The intensity (I) reduction due to absorption through a sample can be described by Beer Lamberts law in Eq. 4.11 where the sample length is defined by the parameter $L$. Beer Lamberts law is written as:

$$
I=I_{0} e^{-\mu_{a} L}
$$

where the absorbance through a sample can be described with Eq. 4.12:

$$
\mu_{a}(\lambda) L=-\ln \left(\frac{I}{I_{0}}\right)
$$

using the natural logarithm for the ratio between transmitted $(I)$ and incident $\left(I_{0}\right)$ light. 


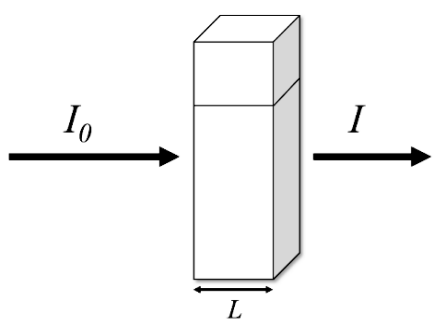

Figure 4.6 Transmission through a sample of width $L$ where parts of the incident light, $I_{0}$, are absorbed by chromophores

\section{Diffusion theory}

The diffuse propagation of light in media such as biological tissue can be described by diffusion theory [88] where the photons are viewed as particles. A medium that scatters light to become diffuse is characterized by a greater scattering coefficient compared with the absorption coefficient $\mu_{s}^{\prime} \gg \mu_{a}$. In the diffuse regime, the length a photon travels before being absorbed or scattered is described by the effective attenuation coefficient $\left(\mu_{e f f}\right)$ in Eq. 4.13. The inverse of $\mu_{e f f}$ can be used as a length scale in which the light attenuates, and is referred to as the diffusion length or optical penetration depth [74].

$$
\mu_{e f f}=\sqrt{3 \mu_{a}\left(\mu_{a}+\mu_{s}^{\prime}\right)}
$$

The diffusion coefficient $(D)$ is shown in Eq. 4.14 [76].

$$
D=\frac{1}{3\left(\mu_{a}+\mu_{s}^{\prime}\right)}
$$

Diffusion theory is capable of describing light transport in tissue when the light has lost its directional preference, which happens after a certain number of scattering events when the light has traveled approximately one $l_{t r}$ through tissue and has become diffuse. This is the reason why a narrow light beam incident to a semi-infinite turbid medium can be modelled using an isotropic point source inside the tissue at one $l_{t r}$ when using the diffusion theory for reflected light [76]. The fluence rate $(U(r))$ for a continuous wave at a distance, $r$, from the isotropic point source with power, $P$, in homogenous tissue can be described using a Green's function when $\mu_{s}^{\prime}>>\mu_{a}$, Eq. 4.15 [76].

$$
U(r)=\frac{P}{4 \pi D r} \exp \left(-\mu_{e f f} r\right)
$$

\section{Boundary conditions}

As Eq. 4.15, also known as the $\mathrm{P}_{1}$ approximation, is valid for a point source inside a homogenous medium a slightly more complex version can be used to model light transport through a surface into a semi-infinite medium using two exponentially decaying terms, representing a source and a sink, as described by Durduran et al., [89]. The Green's function 
for a semi-infinite medium $\left(G_{P 1, S i}\right)$ uses an exponentially decaying source and one sink according to Eq. 4.16 to compensate for boundary effects between two medium. The Green's function $G_{P 1, s i}$ is given by Eq. 4.16, with the distances $r_{a}$ and $r_{b}$ (Eq. 4.17 and 4.18) between the detector and the source or sink respectively for he extrapolated boundary $z_{b}$, Eq. 4.19 seen in Fig. 4.7.

$$
\begin{gathered}
G_{P 1, s i}=\frac{1}{4 \pi D}\left[\frac{\exp \left(-\mu_{e f f} r_{a}\right)}{r_{a}}-\frac{\exp \left(-\mu_{e f f} r_{b}\right)}{r_{b}}\right] \\
r_{a}=\sqrt{\left(z-l_{t r}\right)^{2}+\rho^{2}} \\
r_{b}=\sqrt{\left(z+2 z_{b}+l_{t r}\right)^{2}+\rho^{2}} \\
z_{b}=\frac{2}{\mu_{s}^{\prime}} \frac{1+R_{e f f}}{3\left(1-R_{e f f}\right)} .
\end{gathered}
$$

The effective reflection is set to $R_{e f f}=0.475$ according to previous work [90].

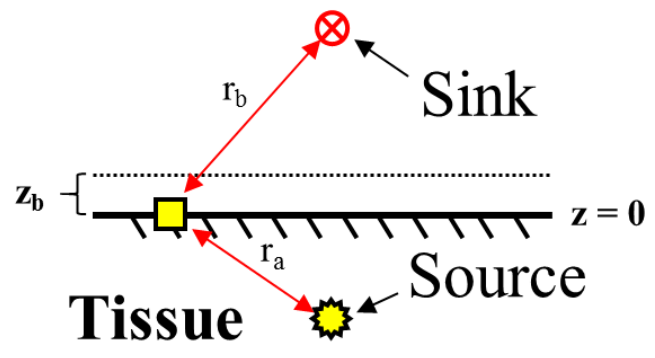

Figure 4.7 A semi-infinite geometry with a source-sink pair used in the $G_{P 1, s i}$ model in Eq. 4.16

However, diffusion theory has the drawback that it cannot properly describe the fluence of reflected light close to the entry point or source, for example close to the delivering end of an optical fiber. The propagation of continuous wave monochromatic light in a scattering medium can be described by the stationary radiative transfer theory. The radiative transfer equation is usually too complex to use with scattering media why simplifications by presenting solutions in the form of spherical harmonics are made [76]. Solutions to the transport equation that rely on truncated Legendre series are generally known as the $\mathrm{P}_{\mathrm{N}}$ approximation where $\mathrm{N}$ represent the order of the Legendre polynomial [91]. These simplified solutions come in the form of systems with connected differential partial derivative equations [76]. 


\section{$\mathrm{P}_{3}$ approximation}

The $\mathrm{P}_{1}$ approximation of light transport is limited to accurately describing light that has lost its initial direction and thereby travels randomly in a diffuse manner. A modified hybrid version of the standard diffusion equation is required to describe light propagation for source-detector distances shorter than $\left(\rho<l_{t r}\right)$ [92]. The $\mathrm{P}_{3}$ approximation is more accurate in describing light transport closer to the source compared with the standard $\mathrm{P}_{1}$ approximation as well as handling situations where the amount of absorption is similar to the level of reduced scattering $\left(\mu_{a} \approx \mu_{s}^{\prime}\right)$ [93]. A Green's function $\left(G_{P 3, s i}\right)$ with the $\mathrm{P}_{3}$ approximation for a semi-infinite medium is described in Eq. 4.20 [92, 94]. This approximation uses the attenuation coefficient, $v^{-}$, as described by Eq. 4.21 with two source-sink pairs as illustrated in Fig. 4.8.

$$
G_{P 3, s i}=\frac{3 \mu_{s}^{\prime}}{4 \pi}\left(\frac{\exp \left(-v^{-} r_{1}\right)}{r_{1}}-\frac{\exp \left(-v^{-} r_{2}\right)}{r_{2}}+\frac{\exp \left(-v^{-} r_{3}\right)}{r_{3}}-\frac{\exp \left(-v^{-} r_{4}\right)}{r_{4}}\right)
$$

The normal $\mu_{e f f}$ is replaced by $v^{-}$which is the asymptotic exponential decay constant to the transport equation [92].

$$
v^{-}=\left[\frac{\left(v_{\beta}-\sqrt{\left|v_{\beta}^{2}-v_{\gamma}\right|}\right)}{18}\right]^{\frac{1}{2}}
$$

The terms in Eq. 4.21 are given by: $v_{\beta}=55 \mu_{a}\left(\mu_{a}+\mu_{s}^{\prime}\right)+35\left(\mu_{a}+\mu_{s}^{\prime}\right)^{2}$ and $v_{\gamma}=$ $3780 \mu_{a}\left(\mu_{a}+\mu_{s}^{\prime}\right)^{3}$. The two source-sink pairs are described by $r_{1-4}$ where the artificial pair $r_{1}$ and $r_{2}$ are defined in Eq. 4.22-23 while the real source is $r_{3}$ with its mirror point sink $r_{4}$ are described in Eq. 4.24-25.

$$
\begin{gathered}
r_{1}=\left[\rho^{2}+\left(\frac{1}{\mu_{s}^{\prime}}\right)^{2}\right]^{\frac{1}{2}} \\
r_{2}=\left[\rho^{2}+\left(2 z_{b}+\frac{1}{\mu_{s}^{\prime}}\right)^{2}\right]^{\frac{1}{2}} \\
r_{3}=\rho \\
r_{4}=\left[\rho^{2}+\left(2 z_{b}\right)^{2}\right]^{\frac{1}{2}}
\end{gathered}
$$

The term $v^{-}$becomes analogous to the effective attenuation coefficient $\left(v^{-} \approx \mu_{e f f}\right)$ when absorption is much smaller than the reduced scattering $\left(\mu_{a} \ll \mu_{s}^{\prime}\right)$. 


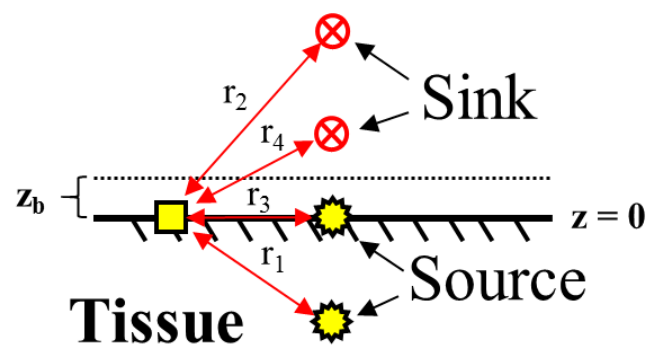

Figure 4.8 Double source-sink pairs in a semi-infinite geometry used for $G_{P 3, s i}$ in Eq. 4.20

\section{Diffuse reflectance spectroscopy}

The importance of using light to analyze our surroundings is obvious to most people as we use our eyes to observe and navigate in daily life. Isaac Newton was first to demonstrate that white light was composed of light with different colors by sending a small slit of white light through a prism to reveal its spectrum. Around 1860, Bunsen and Kirchhoff invented a simple spectroscope to study the spectrum of light transmitted through a sample. They also concluded that each element had a characteristic set of absorbed or emitted wavelengths, thereby making spectroscopy useful as a method to determine which elements that are present in a sample [78]. Although the principle of spectroscopy remains the same as when it was invented much research has been put into refining spectroscopic methods and creating theoretical and empirical models to analyze the wavelength components of light from a sample. The field of diffuse reflectance spectroscopy has been expanding in the latest decades where many groups develop methodology to measure and analyze tissue composition for various applications. DRS is for example used in oncology for improving biopsy and diagnostics or aiding surgical navigation. In a typical DRS setup illustrated in Fig 4.9, the tissue is illuminated using a wide spectrum light source delivered through an optical fiber probe where the intensity of collected wavelengths and shapes in the reflected light spectrum is used to determine optical properties such as absorption and scattering [7]. The light is generally diffracted using a dispersive grating to spatially decompose the light into wavelengths that are registered on a detector surface inside a spectrometer. If the incident light delivered to the tissue undergoes multiple scattering the direction will become randomized resulting in diffuse reflectance. The generated signal contains information about scattering and absorption in a variety of sampling depths in the tissue and thereby represents an average of optical properties in the sampling volume [91]. Though in some respects challenging, diffuse reflectance spectroscopy is one of the most straightforward principles of measuring light that interacts with biological tissue. Depending on which type of chromophores the light encounters the absorption profile of the returning light will be different. 


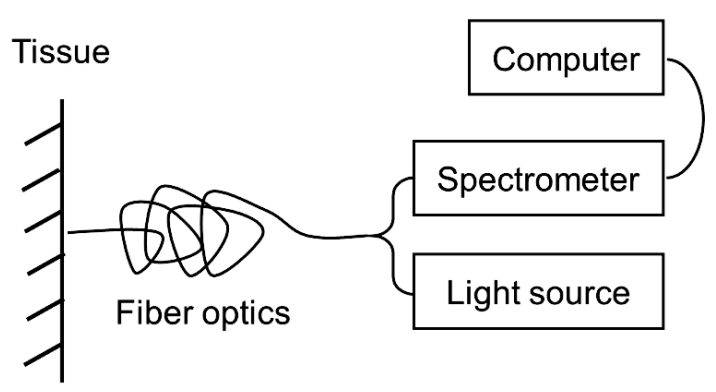

Figure 4.9 A typical diffuse reflectance spectroscopy (DRS) setup including a white light source, spectrometer, computer and an optical fiber probe

\section{Light transport in biological tissue}

As mentioned earlier, light propagation can be described in different ways where one is electromagnetic waves, another is ballistic photons that travel in a direction and can be deflected through scattering and the third way is concentration of energy that diffuses along a concentration gradient in the medium [93]. The first description is used in interferometry, the second in Monte Carlo modeling and the third is used in diffusion theory. It is important to note that diffusion describes transport of a quantity that does not have a preferential direction whereas collimated light that is led into tissue through an optical fiber definitely has a strong directional movement. Therefore, the net movement of the diffusing quantity follows along a concentration gradient. As light interacts with tissue and scatters, the directionality is lost and diffusion becomes applicable [95].

\section{Use in medicine}

DRS has been used in medicine for tissue characterization and diagnostics [91]. The DRS measurements are processed to assess the chromophore content which can be related to physiological parameters such as hemoglobin concentration and $\mathrm{SO}_{2}$ in different types of tissue. DRS has been suggested as a tool for clinical tissue biopsy where the reflectance spectra can be used to either aid in taking, or to replace, invasive biopsies. DRS can provide an objective measurement compared with visual inspection and may be used to get instant feedback in comparison with the histological studies which today are the gold standard for pathological tissue diagnostics [96]. For example, DRS has the potential to be used as a tool in various clinical and surgical applications. Examples of clinical applications are investigation of skin lesions, surgical tumor margins in breast tissue, sentinel lymph nodes, endoscopic colonoscopy, dosimetry during photodynamic therapy and brain tissue characterization [91, 94, 97]. 


\section{Laser Doppler flowmetry}

LDF, also known as laser Doppler perfusion monitoring, is a technique that relies on light being frequency shifted when interacting with small moving particles. The frequency shift is related to the amount of particles and their average velocity [6]. The Doppler effect is used to assess the movement of RBCs in tissue, mainly targeting the microvascular blood flow in small blood vessels with a diameter smaller than $100 \mu \mathrm{m}$. The first LDF measurements in living tissue were presented by Stern et al., in 1975 [6, 98]. The technique was improved by Nilsson et al., [99, $100]$ using fiber optics and a dual photo-detection system that reduced noise common to both detectors [101]. LDF was later developed to function as an imaging system [102]. Monochromatic light that is scattered by a moving particle, such as a RBC, undergoes a small frequency shift known as a Doppler shift. When such shifted light reaches a photodetector surface, the shifted light will mix with the non-shifted light and cause destructive or constructive interference. The interference pattern on the detector surface, illustrated in Fig. 4.10, also known as a speckle pattern will fluctuate over time in relation to the concentration and movement of the particles.

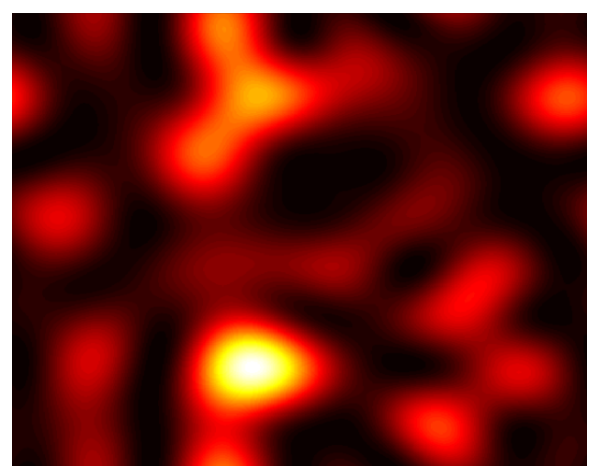

Figure 4.10 Simulated speckle pattern similar to that which is produced on the photodetector surface, generated using code from Gascón and Salazar [103]

\section{The Doppler effect}

The Doppler effect is a wave phenomenon where the frequency of the wave changes relative to the observer when the source of the wave is moving. The shift in wavelength is used in LDF to assess the blood flow in tissues. The change in frequency is related to the difference in velocity between the source and the observer $(\Delta v)$, the velocity of wave propagation in the medium $(c)$ and the initial frequency $\left(f_{0}\right)$ Eq. 4.26.

$$
\Delta f=\frac{\Delta v}{c} f_{0}
$$

Scattering in moving objects such as RBCs causes a frequency shift and a broadening of the wavelength of initially monochromatic laser light. The size of a single Doppler shift is the 
difference in frequency $(\Delta f)$ between incident $\left(f_{i}\right)$ and scattered light $\left(f_{s}\right)$, described by the scalar product of the velocity vector $(\mathbf{v})$ of the particle and the scattering vector $(\mathbf{q})$, Eq. 4.27.

$$
\Delta f=f_{i}-f_{s}=\mathbf{v} \cdot \mathbf{q}
$$

A single Doppler shift is illustrated in Fig. 4.11 which displays $\mathbf{q}$ with the scattering angle $(\theta)$ and $\mathbf{v}$ of the scattered particle where $\varphi$ is the angle between $\mathbf{q}$ and $\mathbf{v}$ in Eq. 4.28 [104]. The scattering vector, $\mathbf{q}$, is described by the difference between the initial particle propagation vector $\left(\mathbf{k}_{\mathbf{i}}\right)$ and the scattered propagation vector $\left(\mathbf{k}_{\mathbf{s}}\right)$ in Eq. 4.28.

$$
|\mathbf{q}|=\left|\mathbf{k}_{\mathbf{i}}-\mathbf{k}_{\mathbf{s}}\right| \approx \frac{2}{\lambda} \sin \frac{\theta}{2} \cos \varphi
$$

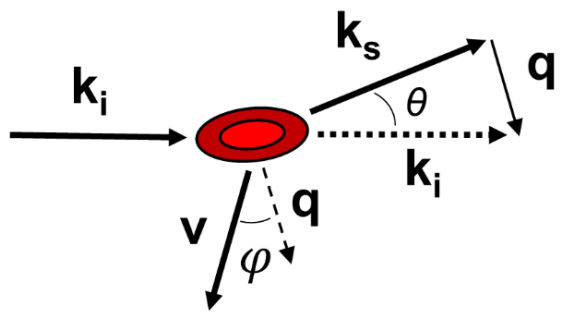

Figure 4.11 A Doppler shift with a moving light scattering particle

\section{Laser Doppler signal}

The speckle pattern that is formed on the photodetector surface in LDF changes over time and these changes are related to the amount of moving objects and their speed. The current from the photodetector consists of both a static $\left(i_{d c}\right)$ part and a time varying $\left(i_{a c}\right)$ part. The $i_{a c}$ represents the velocity and concentration of moving red blood cells (CMBC). The sum of the photocurrent reflects the total light intensity (TLI) that is backscattered from the sample which can be related to the tissue structure and scattering properties of the sampled tissue. The TLI signal can thus be used to discriminate between tissues with different scattering properties such as gray and white matter (Paper II). The relation between the power spectral density $P(\omega)$ and the CMBC is described by Eq. 4.29.

$$
\langle C M B C\rangle=\frac{\int P(\omega) d \omega}{i_{d c}^{2}}
$$

The perfusion signal is calculated according to Eq. 4.30 and relates to the CMBC and their average velocity calculated using the integral between the frequencies $\omega_{1}$ and $\omega_{12}\left(\omega_{1}=20 \mathrm{~Hz}\right.$ and $\omega_{2}=12 \mathrm{kHz}$ for the LDF system in this thesis) [104, 105].

$$
\langle p e r f\rangle=\frac{\int_{\omega_{1}}^{\omega_{2}} \omega P(\omega) d \omega}{i_{d c}^{2}} \approx C M B C \cdot\langle\mathrm{v}\rangle
$$


Chapter 4 - Biomedical optics 


\section{Aim of the thesis}

The aim of this thesis was to:

- Adapt DRS and LDF for assessing human cerebral microcirculation.

- Develop an algorithm for $\mathrm{SO}_{2}$ estimation in white brain matter from diffuse reflectance spectra using theoretical models and experiments with optical phantoms.

- Investigate parameters obtained from LDF and DRS and their applicability for multimodal brain monitoring.

- Evaluate DRS and LDF in a clinical setting during neurosurgical interventions and monitoring in neurointensive care. 
Chapter 5 - Aim of the thesis 


\section{Measurement and experimental setup}

This chapter describes the clinical and experimental measurement setups and the devices of the LDF and DRS systems together with a custom-made fiber optic probe. The optical phantoms and the setup used to regulate the $\mathrm{pO}_{2}$ during experiments are presented.

\section{Hardware}

A setup capable of real-time monitoring of regional perfusion and oxygenation with the LDF and DRS techniques was adapted to intraoperative measurements and use in neurocritical care. The setup was complemented with custom-made software and an optical fiber probe that were specially designed for application in neurosurgery and neurointensive care. The devices illustrated in Fig. 6.1 were placed on a portable trolley to enable easy transportation in relation to intraoperative or bedside measurements.

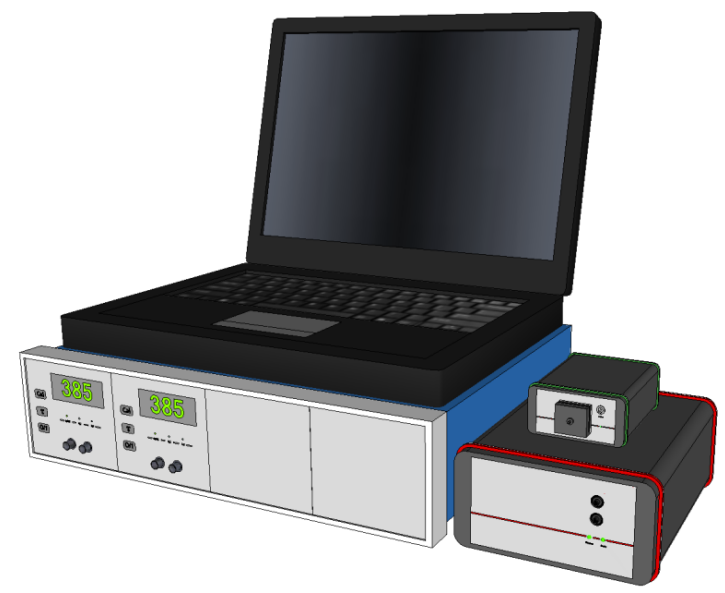

Figure 6.1 Measurement setup with a computer, LDF and DRS instruments

The LDF part of the setup consists of a commercial Periflux 5000 system (Perimed AB, Järfälla, Sweden) with serial output for extraction of produced signals (perfusion and TLI). The range of the perfusion and TLI signals are 0-999 and 0-10 arbitrary units (a.u.), respectively. The DRS system comprises a spectrometer AvaSpec 2048-2 with a bandwidth of 460-990 nm and a resolution of $2.1 \mathrm{~nm}$ and a halogen light source AvaLight HAL-S (Avantes BV, The Netherlands) with wavelengths covering the visible spectrum between 360 and $2000 \mathrm{~nm}$. A white reference standard (WS-2, Avantes BV, The Netherlands) was used to characterize the emitted spectrum from the light source and used in the reflectance normalization. The two optical systems (DRS and LDF) were both connected to a single optical probe to enable parallel use for sampling brain tissue. 


\section{Fiber-optic probe}

The probe was designed using specifications tailored to the application of monitoring in neurointensive care. Important aspects that were considered during the design phase were the diameter and shape of the probe tip as any object introduced to the brain needs to be small in order to minimize displacement of brain tissue and have a low risk of causing bleedings. The probe diameter was limited in size to allow measurements in brain tissue where the tip geometry was slightly rounded to assure smooth insertion, which may help reduce the risk of puncturing blood vessels. The custom-made optical fiber probe was made with a catheter-like design and was produced with a flexible end and a rounded tip that easily can be placed inside brain tissue. The optical fibers had a NA of 0.37 with a core diameter of $125 \mu \mathrm{m}$ and outer diameter of $250 \mu \mathrm{m}$. Four optical fibers were aligned along the interior of the probe and fixed adjacent to each other at the tip as seen in Fig 6.3. One source-detector (SD) pair was used for LDF and the other pair for DRS measurements. The protective outer cable was made of dark polyvinyl chloride and ended with a transparent $0.3 \mathrm{~m}$ long flexible tip of medical grade polyvinyl chloride with an outer diameter of $1.7 \mathrm{~mm}$ [106]. To enable a clear detection in CT imaging a thin steel thread $(\varnothing=0.12 \mathrm{~mm}, 6 \mathrm{~cm}$ long) was incorporated inside the measuring end of the probe. The total length of the cable was approximately $5 \mathrm{~m}$ to ensure sufficient distance between the patient and the LDF and DRS equipment. The probe was washed and sterilized using a low temperature radiation based procedure known as STERRAD ${ }^{\circledR}$ before any clinical measurements were performed [107].
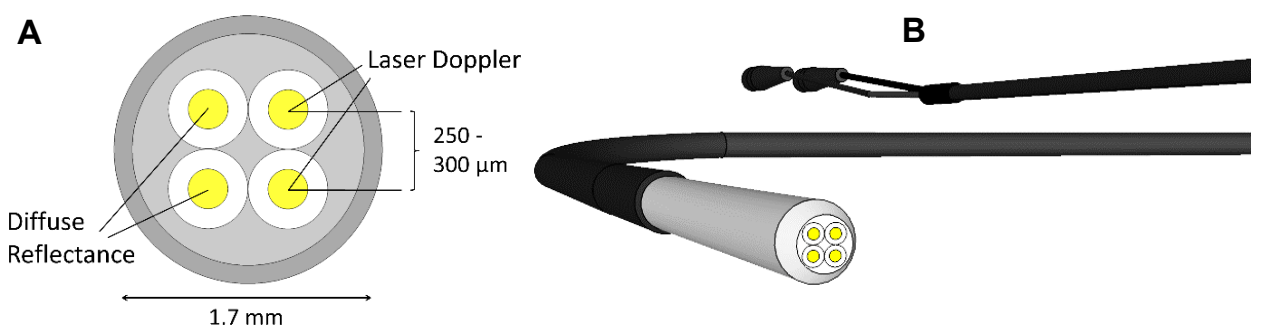

Figure 6.3 a) Optical probe configuration with four optical fibers, one source-detector (SD) pair used for LDF and the other SD pair for DRS and b) probe illustration

\section{Optical phantoms}

Optical phantoms facilitate evaluation, validation and calibration of techniques and methods by simulating optical properties of tissue [76]. To make an optical phantom, components that mimic the absorption and scattering of the desired tissue are required. A common way to prepare an optical phantom is to mix solutions with specific dyes and/or scattering agents in order to simulate a specific type of tissue. The phantoms can be either liquid or solid consisting entirely of liquid components or with more or less solid materials such as polymers, silicone or gelatin. A simple type of phantom consists of an absorbing and scattering component diluted in solvent while more complex phantoms contain a mix of different absorbers and scattering 
components or even RBCs. Examples of common absorbers are dyes such as black or blue ink and food coloring dyes of different colors while common scattering components can consist of polymeric micro-spheres, oxide powders, and milk or other fat emulsions such as Intralipid $[108,109]$.

In this work (Paper III) phantoms were made with RBCs, Intralipid (20\%) diluted with phosphate buffered saline. Phantoms were prepared with 0.5 to $3 \%$ blood, Intralipid with a total lipid volume of $5 \%$. The blood volume was selected to cover the range 0 to $3 \%$ blood expected to be found in human white brain tissue $[110,111]$. The reduced scattering in the phantoms was calculated to match that of white brain matter $\left(\mu_{s}^{\prime} \approx 6.5 \mathrm{~mm}^{-1}\right)$ using data of the well characterized Intralipid 20\% solution from Michels et al., at $630 \mathrm{~nm}$ [109].

\section{Experimental setup}

\section{Controlling the phantom environment}

Experiments involving RBCs require control of the environment with specific regard to the parameters that affect the oxygen binding properties of hemoglobin. Therefore, considerations regarding the temperature, $\mathrm{pH}, \mathrm{CO}_{2}$ concentration and amount of $\mathrm{BPG}$ during the experiments had to be taken. The ODC of hemoglobin described in Fig. 2.4 changes appearance when any of the above-mentioned parameters change. Important parameters that influence the ODC [112] are temperature, $\mathrm{pH}, \mathrm{CO}_{2}$ and $\mathrm{BPG}$ concentration.

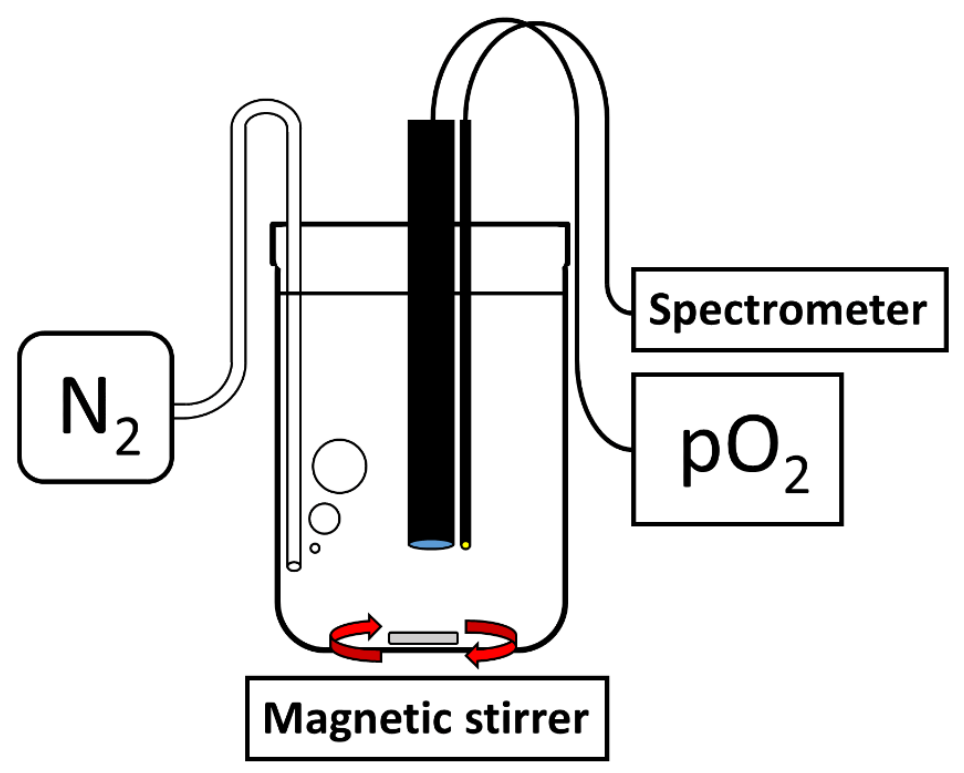

Figure 6.4 Experimental setup, with a spectroscope, fiber-optic probe, $\mathrm{pO}_{2}$-electrode, gas regulation system and a magnetic stirrer for optical phantom measurements 
The experimental setup illustrated in Fig. 6.4, used nitrogen gas to regulate the $\mathrm{O}_{2}$ level in the liquid phantom during the optical experiments. In addition to the DRS equipment and probe, the experimental setup consists of a sample container positioned in a water bath for regulating the temperature, a magnetic stirrer to refresh the $\mathrm{pO}_{2}$ electrode and a gas-regulation system. During the experiments, the sample's temperature was kept at $37 \pm 1{ }^{\circ} \mathrm{C}$ in order to mimic physiological conditions. The $\mathrm{pH}$ in the phantom solution was controlled using a phosphate buffer as the solvent solution. The buffer was prepared to keep $\mathrm{pH}$ at a value around 8.0. The concentrations of $\mathrm{CO}_{2}$ and $\mathrm{BPG}$ were not regulated but assumed to remain stable during the experiments. 


\section{Signal analysis and software}

The chapter describes how the signals acquired from the LDF and DRS systems were analyzed and interpreted into parameters relevant to the microcirculation. Software modules designed to collect and record signals from the LDF and DRS systems were made using LabVIEW ${ }^{\text {TM }} 2010$ (National Instruments Inc., USA). The software and user interface were programmed to include basic functions such as saving signals to file and to convey relevant information from the produced optical signals in a perspicuous manner.

\section{Laser Doppler flowmetry signals and software}

The perfusion signal from the LDF system was analyzed and processed to extract HR and PI parameters along with signal trend lines in a dedicated, custom-made, software module. The LDF software module provides a user interface featuring signal trends, heart rate (HR) estimation and PI as seen in Fig. 7.1. Trends of signals and parameters (perf, TLI, HR and PI) were displayed with averages for a preselected time interval between 10 and 60 seconds (Paper II).

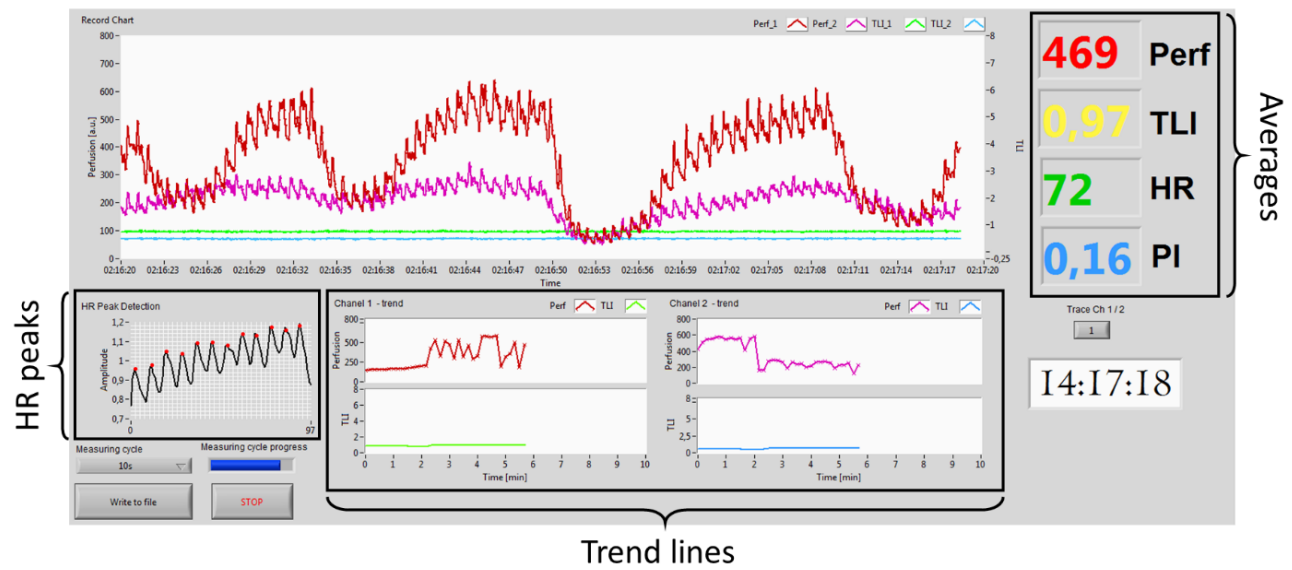

Figure 7.1 The user interface for the laser Doppler flowmetry software with parameter averages, trend lines for perfusion and TLI as well as detected peaks for the heart rate (HR) estimation

\section{Heart rate}

The HR was estimated using peak finding in the perfusion signal where systolic pulsations were detected, as seen in Fig. 7.2. The number of pulsations over a preselected time interval $(10,20$, 30 or $60 \mathrm{~s}$ ) were counted and multiplied by a factor translating the number of peaks into HR corresponding to beats per minute. Prior to the HR estimation in the LDF software module the perfusion signal was low-pass filtered (cutoff frequency of $20 \mathrm{~Hz}$ ) to avoid detection of the dicrotic notch in the cardiac cycle (Paper II). 


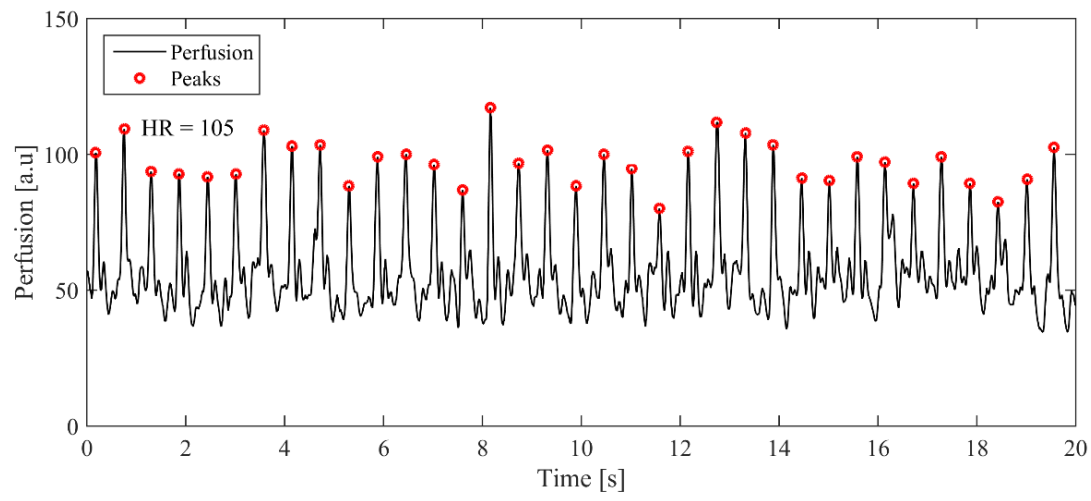

Figure 7.2 The number of detected systolic perfusion peaks was translated into heart rate (HR)

\section{Pulsatility index}

The PI also known as the Gosling (Pulsatility) index is calculated using the average difference between systolic peaks and diastolic troughs divided by the average value of the blood flow waveform from the cardiac cycle [49]. The PI has been proposed to relate to the distal vascular resistance in TCD measurements [50]. In this work, the PI was calculated according to Eq. 7.1, in which the flow velocity from Eq. 3.1 as used in TCD was replaced with corresponding parameters from the perfusion signal. The systolic and diastolic perfusion values were detected by finding the peaks and troughs in the perfusion signal. The difference between average systolic perfusion and the average diastolic perfusion was divided by the average perfusion over a user-selected interval as seen in Fig. 7.3.

$$
P I=\frac{\operatorname{per} f_{\text {sys }}-\text { perf } f_{\text {dias }}}{\operatorname{per} f_{\text {mean }}}
$$

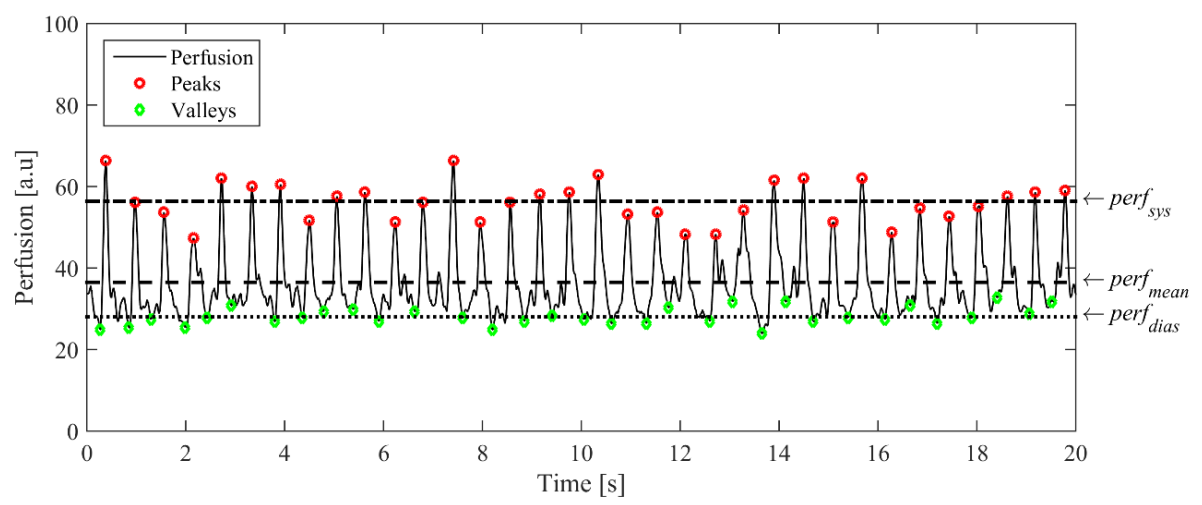

Figure 7.3 The pulsatility index (PI) was calculated through peak and troughs detection combined with the signal average in the perfusion signal over a selected interval 


\section{Diffuse reflectance spectroscopy signal and software}

The DRS software features signal averages, $\mathrm{SO}_{2}$ and $\mathrm{f}_{\mathrm{B}}$ estimations. The $\mathrm{f}_{\mathrm{B}}$ was estimated using three isobestic wavelengths and was used in the $\mathrm{SO}_{2}$ calculation. The $\mathrm{SO}_{2}$ and $\mathrm{f}_{\mathrm{B}}$ estimations calculated from the spectroscopic signal using a recently developed algorithm were both displayed in real-time on the user-interface, Fig. 7.4, of the dedicated software. In addition to the real-time estimations, the user interface of the DRS software module also display the trend of estimated $\mathrm{SO}_{2}$ over time.

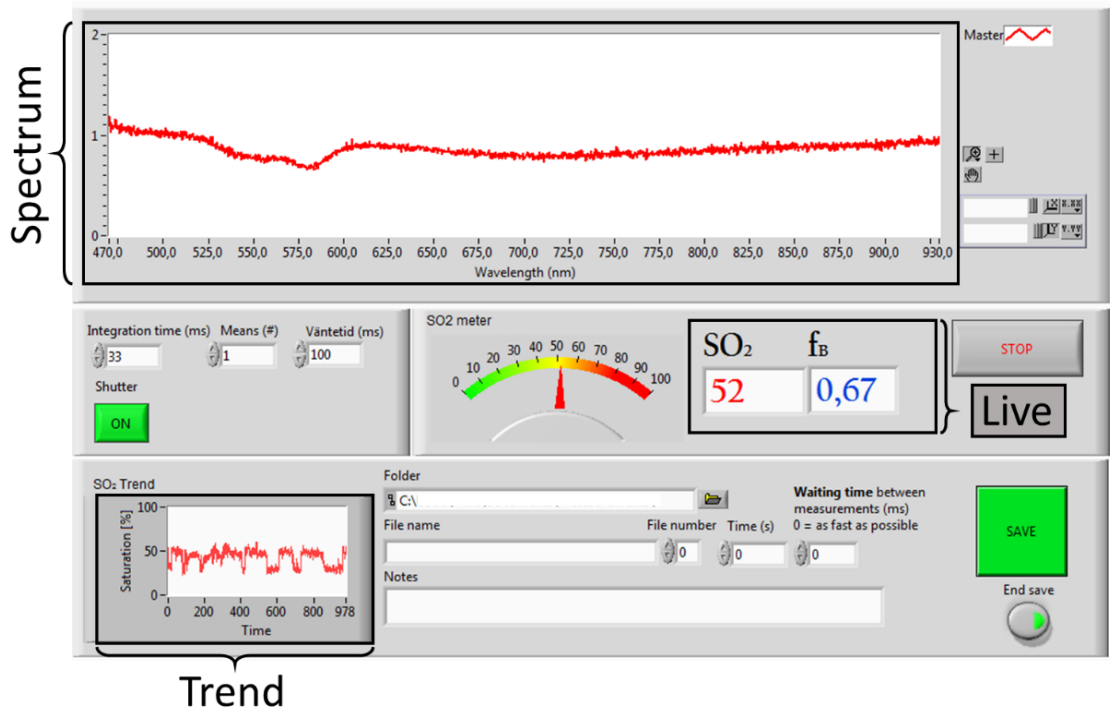

Figure 7.4 The user interface for the diffuse reflectance spectroscopy software with real-time estimation of $\mathrm{SO}_{2}$ and $\mathrm{f}_{\mathrm{B}}$ as well as the trend of $\mathrm{SO}_{2}$

\section{Spectrum normalization}

Before analyzing the diffuse reflectance signal, normalization with a reference standard with uniform reflectivity over a wide range of wavelengths was made in order to minimize the influence of the light source and effects inherent to the spectrometer. In this work, an enclosed tile made of polytetrafluoroethylene with uniform reflectivity over a wide range of wavelengths was used. The normalized signal, $I(\lambda)_{\text {norm }}$, Eq. 7.2, was calculated by division of the raw signal $\left(I(\lambda)_{\text {raw }}\right)$ by a signal from a white reference standard $\left(I(\lambda)_{\text {white }}\right)$ after subtraction of a dark spectra $\left(I(\lambda)_{\text {dark }}\right)$ from both raw and white spectra, where light has been blocked from reaching the sensor.

$$
I(\lambda)_{\text {norm }}=\frac{I(\lambda)_{\text {raw }}-I(\lambda)_{\text {dark }}}{I(\lambda)_{\text {white }}-I(\lambda)_{\text {dark }}}
$$




\section{Forward model using the $\mathrm{P}_{3}$ approximation}

A forward model with spectra generated from known absorption and scattering through the $\mathrm{P}_{3}$ approximation was used to create an estimation model for $\mathrm{SO}_{2}$ for different $\mathrm{f}_{\mathrm{B}}$ that could be used to interpret collected DRS signals.

A fixed reduced scattering, modelled with Eq. 7.3 and the constants $A$ and $B$, similar to that of white brain matter $\left(A=5.44 \mathrm{~mm}^{-1}\right.$ and $\left.B=1.38\right)$ was used to simulate the light intensity of reflected light at a fixed distance, $\rho=0.3 \mathrm{~mm}$, from the light source corresponding to the source-detector distance in the fiber optic probes. The forward model spectra were generated using absorption of hemoglobin and water according to Eq. 7.4, with the known extinction coefficients $\left(\varepsilon_{\mathrm{i}}\right)$ of $\mathrm{HbO}_{2}$ and $\mathrm{Hb}(500-800 \mathrm{~nm}$ [81], 800 - $900 \mathrm{~nm}$ [113]) and water [114].

$$
\begin{gathered}
\mu_{s}^{\prime}(\lambda)=A\left(\frac{\lambda}{700}\right)^{-B} \\
\mu_{a}(\lambda)=\left[f_{B}\right]\left(\varepsilon_{H_{b O_{2}}}(\lambda) S O_{2}+\varepsilon_{H b}(\lambda)\left(1-S O_{2}\right)\right)+\varepsilon_{H_{2} O}
\end{gathered}
$$

The $\mathrm{P}_{3}$ approximation was used to make a forward model of $\mathrm{SO}_{2}$ in human white brain matter using $\alpha$ as predictor parameter over a range of different blood concentrations $\left(f_{\mathrm{B}}\right)$. The model was built using generated spectra for a range of different blood concentrations from 0.1 to $3 \%$ ( $f_{B}=0.001$ to 0.03 ) in 101 steps for which the $\mathrm{SO}_{2}$ was varied between 0 and $100 \%$ in 101 steps. The forward model used to explain the relation between $\mathrm{SO}_{2}$ and the predictor variable $\alpha$ from the quadratic fit for different $f_{B}$ based on the 10201 generated spectra resulted in a 3D-surface, seen in Fig. 7.5, with $f_{B}$ and $\alpha$ on the $\mathrm{x}$ - and z-axis and $\mathrm{SO}_{2}$ on the y-axis.

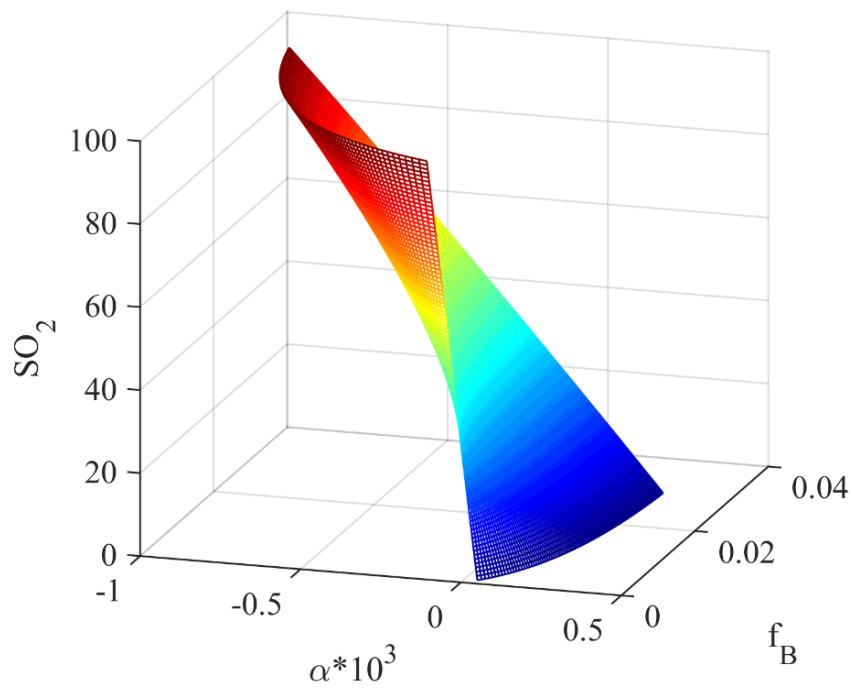

Figure 7.5 3D-surface with $\mathrm{f}_{\mathrm{B}}$ and $\alpha$ parameters used to estimate $\mathrm{SO}_{2}$ based on simulated spectra from the forward $\mathrm{P}_{3}$ approximation model 


\section{Blood fraction estimation}

The amount of hemoglobin must be known in order to accurately estimate the $\mathrm{SO}_{2}$ in the sampled tissue using the quadratic fit approach. Therefore, the $f_{B}$ parameter i.e. the total amount of hemoglobin for a normal concentration $(\mathrm{Hb}=148 \mathrm{~g} / \mathrm{ml})$ was estimated. The $\mathrm{f}_{\mathrm{B}}$ was assessed using the mean intensity $\left(I_{f_{B}}\right)$ of three isobestic wavelengths, Eq. 7.5, of hemoglobin illustrated in Fig. 7.6.

$$
I_{f_{B}}=\left(I_{\lambda=548}+I_{\lambda=570}+I_{\lambda=586}\right) / 3
$$

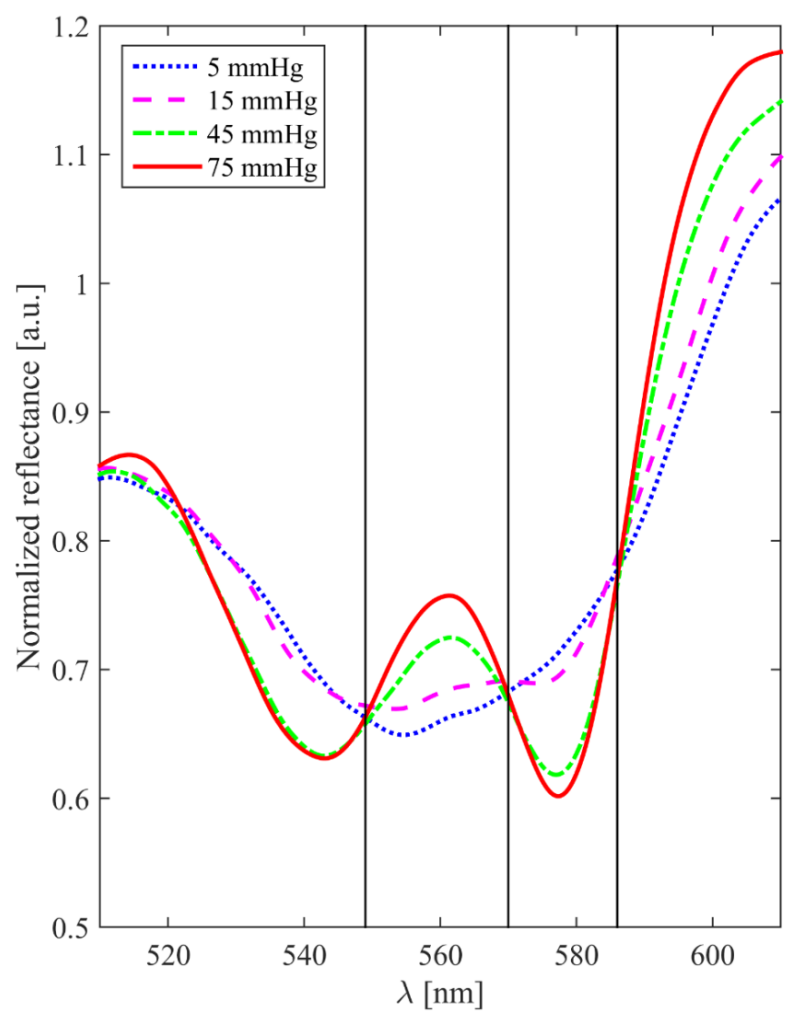

Figure 7.6 Reflectance of hemoglobin for wavelengths between 500 and $650 \mathrm{~nm}$ marked with three isobestic wavelengths $(548,570$ and $586 \mathrm{~nm})$ used for blood fraction $\left(f_{B}\right)$ estimation

The blood fraction was estimated using the isobestic intensity parameter, $I_{f_{B}}$, derived from the generated spectra in the forward $\mathrm{P}_{3}$ approximation model. The constants $\mathrm{k}$ and $\mathrm{m}_{1}$ follow the linear relationship between $f_{B}$ and $\frac{1}{I_{f_{B}}}$ in Eq. 7.6, displayed in Fig. 7.7.

$$
f_{B}=k \frac{1}{I_{f_{B}}}+m_{1}
$$




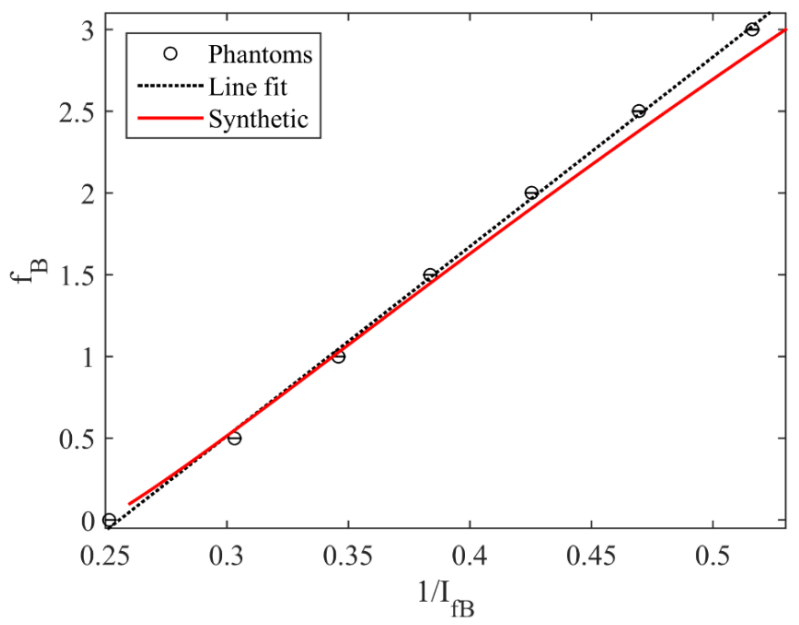

Figure 7.7 Blood fraction $\left(\mathrm{f}_{\mathrm{B}}\right)$ estimation using the relation between the intensity at isobestic wavelengths and the blood concentration

\section{Oxygen saturation estimation}

As the shape of the characteristic hemoglobin absorption changes with the number of carried oxygen molecules the $\mathrm{SO}_{2}$ was estimated through a quadratic polynomial fit (Eq. 7.7) to the spectral region between 545 and $573 \mathrm{~nm}$, Fig, 7.8, in the diffuse reflectance signal.

$$
I=\alpha \lambda^{2}+\beta \lambda+\gamma
$$
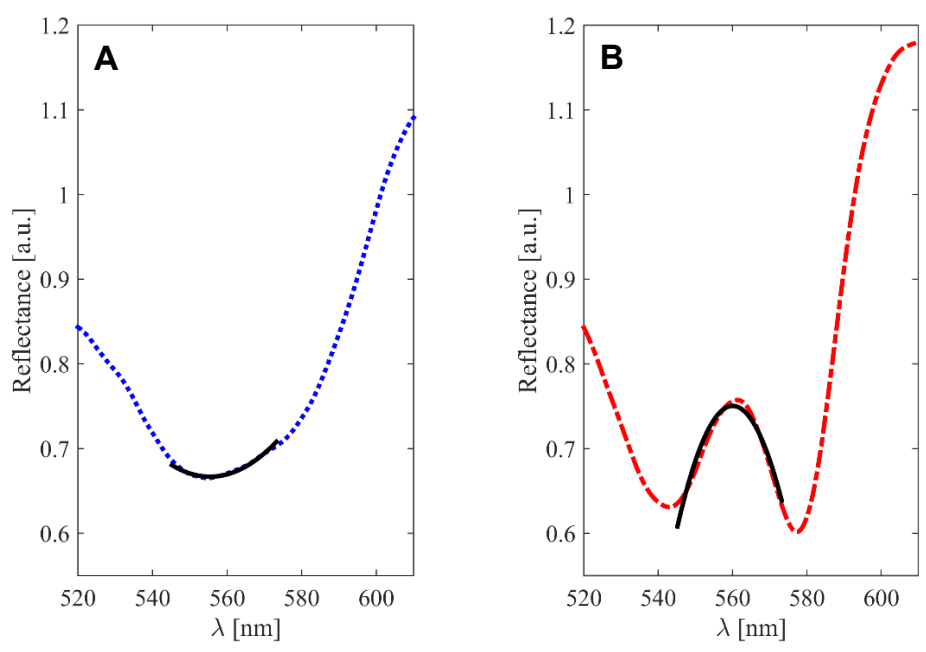

Figure 7.8 Quadratic polynomial fit to a region of interest in the reflected spectra of hemoglobin for a) deoxygenated state and b) oxygenated state 


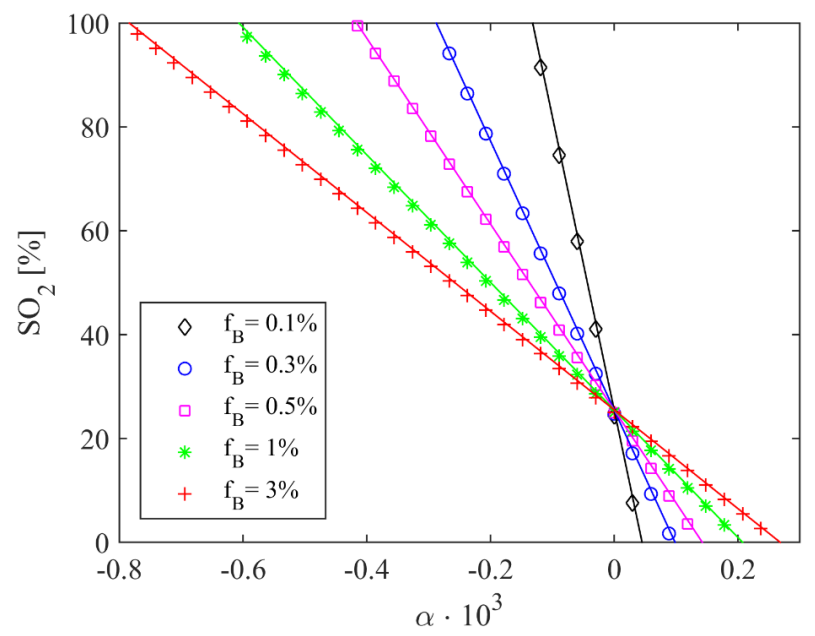

Figure 7.9 Blood fraction $\left(\mathrm{f}_{\mathrm{B}}\right)$ estimation using the relation between the intensity at isobestic wavelengths and the blood concentration

The $\mathrm{SO}_{2}$ estimation uses the $\mathrm{f}_{\mathrm{B}}$ and the alpha coefficient $(\alpha)$ from the polynomial fit in the function described in Eq. 7.8.

$$
S O_{2}=\frac{\mathrm{C} \cdot f_{B}-\mathrm{D}}{f_{B}+\mathrm{E}} \alpha+m_{2}
$$

The constants $\mathrm{C}, \mathrm{D}, \mathrm{E}$ and $\mathrm{m}_{2}$ follow from the relationship between $\mathrm{SO}_{2}$ and $\alpha$ seen in Fig. 7.9. Constants and their values used to estimate the $\mathrm{f}_{\mathrm{B}}$ and $\mathrm{SO}_{2}$ in Eq. 7.6 and 7.8 are listed in Tab. 7.1.

Table 7.1 Values for constants used in the blood fraction $\left(\mathrm{f}_{\mathrm{B}}\right)$ and oxygen saturation $\left(\mathrm{SO}_{2}\right)$ estimation in Eq. 7.6 and 7.8

\begin{tabular}{|l|l|}
\hline Constant & Value \\
\hline $\mathrm{k}$ & 11.7 \\
\hline $\mathrm{m}_{1}$ & -3.00 \\
\hline $\mathrm{m}_{2}$ & 25.5 \\
\hline $\mathrm{C}$ & -67.5 \\
\hline $\mathrm{D}$ & -54.8 \\
\hline $\mathrm{E}$ & 0.0088 \\
\hline
\end{tabular}


Chapter 7 - Signal analysis and software 


\section{Experimental and clinical evaluation}

Optical measurements using LDF and DRS were performed to test and evaluate the methods in experimental and clinical settings. Measurements on skin tissue were performed to test the functionality of the fiber optic probe compared with a standard skin tissue probe. Experimental measurements using optical phantoms with hemoglobin and regulated $\mathrm{pO}_{2}$ were used to develop and validate the $\mathrm{SO}_{2}$ estimation algorithm. LDF was evaluated with intraoperative measurements during brain tumor and DBS surgery. DRS was evaluated using data that had been collected during DBS surgery. The combination of LDF and DRS with real-time estimations of microcirculatory parameters for patient monitoring was evaluated in an initial study in the NICU.

\section{Occlusion with skin tissue}

The custom-made brain probe was compared with a standard LDF skin probe on the finger tips during an occlusion test, in Paper I, where the blood flow through the brachial artery was restricted using a blood pressure cuff. After 90 seconds of occlusion, the pressure in the cuff was released followed by a physiological increase in blood flow known as reactive hyperemia. The standard skin probe (on middle finger) and the brain probe (on index finger) showed a similar response in measured perfusion during the occlusion experiment as seen in Fig. 8.1.

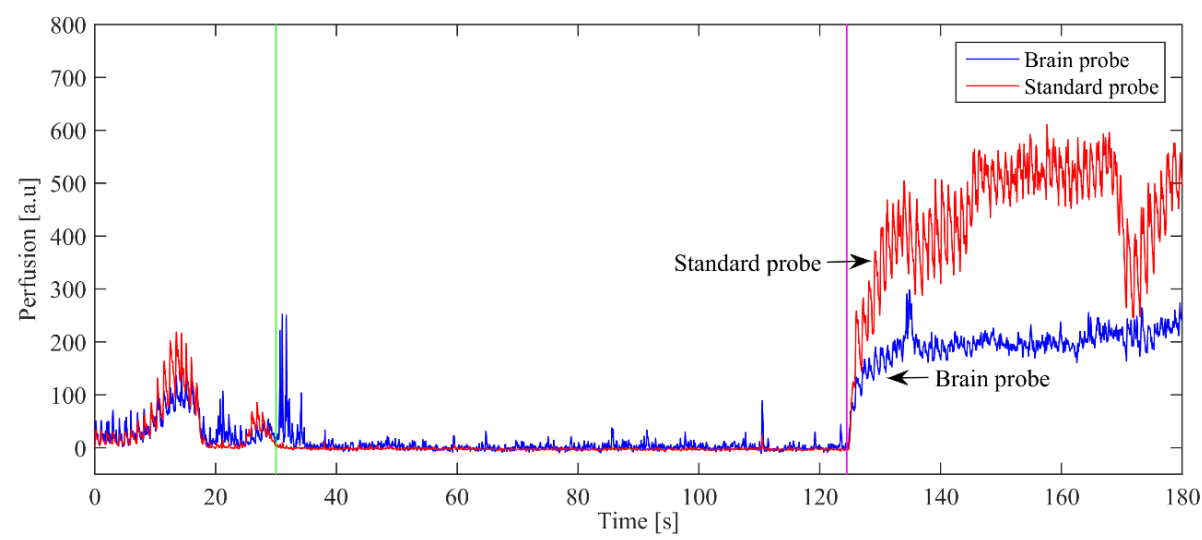

Figure 8.1 Perfusion signal from LDF with a standard skin probe and brain probe during an occlusion provocation on skin tissue

\section{Optical phantom experiments}

Phantom measurements with regulated $\mathrm{pO}_{2}$ from close to 0 up to $100 \mathrm{mmHg}$ induced conformational changes in hemoglobin as it picks up more oxygen. The resulting profile changes in the reflected spectrum can be related to the level of $\mathrm{SO}_{2}$, as previously described in chapter 7 and Paper III. The change from a single to a double valley, for increasing $\mathrm{pO}_{2}$, in the region between 540 and $580 \mathrm{~nm}$ is shown in Fig. 8.2 where smoothed spectra from a phantom measurement illustrate the change in $\mathrm{SO}_{2}$. 


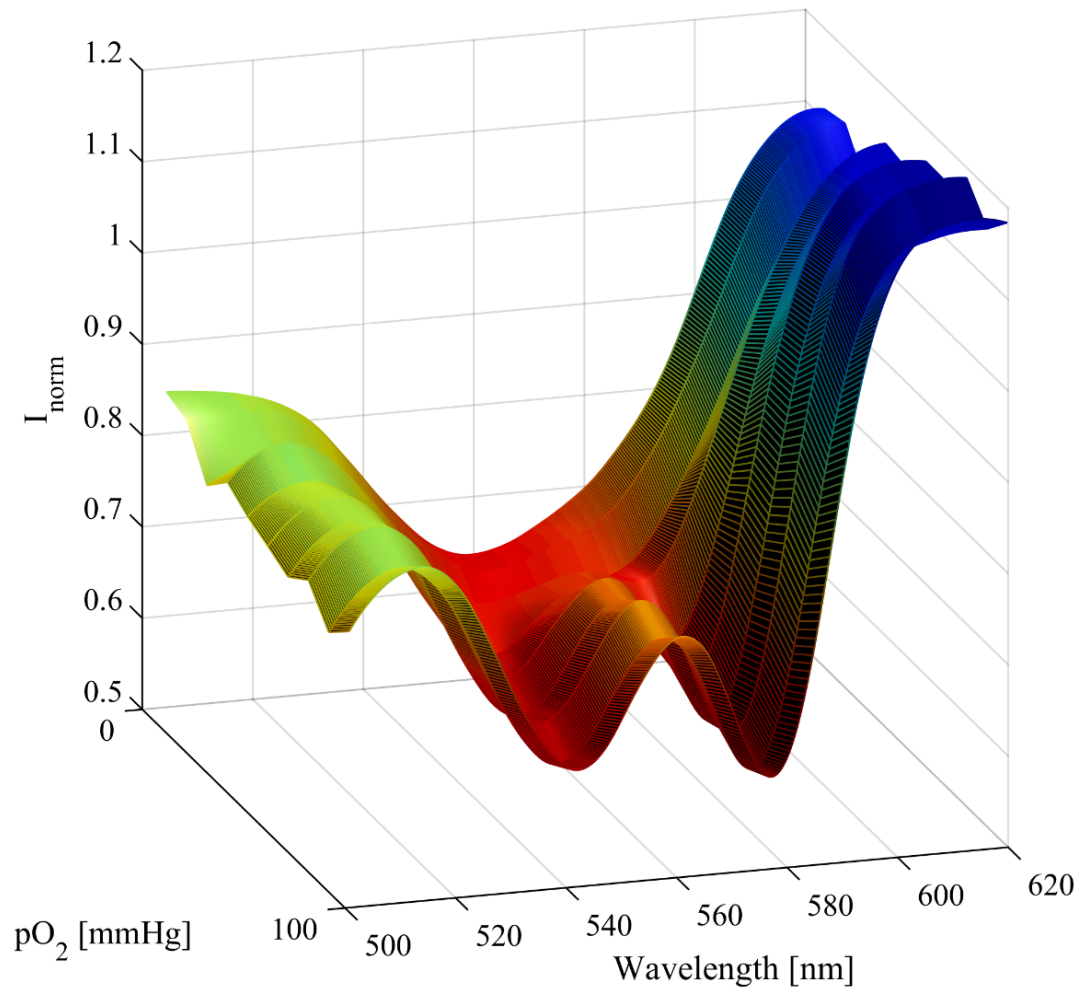

Figure 8.2 Spectral changes in the hemoglobin reflectance during phantom experiment for $\mathrm{SO}_{2}$ variation following regulation of $\mathrm{pO}_{2}$ from 0 to $100 \mathrm{mmHg}$

\section{Phantom and $\mathrm{P}_{3}$ model comparison}

Spectra measured in the phantoms at different $\mathrm{pO}_{2}$ levels were compared with the simulated forward $\mathrm{P}_{3}$ approximation model as seen in Fig. 8.3. The forward model had a root mean square error of 0.015 for the deoxygenated state in Fig. $8.3 \mathrm{a}$ and a root mean square error of 0.018 for the oxygenated state in Fig. 8.3b when compared with the measured spectra from two of the optical phantoms. 

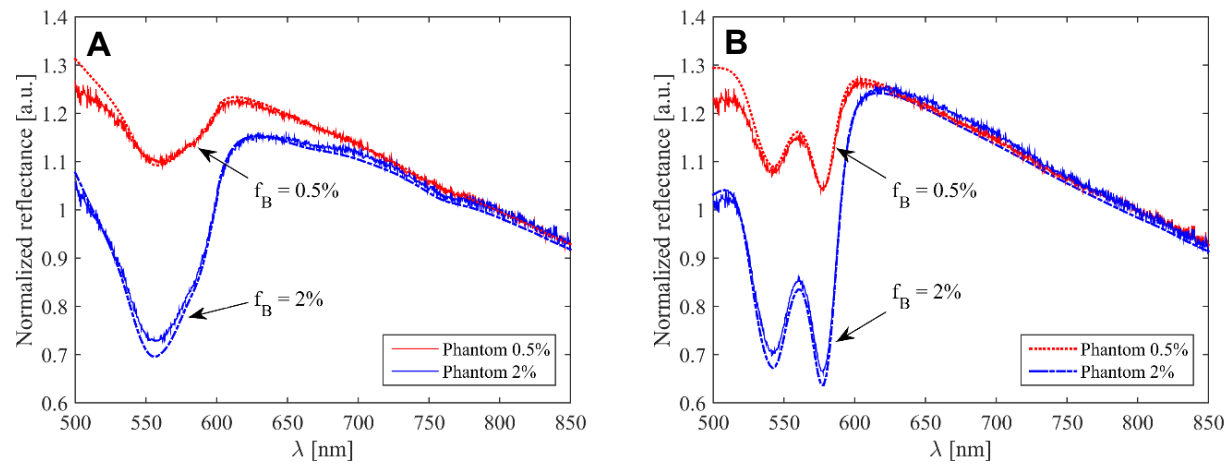

Figure 8.3 Comparison between phantom measurements and $\mathrm{P}_{3}$ forward model from $\mathrm{SO}_{2}$ estimation with a) low oxygen level and b) high oxygen level

\section{Effect of scattering variations}

The algorithm was developed with a fixed scattering level to suit measurement in white human brain matter. The algorithm's sensitivity to scattering variations was investigated with forward modelling using the $\mathrm{P}_{3}$ approximation in the same manner as to the procedure that was used in the development phase. The exponential coefficient (B) for the reduced scattering, modelled by Eq. 7.3, was varied from 0.6 to 1.6 to simulate scattering in gray to white brain matter [95]. This range was determined using previously reported values of optical properties found in gray and white matter after normalization to the $800 \mathrm{~nm}$ wavelength [95, 115]. The forward simulation covering scattering variations between gray and white brain matter resulted in an $\mathrm{SO}_{2}$ estimation variation of up to approximately $4 \%$ points for $\mathrm{SO}_{2}$ between 0 and $50 \%$ or a difference of up to $12 \%$ points for $\mathrm{SO}_{2}$ around $100 \%$.

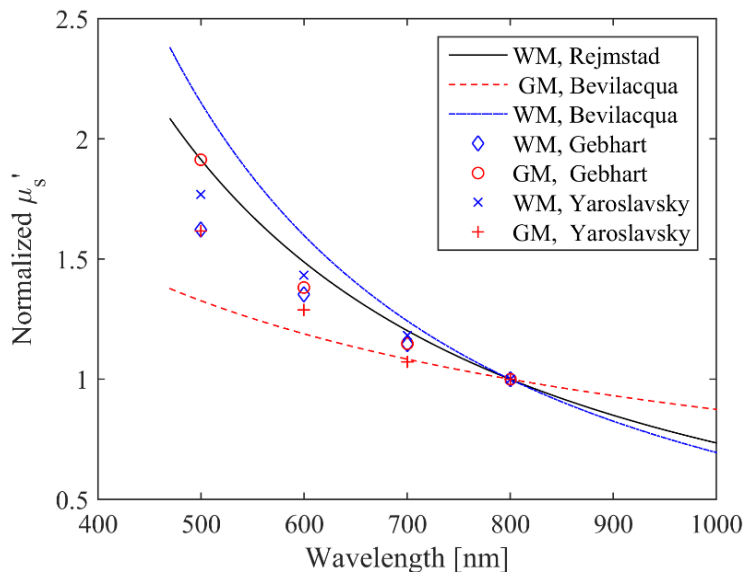

Figure 8.4 Reduced scattering $\left(\mu_{s}^{\prime}\right)$ normalized at $800 \mathrm{~nm}$ for human brain tissue in white matter (WM) and gray matter (GM) based on reported values from Bevilacqua [95], Gebhart [115] and Yaroslavsky [116] in addition to the normalized modelled $\mu_{s}^{\prime}$ of white matter used in this work (Paper III) 


\section{Tumor surgery}

Patients scheduled for tumor surgery $(n=10,6$ females and 4 males, age $38-77)$ at the Department of Neurosurgery at Linköping University Hospital, Sweden were included in a study where the cerebral microcirculatory blood flow was measured during to the surgical tumor removal. The study was approved by the local Ethics Committee (No. M182-04, 2010/359-32). Signals in 76 tissue sites for 10 seconds up to 15 minutes were recorded.

The study showed that the optical system using custom-made, fiber optical probes together with LDF were feasible for use in brain tissue and could be further employed for use in the NICU. The optical signals from LDF for tumor tissue compared with gray and white matter that showed a significant difference between tumor and white matter in terms of perfusion and TLI are seen in Paper II [106].

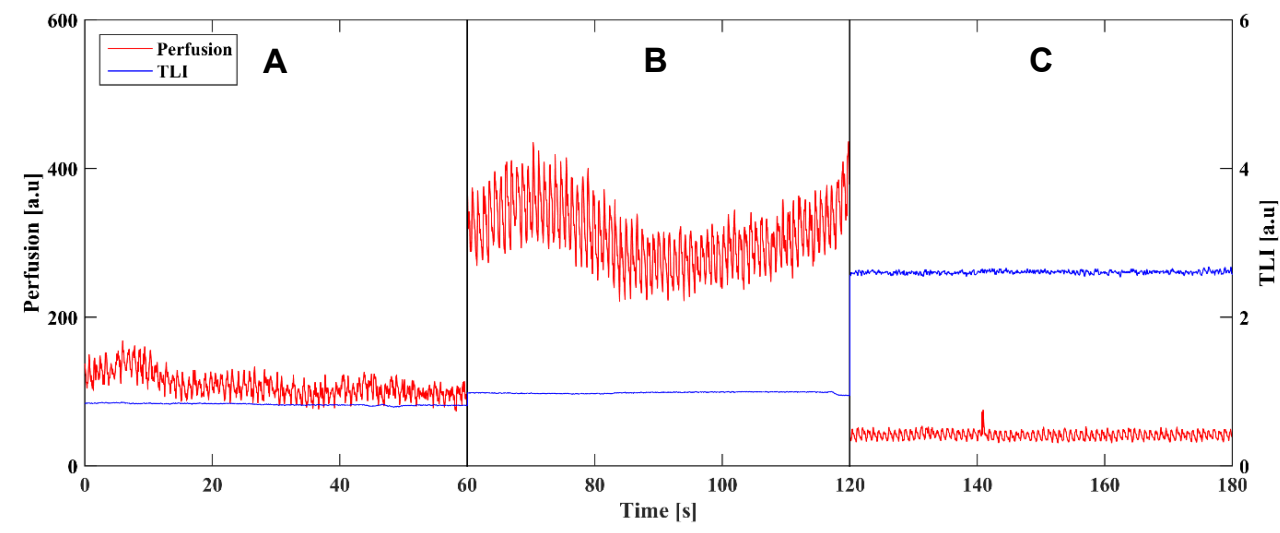

Figure 8.5 LDF signal example from a) tumor tissue, b) superficial tumor tissue and c) white matter

\section{Deep brain stimulation surgery}

Patients $(n=11)$ scheduled for DBS surgery at the Department of Neurosurgery at Linköping University Hospital were included in the study where optical measurements were performed along the trajectory towards a target in the deep brain structures for implantation of DBS electrodes. Written informed consent to participate in the study was given prior to measurements. The patients had movement related symptoms and were diagnosed with Parkinson's disease, essential tremor or dystonia. The study was approved by the local Ethics Committee (No. M182-04, T54-09). The optical measurements were used to build optical barcodes along the trajectories of different targets as a means of intraoperative navigation and sensory system to detect and alert the surgeon of intermediately sized blood vessels that might cause hemorrhages if ruptured [72]. Measurements with LDF [72] and DRS were made for 20 trajectories and 166 sites, in Paper IV. The developed model for estimating the $\mathrm{SO}_{2}$ was used to analyze the spectra collected during the DBS surgeries. Comparisons of $\mathrm{SO}_{2}$ and $\mathrm{f}_{\mathrm{B}}$ estimations between tissue groups are plotted in Fig. 8.6. 

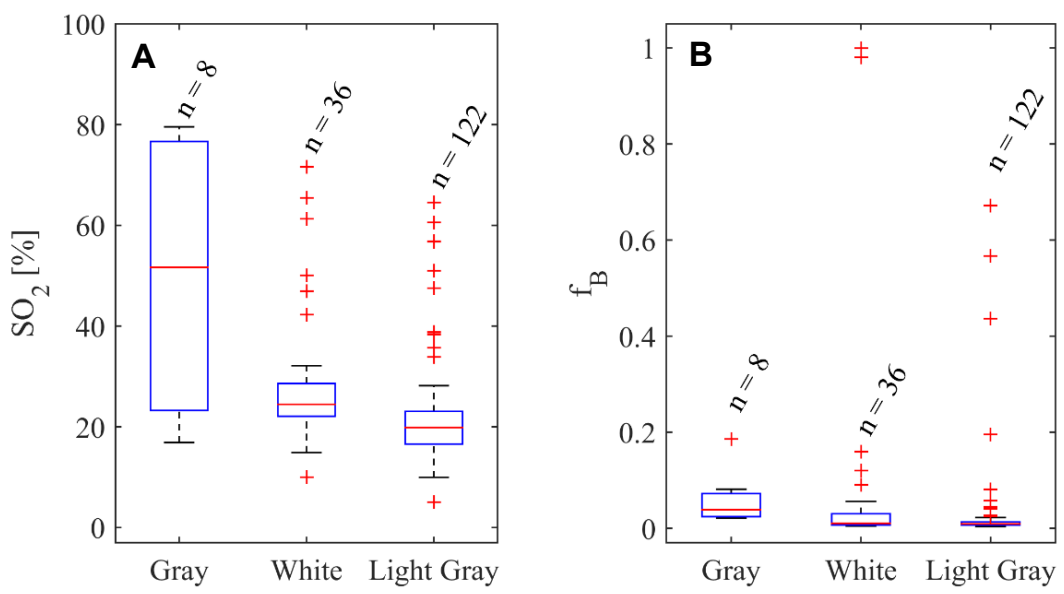

Figure 8.6 a) $\mathrm{SO}_{2}$ estimations and b) $\mathrm{f}_{\mathrm{B}}$ estimations for different tissue groups (gray, white and light gray matter)

\section{Neurointensive care monitoring}

The optical systems were adapted for monitoring NICU patients in risk of secondary brain injury that may be detected with the help of the acquired signals. A patient diagnosed with SAH from a ruptured aneurysm was included in the study. The optical fiber probe was placed in parallel with a standard microdialysis probe during surgery, as seen in Fig 8.7. The local Ethics Committee gave ethical approval of the study (M182-04, 2010/359-32). Written informed consent to participate in the study was given by the immediate family, as the patient was unconscious upon admittance to the hospital.

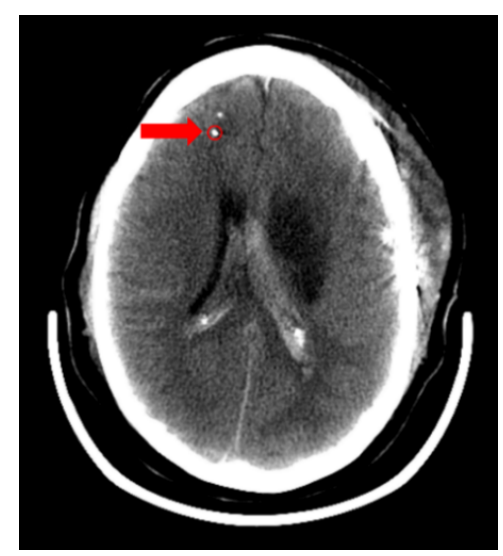

Figure 8.7 CT image with marked fiber optic probe placement 
The perfusion was monitored using LDF and $\mathrm{SO}_{2}$ intermittently measured from DRS during daytime over four days after which the probe was disconnected to the equipment and later removed six days after implantation. Examples of signals collected using LDF and DRS are shown in Fig. 8.8. The collected signals were used to track the variations in local perfusion and $\mathrm{SO}_{2}$ over four days. Data collected during one of the four days is seen in Fig. 8.9.
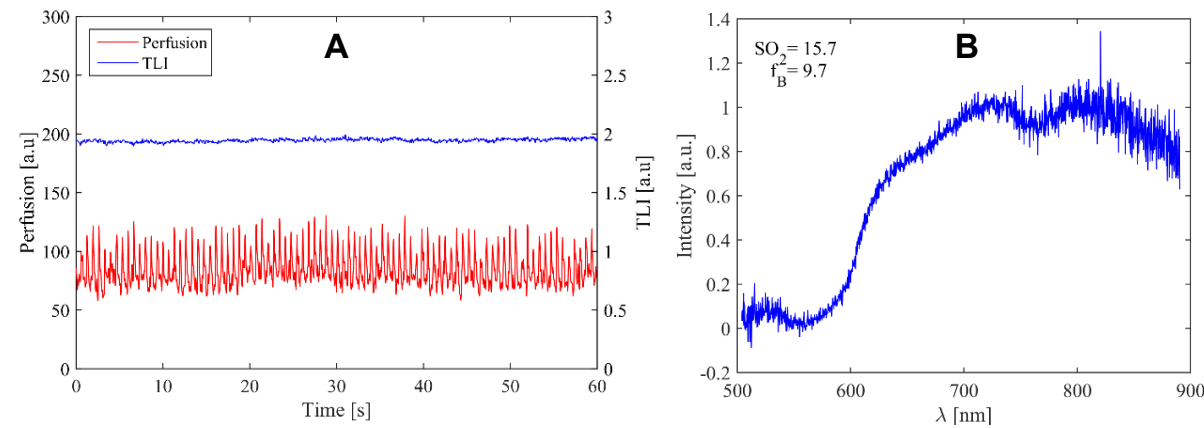

Figure 8.8 Examples of a) LDF and b) DRS signals from NICU measurements

The monitored parameters ICP, CPP, Perf and PI from day one of the four days of monitoring are plotted in Fig 8.9. The PI parameter reacts to changes in the perfusion signal where an inverse relation between the two can be distinguished at some parts in Fig. 8.9.
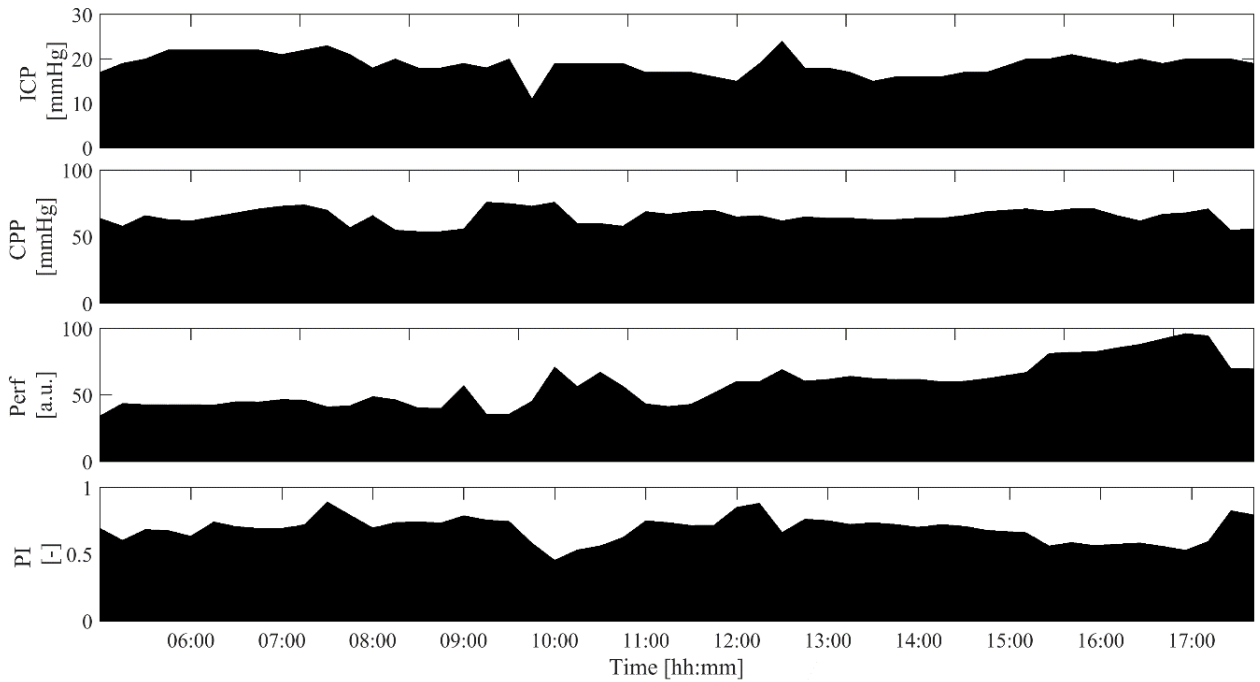

Figure 8.9 Example of monitored parameters in the neurointensive care unit displaying ICP, CPP, perfusion (Perf) and PI from a patient treated for subarachnoid hemorrhage (SAH) 


\section{Overview of papers}

\section{Paper I}

In this initial study LDF is introduced as a potential monitoring system in neurointensive care together with a custom-made, flexible, fiber-optic probe evaluated experimentally on skin tissue and clinically in relation to one tumor surgery. The evaluation on skin resulted in similar signals from the brain probe compared with a standard probe during an occlusion experiment with reactive hyperemia. The clinical measurement in brain tissue showed stable LDF signals for up to $15 \mathrm{~min}$.

\section{Paper II}

The second paper presents a continuation of the LDF evaluation study in Paper I, where tissue measurements from 10 patients operated for a brain tumor (tumor resection) were performed and analyzed. LDF was used to monitor the local cerebral perfusion where collected signals were interpreted to display HR and PI along with signal trends. This evaluation showed that the LDF system together with the new type of probe could discriminate between tissue types (gray matter or tumor tissue versus white matter) in terms of microvascular perfusion and amount of backscattered light.

\section{Paper III}

This third paper describes the development of a real-time method estimating the $\mathrm{SO}_{2}$ and $\mathrm{f}_{\mathrm{B}}$ in tissue using DRS. The method was developed from generated spectra using the $\mathrm{P}_{3}$ approximation of light diffusion and experimentally with optical phantoms containing hemoglobin. The $\mathrm{SO}_{2}$ in the phantoms was regulated using nitrogen gas in a setup made to control parameters affecting the oxygen dissociation curve of hemoglobin. The developed method was found capable of estimating the $\mathrm{SO}_{2}$ from diffuse reflected spectrum calibrated for $f_{B}$ between 0.5 to $3 \%$ using optical phantoms.

\section{Paper IV}

The fourth paper presents estimation of $\mathrm{SO}_{2}$ and $\mathrm{f}_{\mathrm{B}}$ using the developed method (Paper III) applied to DRS spectra collected in brain tissue, from 11 patients, in relation to DBS surgery. Spectra were recorded at different positions along stereotactic trajectories toward four different DBS targets (STN, Vim, GPi and Zi). Differences between tissue groups (white, gray and light gray matter) and DBS targets were investigated.

\section{Paper V}

The fifth paper involves an initial study of using LDF and DRS to monitoring the perfusion and $\mathrm{SO}_{2}$ on a patient treated for SAH in the NICU. The optical measurements lasted four days where approximately 40 hours of LDF data were collected with stable signals. The $\mathrm{SO}_{2}$ was calculated from the DRS spectra using the method in Paper III. The gathered parameters were compared with values from the standard monitoring. The relation between the local perfusion and cerebral perfusion pressure was used as an indicator of sustained autoregulation. 
Chapter 9 - Overview of papers 


\section{Discussion and conclusion}

In this thesis, the optical methods LDF and DRS were adapted to monitor perfusion and $\mathrm{SO}_{2}$ for assessing the cerebral microcirculation. A custom-made fiber optic probe for combining LDF and DRS for measurements in brain tissue was evaluated intraoperatively during tumor surgery. A method for estimation of $\mathrm{SO}_{2}$ was developed with optical phantoms and clinically evaluated with intraoperative data before being used for monitoring a patient in neurointensive care.

\section{Diffuse reflectance spectroscopy}

The use of DRS provides fast, non-invasive, and portable measurement of reflectance spectra that can be used for bedside evaluation of $\mathrm{SO}_{2}$. To produce accurate $\mathrm{SO}_{2}$ estimations using DRS the method requires an $\mathrm{Hb}$ signal. The quadratic polynomial fit procedure is straightforward, quick and computationally inexpensive enabling real-time $\mathrm{SO}_{2}$ estimations from reflectance spectra. As with all models, the estimation model used in this thesis is associated with advantages and limitations that influence the performance. The developed algorithm is, for example, limited by using a basic chromophore model, mainly considering the two states of hemoglobin whereas other chromophores were disregarded. The developed $\mathrm{SO}_{2}$ estimation algorithm was based on a model with reduced scattering mimicking white brain matter where large deviations from the model may lead to inaccuracies in the estimations. To quantify this, simulations were made where the scattering was varied resulting in deviations up to $4 \%$ points in $\mathrm{SO}_{2}$ between 0 and $50 \%$ and errors of up to $12 \%$ points at $100 \% \mathrm{SO}_{2}$. Scattering variations as shown in Fig. 8.4 were studied. The calibration with optical phantoms was limited to blood concentrations between 0.5 and $3 \%$ (Paper III) where concentrations outside that range may produce inaccurate estimations. The synthetic spectra were generated with blood concentrations covering the range between $0.1 \%$ and $3 \%$ to include concentrations reported in literature for white brain matter $[110,111]$. The use of different SD-distances for different probes will have an effect on the $\mathrm{SO}_{2}$ estimation using the presented model. In Paper IV, the model used by the $\mathrm{SO}_{2}$ algorithm was modified compared to the original in order to suit the DBS probe with a SDdistance of $0.25 \mathrm{~mm}$. Results from analyzing the same spectra using the two different $\mathrm{SO}_{2}$ models adjusted for either $0.3 \mathrm{~mm}$ and $0.25 \mathrm{~mm}$ SD-distances resulted in a difference of $0.74 \%$ points for $\mathrm{f}_{\mathrm{B}}$ and a difference of $1.9 \%$ points for $\mathrm{SO}_{2}$ when comparing estimations from 166 different spectra found in Paper IV. The relatively low estimated values of the $\mathrm{SO}_{2}$ using DRS should not to be confused with arterial $\mathrm{SO}_{2}$ values from blood gas analysis or pulse oximetry as the measurements with DRS were made mainly on microcirculatory blood vessels. When considering normal physiological baseline values of cerebral $\mathrm{pO}_{2}, \mathrm{pCO}_{2}, \mathrm{pH}$ and temperature in white matter as reported by Hoffman et al., [117] corresponding $\mathrm{SO}_{2}$ was $30.8 \%$ according to the ODC [37]. However, baseline $\mathrm{SO}_{2}$ values for subdural (7 $\mathrm{mm}$ deep) brain tissue measured with a commercial system, "Oxygen-to-see" or O2C, from $20 \mathrm{SAH}$ patients was reported to be $39 \%$ according to a study by Sommers et al., [118] which is comparable to the results in Paper IV. Another research group [119] used a DRS system where the analysis of recorded spectra from human gray $\left(\mathrm{SO}_{2}=54 \%\right)$ and white $\left(\mathrm{SO}_{2}=26 \%\right)$ brain matter resulted in $\mathrm{SO}_{2}$ values which were in agreement with the results in Paper IV. 


\section{Laser Doppler flowmetry}

The advantages of using LDF are, for example, the sensitive, continuous, minimally-invasive, and real-time measurements that provide signals with high temporal resolution from a relatively inexpensive and portable system. The local point based with a sampling volume of approximately $1-2 \mathrm{~mm}^{3}$ can be of use when studying focal ischemia but can also be a limitation when systemic readings are desired [51]. The sensitivity to movement sometimes requires consideration when measuring upon moving tissue or when external movements may cause non-physiological signal artifacts. This issue can be addressed in several ways where fixation or stabilization of the optical probe to the measurement site, e.g. suturing or using a stereotactic frame, is the most reliable alternative. If external movements still cause problems then an option is simply to register artifacts using data analysis and highlight or exclude these parts during signal presentation [120]. The perfusion signal is represents a combination of blood flow velocity and the $\mathrm{CMBC}$ thereby producing values with relative units and without information regarding the direction of blood flow [121].

\section{Monitored parameters}

The signals and parameters used to assess the cerebral microcirculation are $\mathrm{SO}_{2}$ and $\mathrm{f}_{\mathrm{B}}$ from DRS and perfusion, TLI, HR and PI from LDF. The parameters were presented in real-time using custom-made software modules with averages or trends aimed to provide clinicians with information and a quick overview of the microcirculation. The parameters can be utilized to monitor the local perfusion and oxygenation where changes in $\mathrm{SO}_{2}$ can indicate hypoxia [122] and the $f_{B}$ parameter reflects the hemoglobin or blood concentration. Perfusion from LDF enables tracking dynamic changes in blood flow which may be useful for detecting ischemia or hyperemia [51]. The TLI signal indicates which type of tissue the probe interrogates from the intensity of the backscattered light [123]. The level of physical stress and cardiac output is related to the HR parameter which normally is monitored from an ECG but can also verify that the signal is related to blood flow pulsations in LDF. The PI is commonly used in TCD and was until recently used to represent vascular resistance distal to the measurement [124]. When used in LDF the PI may be used to quantify the pulsatility of the perfusion signal and may indicate changes in perfusion and CPP or ICP. Multimodal monitoring approaches are often preferred to single modalities during clinical brain monitoring in order to provide a better overview and understanding of the dynamics of the physiology. By combining the LDF and DRS modalities, the limitations of a single technique can be compensated. Reviews on neurological monitoring and management of patients treated for a brain injury generally recommend using several techniques in parallel to detect signs of delayed brain injury compared to relying on a single modality $[36,125]$. The methods applied and developed here aim at using DRS and LDF in combination with a single optical probe to gather information of both blood flow and oxygenation which play crucial parts in the metabolic balance in the brain.

\section{Multimodal setup comparison and probe placement}

There are numerous different optical setups that can be used for multimodal monitoring to aid surgeons and clinical staff during neurosurgical intervention, or for monitoring patients. A few of these optical setups, which are comparable with the suggested LDF-DRS setup in this thesis, 
are worth mentioning. Giller et al., presented a setup with optical probes that could be used in combination with microelectrode recording or DBS-electrode tests for optical navigation along stereotactic trajectories during DBS electrode implantations with either a forward-looking or side-view field of view using white light and a NIR-sensitive spectrometer to relate to the brain anatomy [15]. Another group used a probe configuration referred to as subdural opto-electrode strips with four optodes close to EEG-electrodes to deliver and receive light from the superficial part of the brain for LDF measurements, in order to study spreading depolarization related to perfusion deficit and ischemic damage in the cerebral cortex in a patient with SAH [126]. The LDF measurements using the optode strip were able to register response to cortical spreading depressions, however, practical issues related to breaks in the optical fibers and movement artifacts were reported in relation to the measurements in $13 \mathrm{SAH}$ patients. Kirkpatrick et al., performed measurements using LDF with a rigid probe design adapted for fixation using a Camino cranial bolt which was placed in order to sample the cortical surface in 22 patients with a severe head injury [121]. In the latter study, four cases involving LDF probe placement on the cortical surface resulted in puncturing the dura where the probe unintentionally was situated inside the brain parenchyma thus the probe had to be repositioned. In a similar study of cerebral autoregulation by Lam et al., LDF probes were placed on the cortical surface where the probes lost contact in 5 out of the 31 patients indicating a relatively high risk of losing the signal quality when placing a LDF probe on the cortical surface [127]. The placement of the brain probe requires careful consideration for the best monitoring results when measuring with point-based methods such as DRS and LDF. As the sampling volume for LDF in brain tissue is limited, approximately $1-2 \mathrm{~mm}^{3}$, probe placement is worth consideration to suit the specific application [51]. Depending on the purpose of the application, probe placement in the penumbra (tissue area affected by hemorrhage) or in unaffected tissue has been discussed [128]. Spatial variations and tissue heterogeneity in the microvasculature is another factor influencing the result of local tissue measurements $[16,129]$. The spatial blood flow variations can clearly be seen by the differences in local values from the Xe-CT scans in Paper V. The average blood flow of the relatively large regions does not necessarily correlate with local perfusion in specific point-measurements. This puts further emphasis on careful planning when placing the optical LDF probe when being used for monitoring.

\section{Autoregulation}

Cerebral autoregulation is being increasingly recognized as an important parameter when treating patients with SAH [32]. The detection of microvascular dysfunction during monitoring of patients with elevated risk of DCI can be performed through assessing the cerebral autoregulation using continuous blood flow measurements with LDF. In the absence of clear signs of pathological deterioration, such as from obvious trends in the monitored parameters, monitoring of the cerebral autoregulation may help to guide management and to predict outcome [130]. Optical methods measuring CBF that enable assessment of cerebral autoregulation have recently gained attention [131]. By combining the information from conventional monitoring equipment in the NICU with signals from the local optical monitoring, the correlation between perfusion or $\mathrm{SO}_{2}$ and the cerebral perfusion pressure could be used to assess the status of cerebral autoregulation. The relation or correlation between CBF and CPP can be used to assess the condition of the cerebral autoregulation as described by the Lassen's 
curve. Kirkpatrick et al., identified a lower autoregulation breakpoint at CPP of approximately $58 \mathrm{mmHg}$ from long-term measurements in 16 patients with a head injury by using LDF [121]. In another study by Lam et al., with 31 brain-injured comatose patients, a linear relationship between perfusion and CPP (for 15 min sections) was used to indicate loss of autoregulation [127]. The relation between perfusion and CPP was studied in Paper V where low correlation indicated intact cerebral autoregulation. In a similar way, a correlation coefficient larger than 0.3 between regional $\mathrm{SO}_{2}$ and $\mathrm{CPP}$ could potentially be used to indicate cerebral autoregulation impairment as suggested by Sekhon et al., [132]. In addition to studying the perfusion CPP relation, the cerebral autoregulation could be assessed by analyzing the presence of slow changing waves in the perfusion signal [133].

\section{Future research and system improvements}

Optical systems such as LDF and DRS could be used as tools to detect regional ischemia or hypoxia in brain tissue during patient monitoring, as indicated by animal and human studies $[118,121,134]$. The sensitive LDF method can detect small changes in the blood flow that may prove useful in detecting signs of patient deterioration related to secondary brain injury at an early stage. For an adequate evaluation, future work would seek to validate the potential of the presented systems using a larger cohort of patients including cases which are diagnosed with DCI or vasospasm. Future improvements to the described $\mathrm{SO}_{2}$ estimation model could, for example, include adaption to other types of tissues such as gray matter, coagulated or damaged tissue. Another way of using DRS could also be to optically detect the presence of blood in the CSF of the ventricles. In the current setup, DRS and LDF were used sequentially whereas parallel and simultaneous estimation would improve the monitoring capability and provide instant feedback if rapid changes in the circulation occurred. This can be accomplished using an optical short pass or a notch filter that blocks the laser light from the LDF system from reaching and saturating the spectrometer [135]. The developed $\mathrm{SO}_{2}$ algorithm has the potential to be used with only a few wavelengths, making the model suitable for use with discrete wavelengths through optical, inexpensive, hardware components. Light emitting diodes such as light sources and photodetectors could be used for producing inexpensive devices to monitor $\mathrm{SO}_{2}$. By combining information regarding blood flow and oxygenation through using DRS and LDF the $\mathrm{CMRO}_{2}$ could potentially be assessed. Boas et al. suggested a way of estimating the change in $\mathrm{CMRO}_{2}$ by using NIRS [136]. Mesquita et al. proposed combining diffuse correlation spectroscopy and NIRS for estimating the relative $\mathrm{CMRO}_{2}$ [137]. This principle was also studied by Verdecchia et al., [138] and Selb et al., [139]. As indicated by the mentioned studies, the relative $\mathrm{CMRO}_{2}$ can be traced by combining the signals of perfusion and $\mathrm{SO}_{2}$ from $\mathrm{LDF}$ and DRS. $\mathrm{CMRO}_{2}$ estimation using optical techniques has mainly been tested in animal models with functional activation of brain areas but could in a future step potentially be of use to clinicians who want to assess the metabolism of damaged tissue. The current DRS-LDF setup could in a future study be compared with other oxygen and CBF sensing modalities such as $\mathrm{pO}_{2}$ electrodes and thermal diffusion to further evaluate and validate the accuracy of the $\mathrm{SO}_{2}$ estimations and applicability of the techniques. Such comparison would help to evaluate advantages and limitations of respective modality. 
In conclusion, LDF and DRS were adapted for multimodal monitoring in neurointensive care with custom-made software and a specifically designed brain probe. An algorithm for real-time estimation of $\mathrm{SO}_{2}$ in brain tissue was developed based on a quadratic polynomial fit to the reflected spectrum. Software modules with a specific user interface for LDF and DRS were programmed to process, record and present parameters such as perfusion, heart rate and $\mathrm{SO}_{2}$ from acquired signals. The systems were successfully evaluated experimentally with optical phantoms and introduced clinically during intraoperative measurements in tumor surgery, deep brain stimulation implantation and in the neurointensive care unit. 
Chapter 10 - Discussion and conclusion 


\section{Acknowledgements}

Many people have contributed to this thesis. First, I would like to thank my main supervisor Professor Karin Wårdell for giving me the opportunity to do research in the interdisciplinary field of biomedical optics related to neuroscience. Thanks to my co-supervisor Professor Göran Salerud for discussions regarding biomedical optics and microcirculation as well as giving feedback on my papers. Thanks to my co-supervisor Dr. Neda Haj Hosseini for the help you provide whenever I felt stuck, daily conversations and contribution to our publications. Thanks to Dr. Johannes Johansson for sharing your knowledge of optical theory and support during article writing.

Thanks to the neurosurgeons MD. Oscar Åneman, MD. Gustav Åkesson, MD. PhD. Peter Zsigmond and MD. Johan Richter, at the Neurosurgical Department at Linköping University Hospital, Region Östergötland. Thanks to Professor Jan Hillman, head of the Department of Neurosurgery for making the clinical collaboration between our departments possible. Thanks to the helpful staff at the Department of Neurosurgery and NIVA Clinic for fruitful collaboration and help in relation to our measurements during various surgeries and monitoring. Special thanks to Per Sveider and Dr. Mats Andersson for skilful probe fabrication, without your contributions, much of our work would not have been possible. Centre for medical imaging and visualization (CMIV) for enabling MRI and CT imaging during clinical projects. I would also like to thank my fellow PhD students at the Department of Biomedical Engineering for sharing experiences and finding solutions to common work related issues during the time we shared. Thanks to Olivier for being a friend who always appreciates discussions of anything regarding life as a $\mathrm{PhD}$ student and guidance when making visualizations of collected data. Thanks to Maria for your positive way and eagerness to organize activities at the department. Malcolm Latorre for engineering discussions and helping me find the proper words in English. Colleagues: Marcus, Ingemar, Hanna, Fabiola and Martin for input on my thesis. Former colleagues Elin and Mattias for welcoming me to the department. Rikard, William, Elin and the people in the systems biology group for pleasant company at the department. Thanks to my former study-mates, Olof and Mats for keeping in touch over sporadic but well appreciated lunch meetings. Thanks to the staff at the department of Biomedical Engineering for always being kind and helpful, I will miss the amusing discussions at the coffee breaks and getting to know each one of you.

I also want to thank my family, especially my parents Gunilla and Lennart and my brother Johan, for always being supportive and interested in my research. Without your encouragement I do not think I would have made it this far. I am very grateful for the support I received from my beloved fiancée Emilie through my various endeavors in life, including the pursuit of getting a $\mathrm{PhD}$ degree.

Finally yet importantly, thanks to Vetenskapsrådet (No. 621-2010-4216 and 621-2013-6078) and Barncancerfonden (No. MT2012-0043) for funding this research. 
Acknowledgements 


\section{References}

1. Le Roux, P., Physiological monitoring of the severe traumatic brain injury patient in the intensive care unit. Curr Neurol Neurosci Rep, 2013. 13(3): p. 331.

2. Vos, P. and R. Diaz-Arrastia, Traumatic Brain Injury. 2014: Wiley.

3. Frontera, J., W. Ziai, K. O'Phelan, P.D. Leroux, P.J. Kirkpatrick, M.N. Diringer and J.I. Suarez, Regional brain monitoring in the neurocritical care unit. Neurocrit Care, 2015. 22(3): p. 348-59.

4. Budohoski, K.P., M. Czosnyka, P. Smielewski, G.V. Varsos, M. Kasprowicz, K.M. Brady, J.D. Pickard and P.J. Kirkpatrick, Cerebral autoregulation after subarachnoid hemorrhage: comparison of three methods. J Cereb Blood Flow Metab, 2013. 33(3): p. 449-56.

5. Barone, D.G. and M. Czosnyka, Brain monitoring: do we need a hole? An update on invasive and noninvasive brain monitoring modalities. ScientificWorldJournal, 2014. 2014: p. 795762.

6. Shepherd, A.P. and P.Å. Öberg, Laser-Doppler Blood Flowmetry. 2013: Springer US.

7. Bydlon, T.M., R. Nachabe, N. Ramanujam, H.J. Sterenborg and B.H. Hendriks, Chromophore based analyses of steady-state diffuse reflectance spectroscopy: current status and perspectives for clinical adoption. J Biophotonics, 2015. 8(1-2): p. 9-24.

8. Kimme, P., U. Gustafsson, A. Sollevi, G. Nilsson and F. Sjoberg, Cerebral blood flow of the exposed brain surface measured by laser Doppler perfusion imaging. Acta Physiol Scand, 1997. 159(1): p. 15-22.

9. Karlsson, M.G., L. Hubbert, U. Lonn, B. Janerot-Sjoberg, H. Casimir-Ahn and K. Wardell, Myocardial tissue motion influence on laser Doppler perfusion monitoring using tissue Doppler imaging. Med Biol Eng Comput, 2004. 42(6): p. 770-6.

10. Antonsson, J., O. Eriksson, P. Lundberg and K. Wårdell, Optical measurements during experimental stereotactic radiofrequency lesioning. Stereotact Funct Neurosurg, 2006. 84(2-3): p. 118-24.

11. Toms, S.A., W.C. Lin, R.J. Weil, M.D. Johnson, E.D. Jansen and A. MahadevanJansen, Intraoperative optical spectroscopy identifies infiltrating glioma margins with high sensitivity. Neurosurgery, 2007. 61(1 Suppl): p. 327-35; discussion 335-6.

12. Benabid, A.L., S. Chabardes, N. Torres, B. Piallat, P. Krack, V. Fraix and P. Pollak, Functional neurosurgery for movement disorders: a historical perspective. Prog Brain Res, 2009. 175: p. 379-91.

13. Lacroix, M., D. Abi-Said, D.R. Fourney, Z.L. Gokaslan, W. Shi, F. DeMonte, F.F. Lang, I.E. McCutcheon, S.J. Hassenbusch, E. Holland, K. Hess, C. Michael, D. Miller and R. Sawaya, A multivariate analysis of 416 patients with glioblastoma multiforme: prognosis, extent of resection, and survival. J Neurosurg, 2001. 95(2): p. 190-8.

14. Wårdell, K., P. Blomstedt, J. Richter, J. Antonsson, O. Eriksson, P. Zsigmond, A.T. Bergenheim and M.I. Hariz, Intracerebral microvascular measurements during deep brain stimulation implantation using laser Doppler perfusion monitoring. Stereotact Funct Neurosurg, 2007. 85(6): p. 279-86.

15. Giller, C.A., H. Liu, D.C. German, D. Kashyap and R.B. Dewey, A stereotactic nearinfrared probe for localization during functional neurosurgical procedures: further experience. J Neurosurg, 2009. 110(2): p. 263-73.

16. Nilsson, G., G. Salerud, T. Strömberg, K. Wårdell and M. Larsson, Laser Doppler perfusion monitoring and imaging. 2003.

17. Pittman, R.N., Oxygen transport in the microcirculation and its regulation. Microcirculation, 2013. 20(2): p. 117-37. 
18. Herculano-Houzel, S., The human brain in numbers: a linearly scaled-up primate brain. Front Hum Neurosci, 2009. 3: p. 31.

19. Johnson, M.D., Human Biology: Concepts and Current Issues. 2004: Pearson Education, Limited.

20. Singh, V., Textbook of Anatomy Head, Neck, and Brain. 2014: Elsevier Health Sciences APAC.

21. Saladin, K., Human Anatomy' 2007 Ed.2007 Edition: Rex Bookstore, Inc.

22. Tuma, R.F., W.N. Duran and K. Ley, Microcirculation. 2011: Elsevier Science.

23. Hartmann, A. and S. Hoyer, Cerebral Blood Flow and Metabolism Measurement. 2012: Springer Berlin Heidelberg.

24. Mellander, S., Perifer cirkulation: blodkärlens fysiologi. 1976: Sandoz.

25. Payne, S., Cerebral Autoregulation: Control of Blood Flow in the Brain. 2016: Springer International Publishing.

26. Boron, W.F. and E.L. Boulpaep, Medical Physiology. 2016: Elsevier Health Sciences.

27. Krogh, A., The rate of diffusion of gases through animal tissues, with some remarks on the coefficient of invasion. J Physiol, 1919. 52(6): p. 391-408.

28. Tortora, G.J. and B. Derrickson, Principles of anatomy and physiology. 12th ed. 2010, Hoboken, NJ: John Wiley \& Sons.

29. Lajtha, A., Handbook of Neurochemistry: Volume 5 Metabolic Turnover in the Nervous System. 2013: Springer US.

30. Cipolla, M.J., in The Cerebral Circulation. 2009: San Rafael (CA).

31. Tandon, P.N., R. Ramamurthi and P.K.N. Jain, Manual of Neurosurgery - Two Volume Set. 2014: Jaypee Brothers,Medical Publishers Pvt. Limited.

32. Budohoski, K.P., M. Guilfoyle, A. Helmy, T. Huuskonen, M. Czosnyka, R. Kirollos, D.K. Menon, J.D. Pickard and P.J. Kirkpatrick, The pathophysiology and treatment of delayed cerebral ischaemia following subarachnoid haemorrhage. J Neurol Neurosurg Psychiatry, 2014. 85(12): p. 1343-53.

33. Lassen, N.A., Cerebral blood flow and oxygen consumption in man. Physiol Rev, 1959. 39(2): p. 183-238.

34. Murray, M.J., S.H. Rose, D.J. Wedel, C.T. Wass, B.A. Harrison and J.T. Mueller, Faust's Anesthesiology Review. 2014: Elsevier Health Sciences.

35. Steiner, L.A. and P.J. Andrews, Monitoring the injured brain: ICP and CBF. Br J Anaesth, 2006. 97(1): p. 26-38.

36. Roh, D. and S. Park, Brain Multimodality Monitoring: Updated Perspectives. Curr Neurol Neurosci Rep, 2016. 16(6): p. 56.

37. Severinghouse, J.W., New physiological observations on the effect of anoxia. Nord Med, 1971. 85(24): p. 754-5.

38. Campbell, M.K. and S.O. Farrell, Biochemistry. 2011: Cengage Learning.

39. Mammen, P.P., J.M. Shelton, S.C. Goetsch, S.C. Williams, J.A. Richardson, M.G. Garry and D.J. Garry, Neuroglobin, a novel member of the globin family, is expressed in focal regions of the brain. J Histochem Cytochem, 2002. 50(12): p. 1591-8.

40. Turgeon, M.L., Clinical Hematology: Theory and Procedures. 2005: Lippincott Williams \& Wilkins.

41. Felise S. Zollman, M.D.F.F., Manual of Traumatic Brain Injury: Assessment and Management. 2016: Springer Publishing Company.

42. Izzy, S. and S. Muehlschlegel, Cerebral vasospasm after aneurysmal subarachnoid hemorrhage and traumatic brain injury. Curr Treat Options Neurol, 2014. 16(1): p. 278.

43. Rinkel, G.J.E. and P. Greebe, Subarachnoid Hemorrhage in Clinical Practice. 2015: Springer International Publishing. 
44. Rodriguez-Rodriguez, A., J.J. Egea-Guerrero, Z. Ruiz de Azua-Lopez and F. MurilloCabezas, Biomarkers of vasospasm development and outcome in aneurysmal subarachnoid hemorrhage. J Neurol Sci, 2014. 341(1-2): p. 119-27.

45. Kinoshita, K., Traumatic brain injury: pathophysiology for neurocritical care. J Intensive Care, 2016. 4: p. 29.

46. Adams, J.P., D. Bell and J. McKinlay, Neurocritical Care: A Guide to Practical Management. 2010: Springer London.

47. Mahapatra, A.K. and K. Raj, Textbook of Traumatic Brain Injury. 2012: Jaypee Brothers, Medical Publishers.

48. Narayan, R.K., J.E. Wilberger and J.T. Povlishock, Neurotrauma. 1995, New York: McGraw Hill, Health Professions Disivion.

49. Gosling, R.G. and D.H. King, Arterial assessment by Doppler-shift ultrasound. Proc R Soc Med, 1974. 67(6 Pt 1): p. 447-9.

50. Lim, M.H., Y.I. Cho and S.K. Jeong, Homocysteine and pulsatility index of cerebral arteries. Stroke, 2009. 40(10): p. 3216-20.

51. Bhatia, A. and A.K. Gupta, Neuromonitoring in the intensive care unit. I. Intracranial pressure and cerebral blood flow monitoring. Intensive Care Med, 2007. 33(7): p. 1263-71.

52. Hillman, J., P. Sturnegk, H. Yonas, J. Heron, M. Sandborg, T. Gunnarsson and P. Mellergård, Bedside monitoring of CBF with xenon-CT and a mobile scanner: a novel method in neurointensive care. Br J Neurosurg, 2005. 19(5): p. 395-401.

53. Dhawan, V. and M. DeGeorgia, Neurointensive care biophysiological monitoring. J Neurointerv Surg, 2012. 4(6): p. 407-13.

54. Vajkoczy, P., H. Roth, P. Horn, T. Lucke, C. Thome, U. Hubner, G.T. Martin, C. Zappletal, E. Klar, L. Schilling and P. Schmiedek, Continuous monitoring of regional cerebral blood flow: experimental and clinical validation of a novel thermal diffusion microprobe. J Neurosurg, 2000. 93(2): p. 265-74.

55. Cyrous, A., B. O'Neal and W.D. Freeman, New approaches to bedside monitoring in stroke. Expert Rev Neurother, 2012. 12(8): p. 915-28.

56. Nortje, J. and A.K. Gupta, The role of tissue oxygen monitoring in patients with acute brain injury. Br J Anaesth, 2006. 97(1): p. 95-106.

57. Hillman, J., O. Åneman, C. Anderson, F. Sjögren, C. Saberg and P. Mellergård, $A$ microdialysis technique for routine measurement of macromolecules in the injured human brain. Neurosurgery, 2005. 56(6): p. 1264-8; discussion 1268-70.

58. Diczfalusy, E., P. Zsigmond, N. Dizdar, A. Kullman, D. Loyd and K. Wårdell, $A$ model for simulation and patient-specific visualization of the tissue volume of influence during brain microdialysis. Med Biol Eng Comput, 2011. 49(12): p. 145969.

59. Ferlay, J., E. Steliarova-Foucher, J. Lortet-Tieulent, S. Rosso, J.W. Coebergh, H. Comber, D. Forman and F. Bray, Cancer incidence and mortality patterns in Europe: estimates for 40 countries in 2012. Eur J Cancer, 2013. 49(6): p. 1374-403.

60. Wiranowska, M. and F.D. Vrionis, Gliomas: Symptoms, Diagnosis and Treatment Options. 2013: Nova Science Publishers, Incorporated.

61. Ishii, H., Organ Microcirculation: A Gateway to Diagnostic and Therapeutic Interventions. 2005: Springer.

62. Nagy, J.A., S.H. Chang, A.M. Dvorak and H.F. Dvorak, Why are tumour blood vessels abnormal and why is it important to know? Br J Cancer, 2009. 100(6): p. 8659.

63. Voest, E.E. and P.A. D'Amore, Tumor Angiogenesis and Microcirculation. 2001: Taylor \& Francis. 
64. Dudley, A.C., Tumor endothelial cells. Cold Spring Harb Perspect Med, 2012. 2(3): p. a006536.

65. Haj-Hosseini, N., Fluorescence Spectroscopy for Quantitative Demarcation of Glioblastoma Using 5-Aminolevulinic Acid. 2012: Linköping Studies in Science and Technology. Dissertations, 1463.

66. Stummer, W., U. Pichlmeier, T. Meinel, O.D. Wiestler, F. Zanella and H.J. Reulen, Fluorescence-guided surgery with 5-aminolevulinic acid for resection of malignant glioma: a randomised controlled multicentre phase III trial. Lancet Oncol, 2006. 7(5): p. 392-401.

67. Haj-Hosseini, N., J.C. Richter, M. Hallbeck and K. Wårdell, Low dose 5aminolevulinic acid: Implications in spectroscopic measurements during brain tumor surgery. Photodiagnosis Photodyn Ther, 2015. 12(2): p. 209-14.

68. Kandel, E.I., Functional and Stereotactic Neurosurgery. 2012: Springer US.

69. Hemm, S. and K. Wårdell, Stereotactic implantation of deep brain stimulation electrodes: a review of technical systems, methods and emerging tools. Med Biol Eng Comput, 2010. 48(7): p. 611-24.

70. Hariz, M.I., Safety and risk of microelectrode recording in surgery for movement disorders. Stereotact Funct Neurosurg, 2002. 78(3-4): p. 146-57.

71. Lozano, A.M., P.L. Gildenberg and R.R. Tasker, Textbook of Stereotactic and Functional Neurosurgery. 2009: Springer.

72. Wårdell, K., S. Hemm-Ode, P. Rejmstad and P. Zsigmond, High-Resolution Laser Doppler Measurements of Microcirculation in the Deep Brain Structures: A Method for Potential Vessel Tracking. Stereotact Funct Neurosurg, 2016. 94(1): p. 1-9.

73. Splinter, R. and B.A. Hooper, An Introduction to Biomedical Optics. 2006: Taylor \& Francis.

74. Bigio, I.J. and S. Fantini, Quantitative Biomedical Optics: Theory, Methods, and Applications. 2016: Cambridge University Press.

75. JoelMobley, TuanVo-Dinh and V. Tuchin, Optical Properties of Tissue, in Biomedical Photonics Handbook, Second Edition. 2014, CRC Press. p. 23-122.

76. Tuchin, V.V. and S.o.P.-o.I. Engineers, Tissue Optics: Light Scattering Methods and Instruments for Medical Diagnosis. 2015: SPIE.

77. Ghatak, A. and K. Thyagarajan, An Introduction to Fiber Optics. 1998: Cambridge University Press.

78. Ball, D.W., The Basics of Spectroscopy. 2001: SPIE- The International Society for Optical Engineering.

79. Tortora, G.J. and B. Derrickson, Principles of anatomy \& physiology. 13th ed. 2012, Hoboken, NJ: Wiley.

80. Zecca, L., D. Tampellini, M. Gerlach, P. Riederer, R.G. Fariello and D. Sulzer, Substantia nigra neuromelanin: structure, synthesis, and molecular behaviour. Mol Pathol, 2001. 54(6): p. 414-8.

81. Zijlstra, W.G., A. Buursma and O.W. van Assendelft, Visible and Near Infrared Absorption Spectra of Human and Animal Haemoglobin: Determination and Application. 2000: Taylor \& Francis.

82. Segelstein, D.J., The complex refractive index of water. 1981, University of MissouriKansas City.

83. van Veen, R.L.P., H.j.c.m. Sterenborg, A. Pifferi, A. Torricelli and R. Cubeddu. Determination of VIS-NIR absorption coefficients of mammalian fat, with time- and spatially resolved diffuse reflectance and transmission spectroscopy. in Biomedical Topical Meeting. 2004. Miami Beach, Florida: Optical Society of America.

84. Wang, L.V. and H. Wu, Biomedical Optics: Principles and Imaging. 2012: Wiley. 
85. Tuchin, V., Light-Tissue Interactions, in Biomedical Photonics Handbook, Second Edition. 2014, CRC Press. p. 123-168.

86. Welch, A.J., M.J.C. van Gemert, W.M. Star and B.C. Wilson, Definitions and Overview of Tissue Optics, in Optical-Thermal Response of Laser-Irradiated Tissue, A.J. Welch and M.J.C. Van Gemert, Editors. 1995, Springer US: Boston, MA. p. 1546.

87. Friebel, M., A. Roggan, G. Muller and M. Meinke, Determination of optical properties of human blood in the spectral range 250 to $1100 \mathrm{~nm}$ using Monte Carlo simulations with hematocrit-dependent effective scattering phase functions. J Biomed Opt, 2006. 11(3): p. 34021.

88. Star, W.M., Diffusion Theory of Light Transport, in Optical-Thermal Response of Laser-Irradiated Tissue, A.J. Welch and M.J.C. Van Gemert, Editors. 1995, Springer US: Boston, MA. p. 131-206.

89. Durduran, T., R. Choe, W.B. Baker and A.G. Yodh, Diffuse Optics for Tissue Monitoring and Tomography. Rep Prog Phys, 2010. 73(7).

90. Johansson, J.D., M. Mireles, J. Morales-Dalmau, P. Farzam, M. Martinez-Lozano, O. Casanovas and T. Durduran, Scanning, non-contact, hybrid broadband diffuse optical spectroscopy and diffuse correlation spectroscopy system. Biomed Opt Express, 2016. 7(2): p. 481-98.

91. McGee, S., J. Mirkovic and M. Feld, Reflectance Spectroscopy, in Handbook of Biomedical Optics. 2011, CRC Press. p. 103-130.

92. Hull, E.L. and T.H. Foster, Steady-state reflectance spectroscopy in the P3 approximation. Journal of the Optical Society of America A, 2001. 18(3): p. 584-599.

93. Jacques, S.L. and B.W. Pogue, Tutorial on diffuse light transport. J Biomed Opt, 2008. 13(4): p. 041302.

94. Wang, H.W., J.K. Jiang, C.H. Lin, J.K. Lin, G.J. Huang and J.S. Yu, Diffuse reflectance spectroscopy detects increased hemoglobin concentration and decreased oxygenation during colon carcinogenesis from normal to malignant tumors. Opt Express, 2009. 17(4): p. 2805-17.

95. Jacques, S.L., Optical properties of biological tissues: a review. Phys Med Biol, 2013. 58(11): p. R37-61.

96. Wang, Z. and L. Feng, Optical Diagnosis of Head and Neck Cancers. Rev Recent Clin Trials, 2016. 11(1): p. 2-11.

97. Antonsson, J., O. Eriksson, P. Blomstedt, A.T. Bergenheim, I.H. M, J. Richter, P. Zsigmond and K. Wårdell, Diffuse reflectance spectroscopy measurements for tissuetype discrimination during deep brain stimulation. J Neural Eng, 2008. 5(2): p. 18590.

98. Stern, M.D., In vivo evaluation of microcirculation by coherent light scattering. Nature, 1975. 254(5495): p. 56-8.

99. Nilsson, G.E., T. Tenland and P.Å. Öberg, A new instrument for continuous measurement of tissue blood flow by light beating spectroscopy. IEEE Trans Biomed Eng, 1980. 27(1): p. 12-9.

100. Nilsson, G.E., T. Tenland and P.Å. Öberg, Evaluation of a laser Doppler flowmeter for measurement of tissue blood flow. IEEE Trans Biomed Eng, 1980. 27(10): p. $597-$ 604.

101. Leahy, M.J., F.F. de Mul, G.E. Nilsson and R. Maniewski, Principles and practice of the laser-Doppler perfusion technique. Technol Health Care, 1999. 7(2-3): p. 143-62.

102. Wårdell, K., A. Jakobsson and G.E. Nilsson, Laser Doppler perfusion imaging by dynamic light scattering. IEEE Trans Biomed Eng, 1993. 40(4): p. 309-16. 
103. Gascón, F. and F. Salazar, Simulation of Rough Surfaces and Analysis of Roughness by MATLAB. 2011: INTECH Open Access Publisher.

104. Nilsson, G.E., G.E. Salerud, N.O.T. Strömberg and K. Wårdell, Laser Doppler perfusion monitoring and imaging, in Biomedical Photonics Handbook, T. Vo-Dinh, Editor. 2003, CRC press. p. Chapter 15, 1-24.

105. Wårdell, K., C. Fors, J. Antonsson and O. Eriksson, A laser Doppler system for intracerebral measurements during stereotactic neurosurgery. Conf Proc IEEE Eng Med Biol Soc, 2007. 2007: p. 4083-6.

106. Rejmstad, P., G. Åkesson, O. Åneman and K. Wårdell, A laser Doppler system for monitoring cerebral microcirculation: implementation and evaluation during neurosurgery. Med Biol Eng Comput, 2016. 54(1): p. 123-31.

107. Jacobs, P., Sterrad 100S, Sterilisation system. Johnson \& Johnson, 2006.

108. Pogue, B.W. and M.S. Patterson, Review of tissue simulating phantoms for optical spectroscopy, imaging and dosimetry. J Biomed Opt, 2006. 11(4): p. 041102.

109. Michels, R., F. Foschum and A. Kienle, Optical properties of fat emulsions. Opt Express, 2008. 16(8): p. 5907-25.

110. Leenders, K.L., D. Perani, A.A. Lammertsma, J.D. Heather, P. Buckingham, M.J. Healy, J.M. Gibbs, R.J. Wise, J. Hatazawa, S. Herold and et al., Cerebral blood flow, blood volume and oxygen utilization. Normal values and effect of age. Brain, 1990. 113 ( Pt 1): p. 27-47.

111. Rostrup, E., G.M. Knudsen, I. Law, S. Holm, H.B. Larsson and O.B. Paulson, The relationship between cerebral blood flow and volume in humans. Neuroimage, 2005. 24(1): p. 1-11.

112. Dash, R.K. and J.B. Bassingthwaighte, Erratum to: Blood $\mathrm{HbO} 2$ and $\mathrm{HbCO} 2$ dissociation curves at varied O2, CO2, pH, 2,3-DPG and temperature levels. Ann Biomed Eng, 2010. 38(4): p. 1683-701.

113. Takatani, S. and M.D. Graham, Theoretical analysis of diffuse reflectance from a twolayer tissue model. IEEE Trans Biomed Eng, 1979. 26(12): p. 656-64.

114. Kou, L., D. Labrie and P. Chylek, Refractive indices of water and ice in the 0.65- to 2.5-microm spectral range. Appl Opt, 1993. 32(19): p. 3531-40.

115. Bashkatov, A., E. Genina and V. Tuchin, Tissue Optical Properties, in Handbook of Biomedical Optics. 2011, CRC Press. p. 67-100.

116. Yaroslavsky, A.N., P.C. Schulze, I.V. Yaroslavsky, R. Schober, F. Ulrich and H.J. Schwarzmaier, Optical properties of selected native and coagulated human brain tissues in vitro in the visible and near infrared spectral range. Phys Med Biol, 2002. 47(12): p. 2059-73.

117. Hoffman, W.E., F.T. Charbel, G. Gonzalez-Portillo and J.I. Ausman, Measurement of ischemia by changes in tissue oxygen, carbon dioxide, and pH. Surg Neurol, 1999. 51(6): p. 654-8.

118. Sommer, B., M. Kreuzer, B. Bischoff, D. Wolf, H. Schmitt, I.Y. Eyupoglu, K. Rossler, M. Buchfelder, O. Ganslandt and K. Wiendieck, Combined Laser-Doppler Flowmetry and Spectrophotometry: Feasibility Study of a Novel Device for Monitoring Local Cortical Microcirculation during Aneurysm Surgery. J Neurol Surg A Cent Eur Neurosurg, 2016.

119. Johns, M., C.A. Giller and H. Liu. Calculation of hemoglobin saturation from in vivo human brain tissues using a modified diffusion theory model. 2001.

120. Humeau, A., W. Trzepizur, D. Rousseau, F. Chapeau-Blondeau and P. Abraham, Localization of transient signal high-values in laser Doppler flowmetry signals with an empirical mode decomposition. Med Phys, 2009. 36(1): p. 18-21. 
121. Kirkpatrick, P.J., P. Smielewski, M. Czosnyka and J.D. Pickard, Continuous monitoring of cortical perfusion by laser Doppler flowmetry in ventilated patients with head injury. J Neurol Neurosurg Psychiatry, 1994. 57(11): p. 1382-8.

122. Rohlwink, U.K. and A.A. Figaji, Methods of monitoring brain oxygenation. Childs Nerv Syst, 2010. 26(4): p. 453-64.

123. Wårdell, K., P. Zsigmond, J. Richter and S. Hemm, Relationship between laser Doppler signals and anatomy during deep brain stimulation electrode implantation toward the ventral intermediate nucleus and subthalamic nucleus. Neurosurgery, 2013. 72(2 Suppl Operative): p. ons127-40; discussion ons140.

124. de Riva, N., K.P. Budohoski, P. Smielewski, M. Kasprowicz, C. Zweifel, L.A. Steiner, M. Reinhard, N. Fabregas, J.D. Pickard and M. Czosnyka, Transcranial Doppler pulsatility index: what it is and what it isn't. Neurocrit Care, 2012. 17(1): p. 58-66.

125. Francoeur, C.L. and S.A. Mayer, Management of delayed cerebral ischemia after subarachnoid hemorrhage. Crit Care, 2016. 20(1): p. 277.

126. Dreier, J.P., S. Major, A. Manning, J. Woitzik, C. Drenckhahn, J. Steinbrink, C. Tolias, A.I. Oliveira-Ferreira, M. Fabricius, J.A. Hartings, P. Vajkoczy, M. Lauritzen, U. Dirnagl, G. Bohner and A.J. Strong, Cortical spreading ischaemia is a novel process involved in ischaemic damage in patients with aneurysmal subarachnoid haemorrhage. Brain, 2009. 132(Pt 7): p. 1866-81.

127. Lam, J.M., J.N. Hsiang and W.S. Poon, Monitoring of autoregulation using laser Doppler flowmetry in patients with head injury. J Neurosurg, 1997. 86(3): p. 438-45.

128. Ponce, L.L., S. Pillai, J. Cruz, X. Li, H. Julia, S. Gopinath and C.S. Robertson, Position of probe determines prognostic information of brain tissue PO2 in severe traumatic brain injury. Neurosurgery, 2012. 70(6): p. 1492-502; discussion 1502-3.

129. Wårdell, K., I.M. Braverman, D.G. Silverman and G.E. Nilsson, Spatial heterogeneity in normal skin perfusion recorded with laser Doppler imaging and flowmetry. Microvasc Res, 1994. 48(1): p. 26-38.

130. Zweifel, C., C. Dias, P. Smielewski and M. Czosnyka, Continuous time-domain monitoring of cerebral autoregulation in neurocritical care. Med Eng Phys, 2014.

131. Fantini, S., A. Sassaroli, K.T. Tgavalekos and J. Kornbluth, Cerebral blood flow and autoregulation: current measurement techniques and prospects for noninvasive optical methods. Neurophotonics, 2016. 3(3): p. 031411.

132. Sekhon, M.S., P. Smielewski, T.D. Bhate, P.M. Brasher, D. Foster, D.K. Menon, A.K. Gupta, M. Czosnyka, W.R. Henderson, K. Gin, G. Wong and D.E. Griesdale, Using the relationship between brain tissue regional saturation of oxygen and mean arterial pressure to determine the optimal mean arterial pressure in patients following cardiac arrest: A pilot proof-of-concept study. Resuscitation, 2016.

133. Zweifel, C., M. Czosnyka, A. Lavinio, G. Castellani, D.J. Kim, E. Carrera, J.D. Pickard, P.J. Kirkpatrick and P. Smielewski, A comparison study of cerebral autoregulation assessed with transcranial Doppler and cortical laser Doppler flowmetry. Neurol Res, 2010. 32(4): p. 425-8.

134. Yu, L., Y. Wu, J.F. Dunn and K. Murari, In-vivo monitoring of tissue oxygen saturation in deep brain structures using a single fiber optical system. Biomed Opt Express, 2016. 7(11): p. 4685-4694.

135. Jonasson, H., Model-based quantitative assessment of skin microcirculatory blood flow and oxygen saturation. 2016: Linköping Studies in Science and Technology. Dissertations, 1753.

136. Boas, D., G. Strangman, J. Culver, R. Hoge, G. Jasdzewski, R. Poldrack, B. Rosen and $\mathrm{J}$. Mandeville, Can the cerebral metabolic rate of oxygen be estimated with nearinfrared spectroscopy? Phys Med Biol, 2003. 48(15): p. 2405. 


\section{References}

137. Mesquita, R.C., T. Durduran, G. Yu, E.M. Buckley, M.N. Kim, C. Zhou, R. Choe, U. Sunar and A.G. Yodh, Direct measurement of tissue blood flow and metabolism with diffuse optics. Philos Trans A Math Phys Eng Sci, 2011. 369(1955): p. 4390-406.

138. Verdecchia, K., M. Diop, T.Y. Lee and K. St Lawrence, Quantifying the cerebral metabolic rate of oxygen by combining diffuse correlation spectroscopy and timeresolved near-infrared spectroscopy. J Biomed Opt, 2013. 18(2): p. 27007.

139. Selb, J., D.A. Boas, S.T. Chan, K.C. Evans, E.M. Buckley and S.A. Carp, Sensitivity of near-infrared spectroscopy and diffuse correlation spectroscopy to brain hemodynamics: simulations and experimental findings during hypercapnia. Neurophotonics, 2014. 1(1). 


\section{Papers}

The articles associated with this thesis have been removed for copyright reasons. For more details about these see:

http://urn.kb.se/resolve? urn:nbn:se:liu:diva-133781 